\title{
Non-invasive tissue oximetry
}

\author{
Citation for published version (APA):
}

Vranken, N. P. A. V. (2017). Non-invasive tissue oximetry: current and prospective applications. [Doctoral Thesis, Maastricht University]. Datawyse / Universitaire Pers Maastricht. https://doi.org/10.26481/dis.20171218nv

Document status and date:

Published: 01/01/2017

DOI:

10.26481/dis.20171218nv

Document Version:

Publisher's PDF, also known as Version of record

\section{Please check the document version of this publication:}

- A submitted manuscript is the version of the article upon submission and before peer-review. There can be important differences between the submitted version and the official published version of record.

People interested in the research are advised to contact the author for the final version of the publication, or visit the DOI to the publisher's website.

- The final author version and the galley proof are versions of the publication after peer review.

- The final published version features the final layout of the paper including the volume, issue and page numbers.

Link to publication

\footnotetext{
General rights rights.

- You may freely distribute the URL identifying the publication in the public portal. please follow below link for the End User Agreement:

www.umlib.nl/taverne-license

Take down policy

If you believe that this document breaches copyright please contact us at:

repository@maastrichtuniversity.nl

providing details and we will investigate your claim.
}

Copyright and moral rights for the publications made accessible in the public portal are retained by the authors and/or other copyright owners and it is a condition of accessing publications that users recognise and abide by the legal requirements associated with these

- Users may download and print one copy of any publication from the public portal for the purpose of private study or research.

- You may not further distribute the material or use it for any profit-making activity or commercial gain

If the publication is distributed under the terms of Article $25 \mathrm{fa}$ of the Dutch Copyright Act, indicated by the "Taverne" license above, 

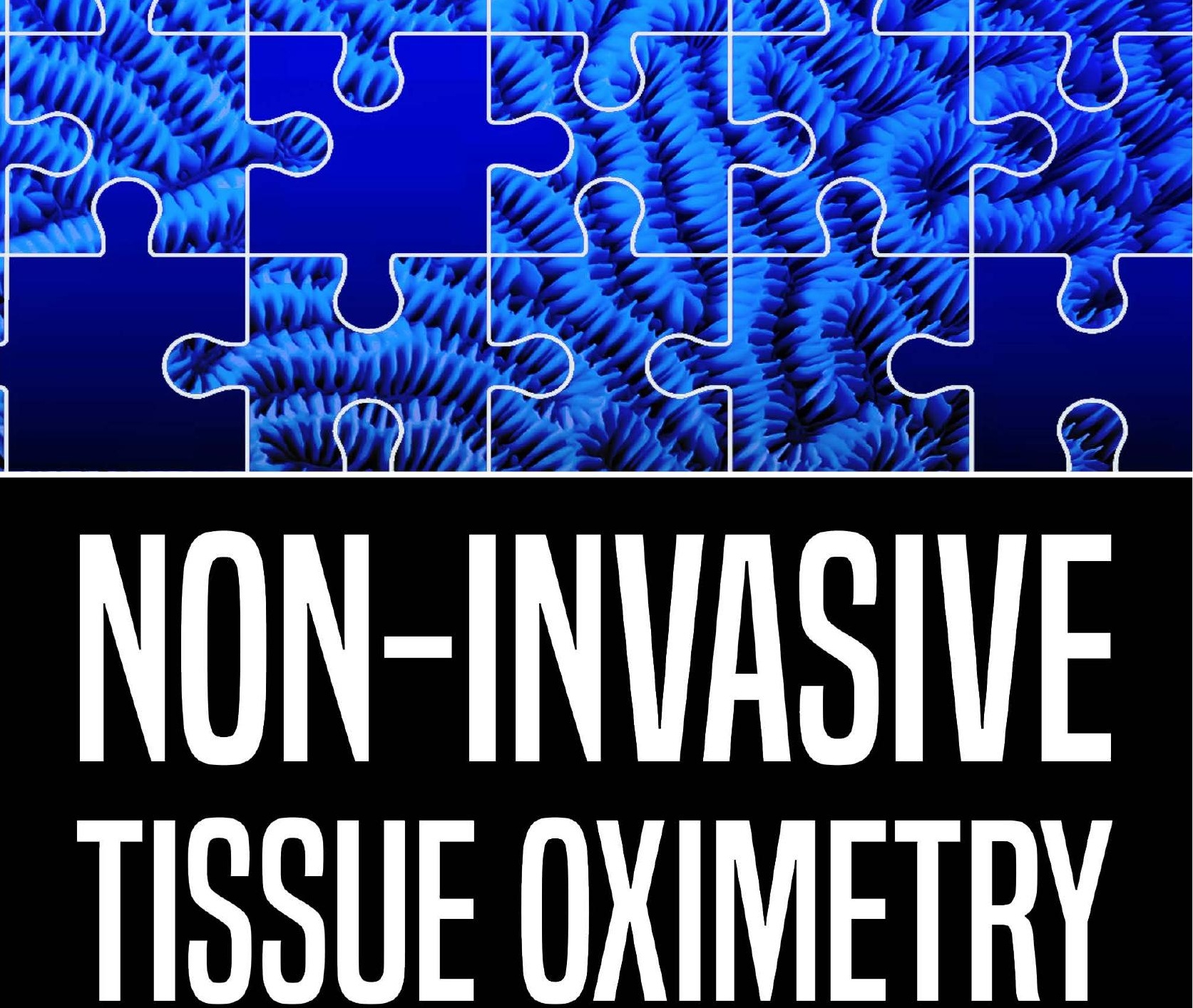

CURRENT AND PROSPECTIVE APPLICATIONS

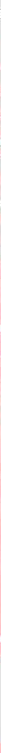


ISBN 9789461597724

Printed by Datawyse | Universitaire Pers Maastricht

Cover design by Fiverr.com/lauria

The author appreciates financial support for her dissertation.

Financial support by Stichting Hartsvrienden RESCAR for the publication of this thesis is gratefully acknowledged.

Additional financial support was granted by Coöperatief Advanced Extracorporeal Therapies U.A., Maquet Netherlands BV, LivaNova Nederland NV, and Laguna Health BV. 


\title{
Non-invasive tissue oximetry:
}

\section{current and prospective applications}

\author{
PROEFSCHRIFT
}

Ter verkrijging van de graad van doctor aan de Universiteit Maastricht, op gezag van de Rector Magnificus,

Prof. dr. R.M. Letschert, volgens het besluit van het college van

Decanen, in het openbaar te verdedigen op maandag 18 december 2017 om 16:00 uur

door

Nousjka Petra Anna Vranken

geboren op 28 september 1991 te Geleen 


\section{PROMOTOR}

Prof. dr. J.G. Maessen

\section{COPROMOTORES}

Dr. P.W. Weerwind

Dr. S. Teerenstra

\section{BEOORDELINGSCOMMISSIE}

Prof. dr. P.M.H.J. Roekaerts (voorzitter)

Prof. dr. O. Bekers

Prof. dr. C. Boer (VU Medisch Centrum, Amsterdam)

Prof. dr. A.J.J.C. Bogers (Erasmus MC, Rotterdam)

dr. A.J.H.M. Houben 


\section{CONTENTS}

$\begin{array}{lll}\text { Chapter } 1 & \text { General introduction } & 7\end{array}$

Chapter 2 Cerebral oximetry and autoregulation during cardiopulmonary bypass: a review

Chapter 3 Hemodilution combined with hypercapnia impairs cerebral autoregulation during normothermic cardiopulmonary bypass

Chapter 4 Cerebral autoregulation during cardiopulmonary bypass

Chapter 5 Impact of intraoperative events on cerebral tissue oximetry in patients undergoing cardiopulmonary bypass

Chapter 6 Cerebral and limb tissue oxygenation during peripheral veno-arterial extracorporeal life support

Chapter 7 Vascular occlusion test to dynamically assess microcirculation during normothermic pulsatile cardiopulmonary bypass

Chapter 8 Non-invasive tissue oximetry following unilateral DIEP-flap reconstruction: a pilot evaluation

Chapter 9 General discussion

Summary

Samenvatting

Valorization

Dankwoord

Curriculum vitae

Publications 

CHAPTER 1

General introduction 
Comprehensive development of diagnostic and monitoring technologies in modern medicine has helped to better understand the complex pathophysiology of acute circulatory failure in critical cases such as surgical patients or patients admitted to the intensive care unit (ICU). In critical care settings it is vital to assess the patient's hemodynamic status for optimization of end-organ tissue oxygenation to prevent or minimize morbidity and mortality. ${ }^{1}$

It is, however, challenging to monitor the state of tissue oxygenation accurately. The use of standard hemodynamic parameters such as blood pressure and pulse oximetry for assessing tissue blood flow is less than accurate. ${ }^{2,3}$ Despite apparently normal macroperfusion (capillary refill, cardiac output, blood pressure), tissue hypoperfusion can persist as a result of microcirculatory perfusion defects. ${ }^{4}$ Various approaches have been introduced to avoid such hypoperfusion - mostly with disappointing or controversial results. As an illustration, a recent study showed that the early goal-directed therapy strategy for septic shock not only proves no survival benefits but also might increase the risk of fluid overload. ${ }^{5}$ Thus, measuring heart rate, cardiac output, arterial blood pressure, and mixed venous oxygen saturation solely provides information regarding the patient's central hemodynamic status, reflecting macroperfusion, and normalization of these hemodynamic variables does not ensure sufficient oxygenation at the peripheral tissue level. ${ }^{6}$

The introduction of near-infrared spectroscopy (NIRS) for assessing the adequacy of regional tissue perfusion was an important landmark in the history of tissue monitoring. ${ }^{7}$ Since then, monitoring regional tissue oxygenation has gained wide interest, and studies began to address the importance of monitoring tissues susceptible to hypoperfusion. This has led to growing interest in noninvasive methods designed to evaluate regional perfusion as a valuable adjunct to standard global parameters to predict or diagnose tissue hypoperfusion.

\section{How common is tissue hypoxia or tissue desaturation during the perioperative period?}

Tissue hypoxia and arterial desaturation events in the perioperative period may be more common than is recognized. In a recent blinded study by Sun et al., arterial desaturation events (defined as $\geq 10 \mathrm{~min} / \mathrm{h}$ with raw pulse oximetry values $<90 \%$ ) were reported to occur in $21 \%$ of non-cardiac surgical patients. ${ }^{8}$ An important finding in their study is that $90 \%$ of these hypoxemic events went undetected at the nursing floor. In a comparable patient population, Ehrenfeld et al. showed a prevalence of $6.8 \%$ for hypoxemic events (pulse oximetry values $<90 \%, \geq 2$ minutes in duration) and $3.5 \%$ for severe hypoxemic events (pulse oximetry values $\leq 85 \%, \geq 2$ minutes in duration). ${ }^{9}$ In the cardiac surgical popula- 
tion, hypoxic events were found to be more common, as illustrated by Ranucci et al. who observed hypoxia in $30.6 \%$ of patients (defining hypoxia as a $\mathrm{P}_{\mathrm{a}} \mathrm{O}_{2} / \mathrm{FiO}_{2}$ ratio $<200 \mathrm{mmHg}$ ). ${ }^{10}$ In another study, Wang et al. reported even higher rates following aortic dissection (49.5\%) using the same definition for hypoxia. ${ }^{11}$ Interventions to correct pulse oximeter-measured oxygen saturation can avert major undesirable outcomes. In a study by Taenzer et al. pulse oximetry monitoring at a medical ward reduced serious adverse outcomes such as ICU admissions. ${ }^{12}$ Although pulse oximetry showed clinical benefit in detection of hypoxemia and hypoxia, discordance on the relationship between pulse oximetry monitoring and complication rate remains to exist. ${ }^{13}$

Desaturation events may occur in the operating room or at the post-anesthesia care unit where patients are closely monitored, but frequently these episodes of a dysbalanced regional oxygen supply/demand occur during the postoperative period when patients are less strictly monitored and exposed to the respiratory depressant effects of opioid pain medications. Some of these desaturations occur in the postoperative period ${ }^{14}$ and to date it is unknown whether intraoperative or postoperative events are more important for clinical outcome. ${ }^{15}$

\section{Physics and principles of near-infrared spectroscopy (NIRS)}

The physics and mathematics of NIRS are based on a modified version of the Beer-Lambert law, which states that a proportion of light transmitted through a solution containing a colored compound (chromophore) is absorbed by the compound. As a result, the intensity of the emerging light is reduced.

The relationship between the absorption and concentration of a chromophore is described by the following Beer-Lambert equation:

$A=\log \left(I_{0} / I\right)=\varepsilon \cdot c \cdot d$,

where $A$ is the absorption of light, expressed as optical density (log of the ratio of the intensities of incident $\left(\mathrm{I}_{0}\right)$ and transmitted (I) light), c the chromophore concentration, $\varepsilon$ its extinction coefficient, and $d$ the width (optical path length) through the solution or medium. ${ }^{16}$ The Beer-Lambert law also explains the difference observed when light passes through large versus small blood vessels. If near-infrared light photons pass through a single red blood cell, only a small percentage of photons is absorbed. However, if the photons were to pass through a blood vessel of $1 \mathrm{~mm}$ thickness, absorbance would be 0.8 and thus only $10 \%$ of the impacting photons would remain unabsorbed. ${ }^{17}$ 
Tissue oxygenation is the result of a complex interaction of perfusion, arterial oxygen tension, hemoglobin $(\mathrm{Hb})$ level and dissociation conditions, and local oxygen consumption. Consequently, each oxygen-monitoring method involves specific assumptions and limitations. Tissue oximetry with near-infrared light is a non-invasive, optical technique that integrates blood oxygenated hemoglobin $\left(\mathrm{HbO}_{2}\right)$ saturation in an anatomical region of interest (Figure 1).

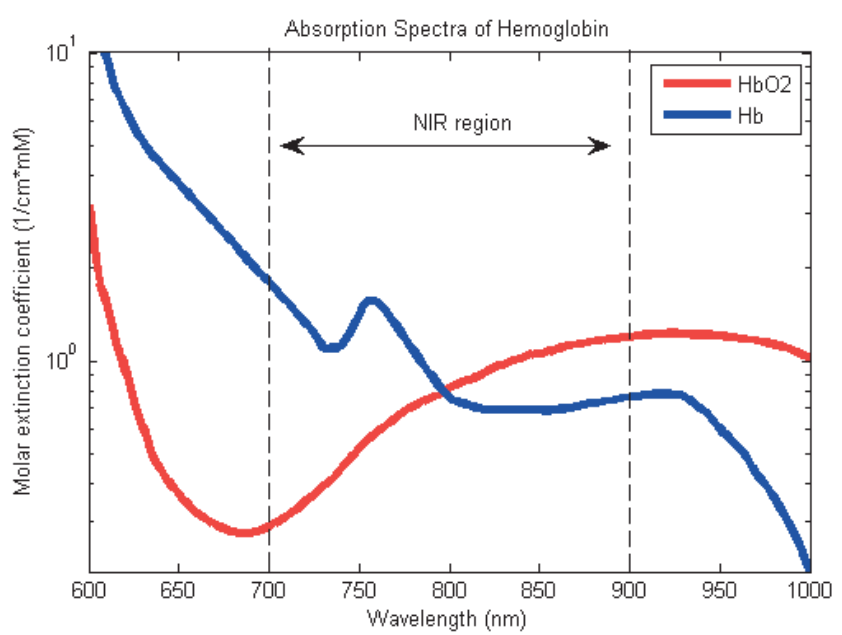

Figure 1. Near-infrared spectra of oxygenated hemoglobin $\left(\mathrm{HbO}_{2}\right)$ and hemoglobin $(\mathrm{Hb}) .^{18}$

By nature of the technique, measurement is limited to the intravascular compartment. It combines measurements of arterial, venous, and capillary blood, depending on the absorbance of different wavelengths of near-infrared light. Unlike pulse oximetry, NIRS does not involve detection of a pulsatile tissue component but relies entirely on the Beer-Lambert law that relates the concentration of a substance to its light absorption. ${ }^{19}$ The ability to discriminate various types of chromophores varies with the number of wavelengths; for example, a NIRS device using two distinct wavelengths cannot discriminate between the levels of oxyhemoglobin, reduced $\mathrm{Hb}$, oxymyoglobin, and reduced myoglobin. ${ }^{20}$ This can be a significant issue when, for example, comparing the readings of an NIRS device on the forehead and thenar muscles, with obvious differences in the amount of myoglobin present in the two tissues. For cerebral NIRS devices, the assumption is that myoglobin is only a minor contributor to the signal and that the vascular $\mathrm{Hb}$-oxygen component predominates. ${ }^{21}$ Cerebral oximeters are calibrated by the manufacturer assuming a constant $70 \%$ or $75 \%$ weighting toward venous blood saturation. ${ }^{22,23}$ Oxygen consumption with insufficient oxygen delivery will lead to an increased concentration of reduced $\mathrm{Hb}$, and since 
$\mathrm{Hb}$ chromophores dominate the near-infrared absorption spectrum, the estimation of $\mathrm{Hb}$-oxygen saturation is arguably less susceptible to errors and signal-tonoise problems than NIRS-based assessment of cytochrome redox status. An in vivo calibration can be accomplished with direct measurement of cerebral venous and arterial saturation in blood samples. ${ }^{23}$ This calibration, incorporated into the calculation algorithm that determines the displayed value of regional oxygen saturation $\left(\mathrm{rSO}_{2}\right)$, should theoretically reduce the interfering effects of different $\mathrm{Hb}$ concentrations and variations in tissue light transmission. However, this calibration approach assumes that all individuals have the same constant ratio of cerebral venous to arterial blood within the tissue where the measurement is performed. Given the great inter- and intrapersonal variations in hemodynamics and anatomy, this assumption is likely incorrect.

\section{NIRS accuracy for measuring brain tissue oxyhemoglobin saturation}

Today, physicians can choose from a wide variety of devices for monitoring $\mathrm{rSO}_{2}$, including INVOS ${ }^{\mathrm{TM}}$ (Medtronic, Minneapolis, MN, USA), FORE-SIGHT ${ }^{\mathrm{TM}}$ (CAS Medical Systems, Branford, CT, USA), EQUANOX ${ }^{\text {TM }}$ (Nonin Medical Inc., Plymouth, MN, USA), CerOx ${ }^{\mathrm{TM}}$ (Ornim Medical, Lod, Israel), NIRO ${ }^{\mathrm{TM}}$ (Hamamatsu Photonics, Hamamatsu City, Japan), and TOS-96 ${ }^{\mathrm{TM}}$ (Tostec Co., LTD., Tokyo, Japan).

Although spatially resolved spectroscopy can be used to compute a scaled concentration of tissue $\mathrm{Hb}$ and relative concentrations of oxy- and deoxyhemoglobin, currently manufactured cerebral oximeters are not designed to provide an "absolute" measurement of regional tissue oxygen saturation. ${ }^{23}$ A study evaluating the accuracy of cerebral oximeters by Bickler et al. ${ }^{23}$ revealed the betweensubject variability and dynamic error of readings that constitute to a challenge in determining absolute thresholds for predicting tissue injury. Furthermore, the measured ratio of venous to arterial blood in brain tissue is variable and about $50: 50^{24}$, whereas oximeter manufacturers calibrate to fixed venous to arterial volume ratios of $70: 30$ or $75: 25 .{ }^{23}$ Moreover, changes in cerebral venous and arterial blood volumes, carbon dioxide or oxygen concentrations will violate assumptions on constancy of arterial to venous blood volume. ${ }^{24}$ Signal contamination originating from blood in extracranial tissue within the sampled volume of interest also complicates the clinical utility of this technology. ${ }^{25}$ Administration of peripherally acting vasoconstrictors (e.g. phenylephrine or norepinephrine) is one example that can affect the contribution of extracranial blood and possibly alter tissue oximetry readings. ${ }^{24}$ In addition, sympathetically-mediated vasoconstriction from pain, hypothermia, and hypovolemia significantly alters peripheral 
tissue oxygenation and may also influence the extracranial component of the reading. Therefore, the measurements are at best relative assessments of tissue oxygenation and are useful as trend monitors, not threshold of injury monitors.

\section{How widespread is the use of tissue oximetry?}

Given the diversity of technologies currently available to assess tissue oxygenation status, it is important to consider its various applications in current clinical practices using NIRS.

\section{Brain monitoring}

The brain is the organ most commonly directly assessed with regional tissue oximetry using NIRS. Although monitoring cerebral oxygenation to prevent the adverse consequences of acute cerebral hypoperfusion is supportable with current knowledge, the issue of predicting longterm outcomes remains less clear. ${ }^{27}$ During cardiac surgery with cardiopulmonary bypass (CPB), (undetected) episodes of hypoperfusion predispose the patient to an increased risk of postoperative neurological complications (PNC). Despite this, routine evaluation of cerebral hemodynamics is still not part of standard clinical practice. Noninvasive tissue oximetry has been advocated to minimize and even prevent vulnerable episodes characterized by a disbalance between regional oxygen supply and demand. In one study, Murkin proposed that cerebral oximetry can be used as an organ index, meaning that maintaining adequate $\mathrm{rSO}_{2}$ levels is beneficial for all vital organs. ${ }^{19}$ The technique has been widely applied in clinical centers and multiple studies have been conducted, suggesting that intraoperative optimization of cerebral oximetry-derived values aids in preventing PNC. ${ }^{19}$ This contributed to the conclusions drawn in systematic reviews that tissue oximetry is a promising technique for preventing PNC following surgical procedures. ${ }^{28}$ The evidence linking $\mathrm{rSO}_{2}$ values and $\mathrm{PNC}$ remains doubtful due to the lack of intervention-guided studies that focus on the causality of the proposed relation between $\mathrm{rSO}_{2}$ and adverse clinical outcome. ${ }^{27}$ Moreover, studies also failed to prove that intraoperative interventions to correct cerebral $\mathrm{rSO}_{2}$ lead to improved neurological outcome. ${ }^{27}$ Part of the explanation can be found in the fact that due to its measurement principle, cerebral oximetry does not take cerebral autoregulatory activity into account. Cerebral autoregulation (CA) is the intrinsic system that maintains adequate cerebral blood flow at a wide range of different perfusion pressures. One example can be found in cerebral hyperperfusion, also referred to as brain luxury perfusion. ${ }^{29}$ In this case, cerebral oximetry readings can be close to baseline values while the CA is severly dis- 
turbed, thereby predisposing the patient to increased risk of cerebral edema and hemorrhage. In order to preserve CA, arterial blood pressure among other factors need to be strictly controlled within certain limits. Together with avoiding large fluctuations in hemodynamic parameters, this may contribute to minimize $\mathrm{PNC}$ occurrence in patients undergoing CPB.

\section{Somatic tissue monitoring}

Besides brain monitoring, tissue oximetry has also been used in various other clinical applications. Continuous assessment of oxygenation in peripheral tissue or free skin flaps may contribute to early detection of circulatory compromise, as indicated by previous work. ${ }^{30-32}$ Despite this, tissue oximetry is not an integrated part of routine monitoring in surgical or ICU patients susceptible to ischemic tissue damage.

\section{Aims and outline of this thesis}

Since the introduction of non-invasive tissue oximetry as a continuous monitor for tissue perfusion, implementation into routine clinical practice has been an ongoing process. For the most part this is due to uncertainties regarding adequate interpretation of $\mathrm{rSO}_{2}$ values and trends. This thesis focuses on current and prospective applications of non-invasive tissue oxygenation monitoring using NIRS, with the intent to describe the current state of knowledge on noninvasive tissue oximetry and clinical outcome parameters, and to identify the gaps in knowledge and technology that would help to resolve the remaining unknowns.

First, the clinical application of non-invasive tissue oximetry in brain monitoring during CPB is described and discussed in chapter 2. The current evidence of a link between cerebral $\mathrm{rSO}_{2}$ readings and the occurrence of $\mathrm{PNC}$ following cardiac surgery with CPB is systematically reviewed. In addition, elucidation is provided on the role and importance of intact CA as part of brain protection during bypass.

Adequate prevention of ischemic complications contributing to PNC requires knowledge of the modifiable factors that determine the extent of CA functionality in patients during CPB. Among these modifiable factors, hemodynamic stability, arterial carbon dioxide level and hemodilution appeared to play a substantial role in CA efficacy (chapters 3 and 4).

During cardiac surgery with $\mathrm{CPB}$, several actions performed by the cardiothoracic surgeon, clinical perfusionist and anesthesiologist affect oxygen supply to the brain. Non-invasive tissue oximetry could aid in early detection of decreas- 


\section{CHAPTER 1}

ing cerebral oxygenation in case of e.g., iatrogenic events, preventing possibly harmful ischemic episodes. It is therefore important to evaluate whether cerebral $\mathrm{rSO}_{2}$ readings are responsive to certain iatrogenic events and if so, the magnitude of the induced change (chapter 5).

Besides its application in CPB during cardiac surgical procedures, patients admitted to the ICU in need of prolonged cardiopulmonary support may also benefit from tissue oximetry measurements (chapter 6). In the case of femoral access, specifically, concerns regarding variations in oxygenation associated with compromised brain and limb perfusion remain to exist. Continuous monitoring of peripheral tissue as well as brain $\mathrm{rSO}_{2}$ may contribute in preventing complications. Tissue oximetry may possibly be superior to existing monitoring methods due to the absence of a clear time delay in the representation of impaired tissue perfusion.

In addition to steady-state tissue oxygen saturation monitoring, dynamic assessment of tissue oxygenation may provide valuable information regarding peripheral vascular reactivity (chapter 7 ). Identification of microvascular dysfunction is of clinical importance due to its relationship with consequential tissue malperfusion. Adequate assessment of vascular reactivity can avert ischemic tissue damage by enabling intervention at the stage where only microvascular dysfunction is apparent, prior to the occurrence of hypoxia.

Another application of tissue oximetry in peripheral tissue monitoring is assessing free flap viability following autologous reconstructive surgery (chapter 8). In the first critical hours following free flap transplantation, the risk of arterial or venous thrombosis is highest and constitutes to risk of partial or complete flap loss as a result of liquefactive fat necrosis. Therefore, extensive and continuous monitoring is warranted to allow timely intervention. 


\section{References}

1. Kipnis E, Ramsingh D, Bhargava M, et al. Monitoring in the intensive care. Crit Care Res Pract 2012;473507.

2. Hoffman GM, Ghanayem NS, Tweddell JS. Noninvasive assessment of cardiac output. Semin Thorac Cardiovasc Surg Pediatr Card Surg Annu 2005;12-21.

3. Tibby SM, Hatherill M, Marsh MJ, Murdoch IA. Clinicians' abilities to estimate cardiac index in ventilated children and infants. Arch Dis Child 1997;77:516-518.

4. Siegenthaler N, Giraud R, Romand JA, Bendjelid K. Physiopathologic aspects of microcirculation in intensive care. Rev Med Suisse 2008;4:2696-2701.

5. Yealy DM, Kellum JA, Huang DT, et al. A randomized trial of protocol-based care for early septic shock. N Engl J Med 2014;370:1683-1693.

6. Gutierrez G, Vincent JL. Update in intensive care and emergency medicine - tissue oxygen utilization. Berlin: Springer-Verlag; 1991.

7. Jobsis, FF. Noninvasive, infrared monitoring of cerebral and myocardial oxygen sufficiency and circulatory parameters. Science 1977;198(4323):1264-1267.

8. Sun Z, Sessler DI, Dalton JE, et al. Postoperative hypoxemia is common and persistent: a prospective blinded observational study. Anesth Analg 2015;121:709-715.

9. Ehrenfeld JM, Funk LM, van Schalwyk J, Merry AF, Sandberg WS, Gawande A. The incidence of hypoxemia during surgery: evidence from two institutions. Can J Anaesth 2010;57(10):888897.

10. Ranucci M, Ballotta M, Teresa la Rovere M, et al. Postoperative hypoxia and length of intensive care unit stay after cardiac surgery: the underweight paradox? PloS one 2014; e93992.

11. Wang $\mathrm{Y}, \mathrm{Xue} \mathrm{S}, \mathrm{Zhu} \mathrm{H}$. Risk factors for postoperative hypoxemia in patients undergoing Stanford A aortic dissection surgery. J Cardiothorac Surg 2013;8:118.

12. Taenzer AH, Pyke JB, McGrath SP, Blike GT. Impact of pulse oximetry surveillance on rescue events and intensive care unit transfers: a before-and-after concurrence study. Anesthesiology 2010;112:282-287.

13. Moller JT, Johannessen NW, Espersen K, et al. Randomized evaluation of pulse oximetry in 20,802 patients: II. Perioperative events and postoperative complications. Anesthesiology 1993;78:445-453.

14. Greenberg SB, Murphy G, Alexander J, Fasanella R, Garcia A, Vender J. Cerebral desaturation events in the intensive care unit following cardiac surgery. J Crit Care 2013;28:270-276.

15. Vranken NPA, Weerwind PW, Sutedja NA, Ševerdija EE, Barenbrug JC, Maessen JG. Cerebral oximetry and autoregulation during cardiopulmonary bypass: a review. J Extra Corpor Technol 2017. Epub ahead of print.

16. Ward KR, Ivatury RR, Barbee RW, et al. Near infrared spectroscopy for evaluation of the trauma patient: a technology review. Resuscitation 2006;68:27-44.

17. Mancini DM, Bolinger L, Li H, Kendrick K, Chance B, Wilson JR. Validation of near-infrared spectroscopy in humans. J Appl Physiol 1994;77:2740-2747.

18. Wikiwand. Functional near-infrared spectroscopy. Retrieved May 1st 2017 from http://www.wikiwand.com/en/Functional_near-infrared_spectroscopy

19. Murkin JM, Arango M. Near-infrared spectroscopy as an index of brain and tissue oxygenation. Br J Anaesth 2009;103.suppl1:i3-i13.

20. Strangman G, Franceschini MA, Boas DA. Factors affecting the accuracy of near-infrared spectroscopy concentration calculations for focal changes in oxygenation parameters. Neuroimage 2003;18(4):865-879.

21. Davis ML, Barstow TH. Estimated contribution of hemoglobin and myoglobin to near infrared spectroscopy. Respir Physiol Neurobiol 2013;186(2):180-187.

22. Ferrari M, Quaresima V. A brief review on the history of human functional near-infrared spectroscopy (fNIRS) development and fields of application. Neuroimage 2012;63:921-935. 


\section{CHAPTER 1}

23. Bickler PE, Feiner JR, Rollins MD. Factors affecting the performance of 5 cerebral oximeters during hypoxia in healthy volunteers. Anesth Analg 2013;117:813-823.

24. Ito $\mathrm{H}$, Ibaraki M, Kanno I, Fukuda $\mathrm{H}$, Miura $\mathrm{S}$. Changes in the arterial fraction of human cerebral blood volume during hypercapnia and hypocapnia measured by positron emission tomography. J Cereb Blood Flow Metab 2005;25:852-857.

25. Ghosh A, Elwell C, Smith M. Review article: cerebral near-infrared spectroscopy in adults: a work in progress. Anesth Analg 2012;115:1373-1383.

26. Sørensen $\mathrm{H}$, Secher NH, Siebenmann $\mathrm{C}$, et al. Cutaneous vasoconstriction affects nearinfrared spectroscopy determined cerebral oxygen saturation during administration of norepinephrine. Anesthesiology 2012;117:263-270.

27. Zheng F, Sheinberg R, Yee MS, et al. Cerebral near-infrared spectroscopy monitoring and neurologic outcomes in adult cardiac surgery patients: a systematic review. Anesth Analg 2013;116:663-676.

28. Taillefer MC, Denault AY. Cerebral near-infrared spectroscopy in adult heart surgery: systematic review of its clinical efficacy. Canadian Journal of Anesthesia 2005:79.

29. Henriksen L. Brain luxury perfusion during cardiopulmonary bypass in humans. A study of the cerebral blood flow response to changes in $\mathrm{CO} 2, \mathrm{O} 2$, and blood pressure. Cereb Blood Flow Metab 1986;6:366-378.

30. Keller A. A new diagnostic algorithm for early prediction of vascular compromise in 208 microsurgical flaps using tissue oxygen saturation measurements. Ann Plast Surg 2009;62:538-543.

31. Keller A. Noninvasive tissue oximetry. Clin Plastic Surg 2011;38:313-324.

32. Repez A, Oroszy, B, Arnez, ZM. Continuous postoperative monitoring of cutaneous free flaps using near infrared spectroscopy. J Plast Reconstr Aesthet Surg 2008;61:71-77. 


\section{CHAPTER 2}

\section{Cerebral oximetry and autoregulation during cardiopulmonary bypass: a review}

NPA Vranken, PW Weerwind, NA Sutedja, EE Ševerdija, PJC Barenbrug, JG Maessen

Published as a featured article in J Extra Corpor Technol 2017;49:182-191. 


\section{CHAPTER 2}

\section{Abstract}

Postoperative neurological complications (PNCs) following cardiac surgery with cardiopulmonary bypass (CPB) is a detrimental complication, contributing to increased mortality rates and health care costs. To prevent intraoperative cerebral desaturations associated with PNC, continuous brain monitoring using near-infrared spectroscopy has been advocated. However, clear evidence for a defined desaturation threshold requiring intervention during CPB is still lacking. Since cerebral oximetry readings are nonspecific, cerebral tissue oxygenation values need to be interpreted with caution and in the context of all available clinical information. Therefore, maintaining an intact autoregulatory activity during CPB rather than solely focusing on regional cerebral oxygen saturation measurements will collectively contribute to optimization of patient care during CPB. 


\section{Introduction}

The advancement of extracorporeal circulation techniques in recent decades has played an essential role in minimizing complications following cardiac surgery with cardiopulmonary bypass (CPB). ${ }^{1}$ The technical advancements have been, however, partially offset by changes in the patient population. These changes involve a more complex disease at advanced age and significant comorbidities $^{2-4}$, resulting in convoluted and lengthier procedures. Moreover, in older patients, the atherosclerotic disease process is farther advanced, which may nourish an increased risk for postoperative complications including perioperative stroke and neurocognitive impairment, including delirium. ${ }^{1,4,5}$ From these, stroke has been reported to be the most detrimental with rates varying from 1.5 to $11 \%{ }^{6-10}$ Furthermore, these postoperative neurological complications (PNC) contribute to prolonged hospital stay, increased mortality rates and health care costs, constituting to an increased burden for health care providers. $^{11,12}$

The mechanism of cerebral injury following cardiac surgery with CPB is not yet clearly understood. Development of PNC possibly involves embolization or hypoperfusion causing cerebral ischemia., ${ }^{5,11,13,14}$ To prevent intraoperative cerebral desaturations associated with ischemic complications of the brain, continuous brain monitoring using near-infrared spectroscopy (NIRS) has been advocated. ${ }^{15,16}$ Although multiple studies proposed cerebral oximetry as a viable monitoring method to prevent these neurologic complications, clear threshold determinants for acute intervention are still lacking. ${ }^{14,17}$

Furthermore, there seems to be a link between disturbed intraoperative cerebral autoregulation (CA) and PNC..$^{18-21}$ The neuroprotective autoregulatory system prevents both hypo- and hyperperfusion by reactive vasodilation and constriction following changes in arterial blood pressure (ABP) and arterial partial pressure for carbon dioxide $\left(\mathrm{P}_{\mathrm{a}} \mathrm{CO}_{2}\right)$, also referred to as modifiable factors. ${ }^{13}$ These factors are mostly based on maintaining a mean ABP of $50-60 \mathrm{mmHg}^{22}$ and $\mathrm{P}_{\mathrm{a}} \mathrm{CO}_{2}$ is only measured intermittently during CPB. Obviously, there is a lack of optimal control for $\mathrm{CA}$ functionality.

Clinical application of cerebral oximetry, its limitations and association with PNC as well as the role of modifiable factors influencing the neuroprotective autoregulatory system during CPB are subsequently reviewed.

\section{Cerebral tissue oximetry}

Cerebral oximetry allows clinicians to monitor regional cerebral tissue oxygen saturation $\left(\mathrm{rSO}_{2}\right)$ real-time in a non-invasive manner. Cerebral $\mathrm{rSO}_{2}$ is depend- 
ent on several physiological variables that affect oxygen supply and consumption of the brain, including cardiac output, inspired oxygen concentration, pulmonary function, cerebral metabolism, temperature, and hemoglobin concentration. ${ }^{23,24}$ Cerebral oximetry readings are proposed to reflect the balance between regional oxygen supply and demand and thereby local cerebral metabolism. ${ }^{11,25-27}$ More specifically, a decreasing cerebral $\mathrm{rSO}_{2}$ due to regional or global ischemia can be explained as an oxygen supply insufficient to meet the metabolic demand caused by, e.g., a decreased cardiac output. ${ }^{26,28}$ Unlike mixed venous oxygen saturation that is measured continuously via a pulmonary artery catheter, cerebral oximetry has shown to reflect alterations in blood pressure real-time. ${ }^{29}$ This suggests that cerebral oximetry enables prompt assessment of tissue oxygenation, serving as a potential early indicator of neurologic injury.

The technique applied in cerebral oximetry uses NIRS based on the BeerLambert law. ${ }^{14,30}$ The elementary particles of near-infrared light are photons that penetrate tissue before reaching the underlying capillary network. Near-infrared light of different wavelengths within the so-called biological spectroscopic window is emitted to penetrate the skin, skull, and dura matter to reach the frontal lobe of either the left or right cerebral hemisphere. ${ }^{11}$ The photons emitted through a NIRS sensor travel via a banana-shaped pathway before being measured by photodiode detectors positioned at a fixed distance from the light emitter when they resurface. Within tissue, the light is partly reflected, scattered, and absorbed. To minimize residual error, two measurements with different emitter-diode spacings are performed simultaneously, resulting in a shallowdeep detector difference. With the light intensity held constant, the quantity of light absorbed by chromophores varies with the ratio of oxygenated hemoglobin relative to the total concentration of hemoglobin, which is used to estimate local oxygen content. ${ }^{14,17}$ Most clinical devices use one near-infrared light emitter in combination with two near-infrared light detectors, whereas other devices use several detectors per emitter. The latter may contribute to the accuracy of cerebral $\mathrm{rSO}_{2}$ estimation; however, the measurement principle remains the same. In addition, the algorithm for estimating the oxygen content in cerebral blood requires an assumption on the ratio venous to arterial blood volume, which differs between clinical oximeter devices. The Food and Drug Administration approved four monitoring devices for clinical use in the United States, which include the Fore-sight cerebral oximeter (Cas Medical Systems, Inc., Branford, CT, USA), Equanox (Nonin Medical Inc., Plymounth, MN, USA), INVOS 5100C (Medtronic, Minnesota, MN, USA), and the CerOx (Ornim Medical, Lod, Israel). Both Foresight and Equanox use the ratio of $70 \%$ venous blood to $30 \%$ arterial blood, whereas INVOS $5100 \mathrm{C}$ and CerOx use a ratio of $75 \%$ venous to $25 \%$ arterial 
blood. ${ }^{29,31}$ Additionally, cerebral oximeters may provide one or several types of measurement, estimating absolute $\mathrm{rSO}_{2}$ values (Fore-sight and Equanox), or values intended for trend monitoring (INVOS 5100C and CerOx).

Corresponding to the cerebral oximetry measurement principle, $\mathrm{rSO}_{2}$ values can only partially reflect oxygen saturation in the anterior circulation of the prefrontal cortex, thereby limiting its monitoring ability to an area of approximately $1 \mathrm{~cm}^{3} \cdot{ }^{23,29,32}$ Also extracerebral tissues including skin, bone, and connective tissue may contaminate the estimation of $\mathrm{rSO}_{2} \cdot{ }^{33} \mathrm{In}$ addition, tissue oximetry derived values are nonspecific, meaning that a decreasing $\mathrm{rSO}_{2}$ may be the result of hypoperfusion, relative hypoxemia, and/or an increased metabolic rate. ${ }^{14}$ Hence, when interpreting changes in cerebral $\mathrm{rSO}_{2}$ it is necessary to consider all available clinical information. ${ }^{23}$

The algorithm to estimate cerebral $\mathrm{rSO}_{2}$ takes the predominant venous part of the cerebral blood volume into account that is reflected by a strong correlation between $\mathrm{rSO}_{2}$ and jugular venous oxygen saturation, an early indicator of brain ischemia. ${ }^{34,35}$ Other studies, however, reported that $\mathrm{rSO}_{2}$ is unable to reflect changes in jugular venous bulb oximetry in the case of head injury. ${ }^{36,37}$ Nevertheless, a recent observational study has shown that cerebral oximetry is sensitive enough to effectively identify changes in $\mathrm{rSO}_{2}$ following iatrogenic events including anesthetic induction, aortic cross clamping, and onset and termination of bypass. ${ }^{38}$ In addition, cerebral oximetry has shown to effectively depict the concomitant decline in cerebral oxygen saturation during cannula malposition ${ }^{39-}$ ${ }^{41}$, a failing oxygen line to the oxygenator in the CPB circuit ${ }^{42}$ and acute innominate artery dissection. ${ }^{43}$ These findings indicate that cerebral oximetry may aid in early detection of potential adverse neurologic events and contribute toward preventing PNC by enabling alteration of current patient management.

Although absolute (fixed value for $\mathrm{rSO}_{2}$ ) and relative (percentage of baseline $\mathrm{rSO}_{2}$ ) desaturation thresholds have been previously applied ${ }^{44,45}$, to date no consensus has been reached on the use of either an absolute or personalized cutoff value requiring prompt intervention. ${ }^{17,46}$ Nonetheless, it is generally accepted that both the extent and duration of cerebral desaturation are important. ${ }^{14,46}$ Furthermore, this lack of standardization may be related to the different monitoring devices which use varying numbers and wavelengths of light emitted as well as sensor-emitter spacings, affecting both the measurement itself and the $\mathrm{rSO}_{2}$ calculation. ${ }^{3,30}$ Differences in applied algorithm between the devices further challenge cerebral oximetry standardization. Moreover, the algorithm itself cannot accommodate for inter-individual differences including variations in cranial anatomy (e.g., asymmetrical brain circulation ${ }^{23}$, different percentages of venous cerebral blood circulating in the frontal lobe $^{47}$ and the influence of nonmodifiable patient characteristics on baseline $\mathrm{rSO}_{2}$ readings). ${ }^{25}$ The algorithm requires the assumption of a constant optical path length that is actually de- 


\section{CHAPTER 2}

creased during CPB due to hemodilution, altering the absorbance of nearinfrared light by chromophores. This may introduce an error in the estimation of the local oxygen content. ${ }^{30}$ In summary, focusing on an $\mathrm{rSO}_{2}$ threshold as suggested by Douds et al. ${ }^{48}$ would be a provocative step towards the use of cerebral oximetry as a preemptive marker for perioperative morbidity to optimize postoperative recovery.

\section{Cerebral tissue oximetry and PNCs}

Since the widespread clinical application of tissue oximetry, several studies investigated the relationship between cerebral oximetry readings and PNC. The current evidence on the relationship between cerebral desaturations as identified by cerebral oximetry and PNC following cardiac surgery with CPB is systematically reviewed in this section.

To identify relevant publications, PubMed and MEDline databases were searched for articles originating from January 2006 to August 2016. Two researchers searched and screened articles on title, abstract, and full text independently. Additional studies were identified by screening the references in the retrieved papers to capture articles that might have been missed.

The articles included were studies that focused on the relationship between cerebral oximetry readings and cognitive decline following cardiac surgery with CPB in adults. The search was limited to publications in English. Studies that were not published as a full-length article or did not discuss PNC outcome in relation to cerebral oximetry readings were excluded. Free search terms were divided in two main groups, the first representing cerebral oximetry and the second representing cardiac surgery with CPB. The cerebral oximetry category included the search terms "near infrared spectroscopy", "infrared spectroscopy", "NIRS", "cerebral oximetry" and "cerebral oxygen saturation" while the cardiac surgery with CPB category included the search terms "cardiac surgery", "CPB", "coronary artery bypass grafting" (CABG), "CABG", and "coronary bypass graft". For each search, one of the aforementioned search terms from both groups was combined.

\section{Results}

The initial search focusing on cerebral oximetry resulted in 507 publications using all combinations of free search terms. Review of the title and abstract led to inclusion of 21 out of 507 articles. A total of 13 observational and 7 interventional studies were identified as depicted in Table 1. 
Several studies found a relationship between cerebral desaturations and neurological complications, including a study by Colak et al. who showed an increased occurrence of stroke in patients with cerebral desaturations, defined by both absolute (area under the curve of $>50$ minutes $\%$ under $50 \%$ absolute $\mathrm{rSO}_{2}$ ) and relative (area under the curve $>150$ minutes $\%$ under $20 \%$ of baseline $\mathrm{rSO}_{2}$ ) thresholds. ${ }^{45}$ Similarly, Slater et al. and de Tournay-Jetté et al. found a signficant relationship with early postoperative neurocognitive decline when the absolute desaturation threshold of $50 \% \mathrm{rSO}_{2}$ was exceeded. ${ }^{50,63}$ In patients undergoing aortic arch surgery, Fischer et al. noted more conservative absolute desaturation thresholds of $65 \%$ and $60 \%$ to indicate an increased risk of adverse outcome..$^{51}$ Contrastingly, Kok et al. in a pilot study failed to show a relationship between cerebral desaturation and $\mathrm{PNC}^{64}$

Moving forward to interventional-guided studies, Slater et al. through a prospective randomized interventional trial found a positive relation between cerebral desaturations and PNC using the mini-mental state examination (MMSE). ${ }^{63}$ In another prospective randomized interventional trial, Murkin et al. studied cerebral desaturations and postoperative morbidity in cardiac surgical patients undergoing CPB. ${ }^{62}$ More patients in the control group $(n=96)$, (i.e., no intervention based on normalization of intraoperative $\mathrm{rSO}_{2}$ within $75 \%$ of baseline) underwent prolonged cerebral desaturation episodes compared to the intervention group ( $n=98)$. Stroke rate, however, did not significantly differ between groups. The authors attributed this finding to the fact that their study lacked adequate statistical power for assessment of stroke ( $n=4$ in the control group, versus $n=1$ in the intervention group), as the a priori power analysis was based on major organ morbidity and mortality. Nevertheless, they conclude that intraoperative monitoring and management using cerebral oximetry may have a clinical benefit for the cardiac surgical patient. 


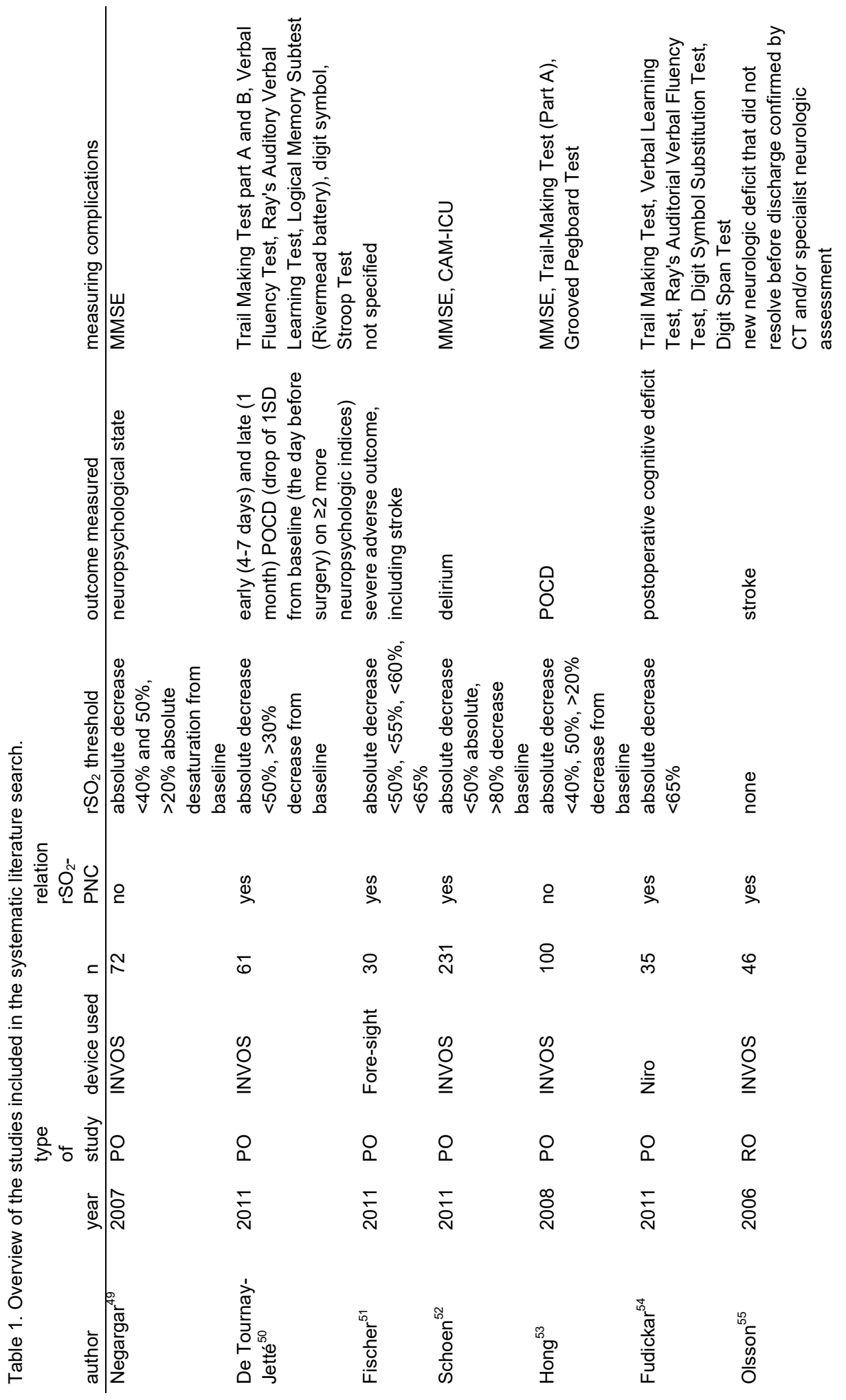




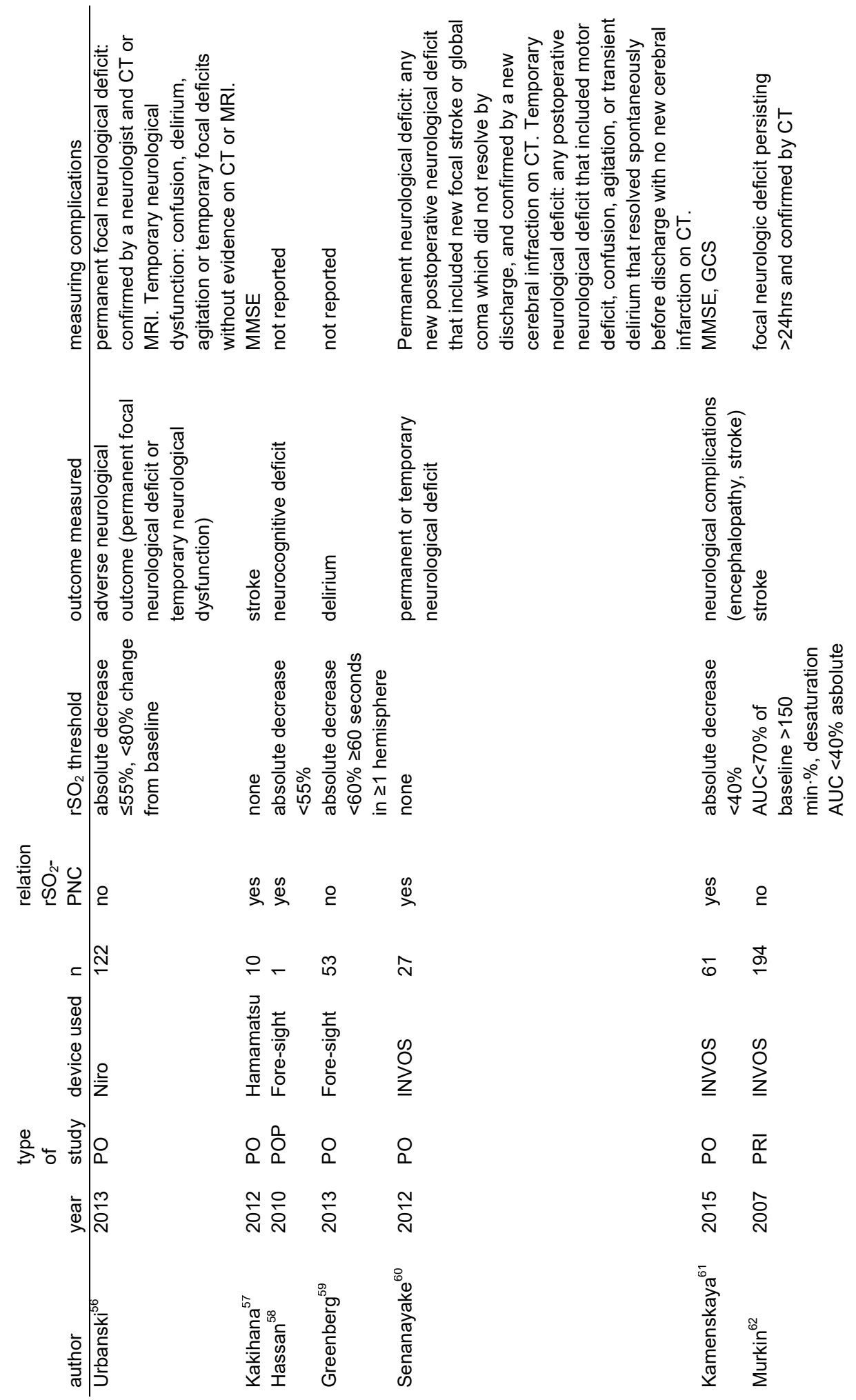




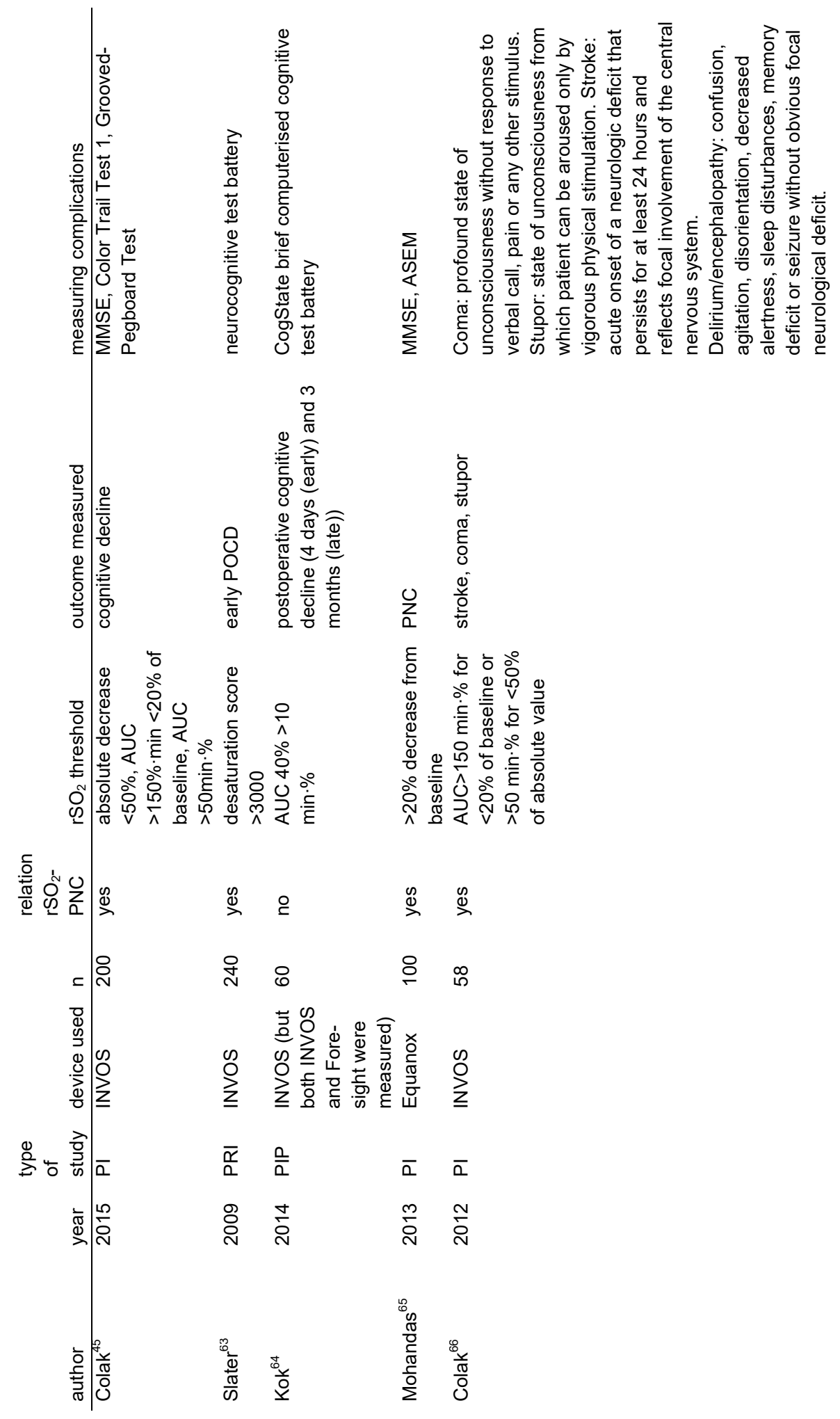




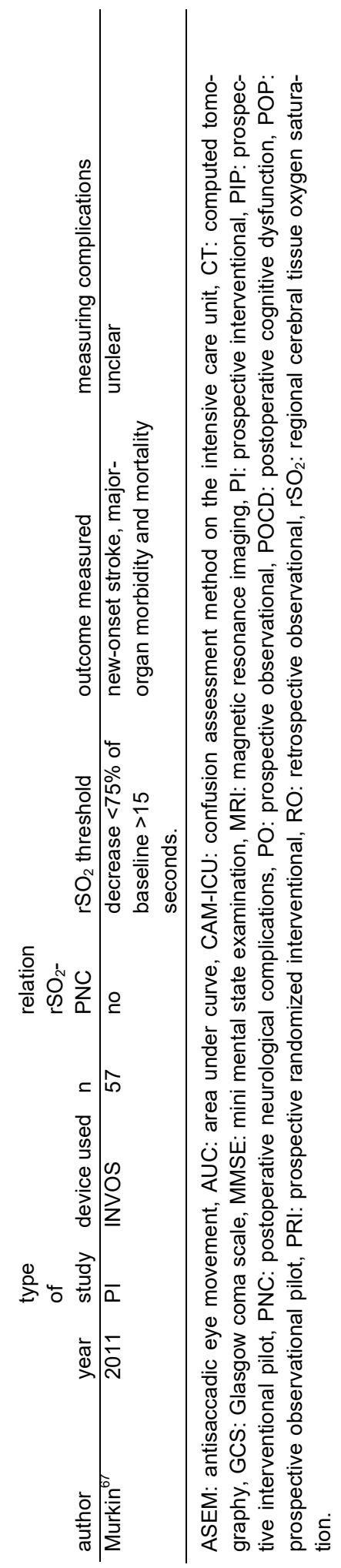




\section{Interpretation}

Several studies suggest that cerebral oximetry is a valuable monitoring tool and implicate that early intervention based on cerebral oximetry monitoring can potentially prevent or decrease the occurrence of PNC. Murkin even proposed that cerebral oximetry can be applied as an index organ, indicating that maintaining adequate cerebral $\mathrm{rSO}_{2}$ values is beneficial for all vital organs. ${ }^{15}$ Despite these findings it remains unclear if this is part of a causal relationship or just a reflection of overall morbidity. ${ }^{14}$

In a recent systematic review, data on the specificity of $\mathrm{rSO}_{2}$ monitoring to ensure cerebral perfusion could not be established, i.e., the absence of acute reductions in $\mathrm{rSO}_{2}$ did not ensure adequate cerebral blood flow (CBF). ${ }^{17}$ Furthermore, Kok et al. reported no relationship between cerebral desaturations and $\mathrm{PNC}$, which can be explained by the fact that low $\mathrm{rSO}_{2}$ occurred only sporadically in their patient population. ${ }^{64}$ This suggests that factors other than intraoperative hypoxic episodes contribute to the development of PNC. Moreover, the incidence of PNC following cardiovascular procedures is relatively low, which affects the ability of studies to demonstrate a signficant association with cerebral desaturations. ${ }^{3,4,68}$ A plausible explanation for the low PNC occurrence can be found in the applied perfusion protocol, which includes maintaining the mean $A B P$ within a certain range $(70-90 \mathrm{mmHg})$, maintaining normoxia (partial arterial oxygen pressure between $11.0-14.0 \mathrm{kPa}$ or $83-105 \mathrm{mmHg}$ ) and normocapnia $\left(\mathrm{P}_{\mathrm{a}} \mathrm{CO}_{2} 4.5-5.5 \mathrm{kPa}\right.$ or $\left.34-41 \mathrm{mmHg}\right)$, with a hematocrit level $>28 \%$ throughout the intraoperative period. ${ }^{69}$ Further, it has been shown that avoiding large fluctuations in hemodynamic parameters during CPB decreases the risk of postoperative neurologic complications. ${ }^{70}$

Besides perfusion protocols, additional factors that likely alter the risk of PNC occurrence include patient and surgery-related parameters. Previous studies identified the factors advanced age, a history of neurologic events, insulindependent diabetes mellitus, congestive heart failure, peripheral vascular disease, prolonged CPB time, and a more complex surgical procedure to be linked to PNC occurrence..$^{6-9,17,20,45,68,71-74}$ In contrast, Fink et al. in a recent review state that the evidence linking cardiovascular procedures to cognitive outcome is scarce, and persistent postoperative cognitive impairment may solely reflect the presence of cognitive impairment prior to surgery. ${ }^{3}$

Moreover, the lack of standardization in the diagnosis of PNCs makes comparison between studies focusing on its determinants challenging. In the current literature, different cognitive assessment methods are applied to identify cognitive decline, of which the MMSE is most frequently used. ${ }^{12}$ These tests require measurements to be performed at different time points prior to and following surgical intervention. For diagnosis of stroke additional computed tomography 
scanning or magnetic resonance imaging is required. ${ }^{75}$ Furthermore, the MMSE does not account for frontal lobe abnormalities, which is the typical area for cerebral $\mathrm{rSO}_{2}$ measurement ${ }^{76}$, possibly causing a false-negative test result.

In summary, there is a lack of intervention-guided trials linking disturbances in cerebral oxygen saturation to occurrence of PNC. It is therefore doubtful whether regional $\mathrm{rSO}_{2}$ can be used as a specific brain monitor.

\section{Cerebral autoregulation}

Besides intraoperative cerebral desaturations, disturbances in the neuroprotective cerebral autoregulatory system are known to result in adverse neurological outcome. ${ }^{18,77,78}$ The definition of CA is the intrinsic ability of the cerebral vasculature to provide a constant $\mathrm{CBF}$ despite changes in cerebral perfusion pressure. ${ }^{79}$ In case of an intact CA, the cerebral perfusion pressure is coupled with the cerebral metabolic demands, preventing both ischemia and hyperemia. ${ }^{77}$ The central homeostatic system of CA provides neuroprotection against hypo-, hyperperfusion, and ischemia through vasodilation and vasoconstriction of the cerebral vasculature. Proportionate alterations in CBF and subsequent maintenance of brain metabolism ensure adequate oxygen saturation and removal of carbon dioxide and other metabolites. The cerebral vasculature receives its postganglionic sympathetic innervation from the superior cervical ganglion containing neuropeptide $Y$ and norepinephrine. This vascular response is dependent on vessel size and mostly initiated by the pial arteries extending from the circle of Willis. ${ }^{80}$ In case of a sudden increase in blood pressure, the cerebral autoregulatory response prevents cerebral hyperemia and disruption of the blood-brain barrier. ${ }^{81}$ This is reflected by the fact that when the CA fails, worsened clinical outcome can be expected, including an increased risk of PNC. ${ }^{82}$

According to previous studies, cerebral oximetry reflects CA by close association with a determinant of autoregulation, i.e., the cross-correlation between middle cerebral artery blood flow velocity and mean $A B P{ }^{83,84}$ Likewise, the positive association of a change in $\mathrm{rSO}_{2}$ with a change in $\mathrm{ABP}$ is thought to reflect the absence of $\mathrm{CA}$, also referred to as pressure passive cerebral perfusion. ${ }^{85,86}$ On the other hand, in the case of hyperperfusion (also referred to as luxury brain perfusion ${ }^{87}$, cerebral $\mathrm{rSO}_{2}$ values can be close to baseline while the $\mathrm{CA}$ is severely disturbed. This can be explained by the fact that the crosscorrelation between middle cerebral artery blood flow velocity and mean ABP is merely an intermediate indicator of $\mathrm{CA}$, as the phase relationship in the autoregulatory response is not taken into account. ${ }^{88}$

For assessing cerebral autoregulatory activity, either its efficiency or its efficiency combined with the time necessary for cerebrovascular resistance to adapt 
can be determined. These two methods are also referred to as steady-state CA or static CA and dynamic CA, respectively. ${ }^{89}$ In both static and dynamic assessment of $C A, A B P$ as well as CBF velocity (CBFV) need to be taken into account. Mostly transcranial Doppler is used for quantification of CBFV, utilizing high-frequency sound waves to penetrate the acoustic temporal window of the cranium. One commonly used method validated for determining the current state of CA using transcranial Doppler is transfer function analysis that estimates phase shift, coherence, and gain. The phase shift is the time difference observed between ABP (input) signal and the CBFV (output) signal, whereas coherence reflects the strength of the the magnitude of the transfer function between CBFV and ABP. ${ }^{90}$ The result of the transfer function analysis is an autoregulation index ranging from 0 (absence of autoregulatory activity) to 9 (strongest autoregulatory activity). ${ }^{91}$ In patients, fluctuations in ABP and thereby CBFV need to be initiated to provoke adaptation in cerebrovascular resistance. In awake subjects, this can be achieved through metronome-triggered breathing while during CPB the indexed pump flow can be varied in a cyclic manner. ${ }^{69}$

Although the association between cerebral desaturations and PNC remains inconclusive, the link between disturbances in the intrinsic autoregulatory system and PNC occurrence is well recognized. ${ }^{18,21,77,82,92-94}$ Despite this fact, disturbances in the CA are reported to occur relatively frequently, in $20 \%$ of patients undergoing $\mathrm{CPB} .{ }^{18}$ The primary requisite to maintain an intact $\mathrm{CA}$ is targeting a mean $A B P$ within a certain range, i.e., the lower and upper autoregulatory limits. A range of $60-150 \mathrm{mmHg}$ has been recommended to attain intact $\mathrm{CA}$, although these pressures can be affected by sympathetic nervous activity ${ }^{95}$, which is the case in chronic hypertension. ${ }^{81}$ Also, the lower limit of CA has a wide inter-individual range, and thereby poses a challenge to predict an intact $\mathrm{CA}$ based on preoperative measurements. ${ }^{84}$ Within the autoregulatory range, CBF velocity appears unaffected by CPB pump flow. ${ }^{96}$ However, when ABP falls below the lower limit of $\mathrm{CA}$, cerebral hypoperfusion and ischemia can result, as the cerebral vasculature cannot compensate any further for the reduction in perfusion pressure. ${ }^{97}$ Low CBF increases the risk of ischemic brain lesions leading to functional neuronal impairment or possibly even permanent neuronal injury. ${ }^{77}$ This has been confirmed by multiple studies reporting a positive relationship between a lowered mean $A B P$ and the occurrence of adverse neurologic events. ${ }^{18,92,94}$ More specifically, a $>15 \mathrm{mmHg}$ reduction in $A B P$ caused a $10 \%$ cerebral desaturation. ${ }^{98}$ In addition, a lowered perfusion pressure during bypass $(60-70 \mathrm{mmHg}$ ) has been previously associated with an increased occurrence of postoperative delirium, while no differences in intraoperative cerebral oximetry values were found between a low and high systemic perfusion pressure group. ${ }^{99}$ On the other hand, an ABP above the upper limit leads to cerebral hyperperfusion and possibly even edema, swelling, and hemorrhag- 
$\mathrm{es}^{77,78,100}$, predisposing the patient to an increased risk of postoperative delirium. ${ }^{94}$ Thus, maintenance of an adequate target $A B P$ is important to enable autoregulatory vascular compensation ${ }^{17}$ and thereby minimizing thrombotic and hypoxic events contributing to PNC. ${ }^{101,102}$ A recent study by Moerman et al. described several patterns of autoregulatory activity in response to a $20 \%$ change in blood pressure by administration of vasoactive drugs ${ }^{29}$ One would expect that when $\mathrm{CA}$ is intact, $\mathrm{CBF}$ and $\mathrm{rSO}_{2}$ remain constant despite changes in perfusion pressure. However, Moerman et al. observed a paradoxical response in some of the patients, i.e., a decrease in $\mathrm{rSO}_{2}$ when the perfusion pressure was increased and an increase in $\mathrm{rSO}_{2}$ when the perfusion pressure was decreased under normocapnic conditions. The authors contributed this phenomenon to an overcompensation of CA and considered it part of the normal physiologic response. Since multiple reaction patterns in cerebral autoregulatory activity were observed, they concluded that individualization of ABP targets might be the optimal approach in order to prevent hypo- and hyperperfusion. For example, in traumatic brain injury patients, CA may vary within a short time scale, underlining the importance of continuous CA monitoring. ${ }^{82}$

Presumably this may prove beneficial in terms of PNC risk. Although carbon dioxide reactivity has shown to influence $\mathrm{CBF}$ and thus $\mathrm{CA}$, all measurements in the study of Moerman et al. were performed at normocapnia, thereby precluding analysis of individual patterns of CA at different levels of $\mathrm{P}_{\mathrm{a}} \mathrm{CO}_{2}$.

Apart from the influence of mean $A B P$, several studies showed elevated levels of $\mathrm{P}_{\mathrm{a}} \mathrm{CO}_{2}$ to be accompanied by a decreased level of $\mathrm{CA}^{69,87,103}$, affecting hemoglobin saturation and $\mathrm{CBF}^{23}$ The report by Ševerdija et al. illustrated that hypercapnia is associated with a decreased autoregulatory activity (compared to normocapnia), whereas under hypocapnic conditions the level of CA is relatively close to baseline values. ${ }^{69}$ This effect has been elucidated through several studies and can be explained by the phenomena of hypocapnia causing an expansion of the autoregulatory plateau, resulting in improved CA functionality. ${ }^{104-106}$ In other words, both $\mathrm{ABP}$ and $\mathrm{P}_{\mathrm{a}} \mathrm{CO}_{2}$ influence cerebral $\mathrm{CBF}$ and are still not tightly controlled within the autoregulatory limits during CPB (mean $A B P$ between 60 and $150 \mathrm{mmHg}$ and $\mathrm{P}_{\mathrm{a}} \mathrm{CO}_{2}$ between 4.7 and $5.3 \mathrm{kPa}$ or 35 and 40 $\mathrm{mmHg})^{69,107}$

Additionally, the extent of hemodilution (hematocrit level $\leq 18 \%$ or $<19 \%$ ) showed to be related to PNC and possibly an increased risk of mortality. ${ }^{108,109}$ Mathew et al. even had to prematurely terminate their study due to the occurrence of adverse events attributed to profound hemodilution. ${ }^{108}$ Specifically, hemodilution has been associated with perioperative stroke in cardiac surgical patients. ${ }^{110}$ This relation can be partially explained by its adverse effects on CA. ${ }^{111}$ Ševerdija et al. showed that patients with a reduced hematocrit $(<28 \%)$ during bypass have decreased levels of $C A^{69}$, whereas Karkouti et al. reported 


\section{CHAPTER 2}

that a $12 \%$ decrease in hematocrit is associated with neurocognitive decline. ${ }^{110}$ Hemodilution combined with hypercapnia even resulted in the largest decrease in autoregulatory activity during CPB ${ }^{69}$ These studies, therefore, emphasize the adverse effects of nadir hemodilution during CPB.

In conclusion, disturbances in CA are associated with cerebral malperfusion, contributing to adverse neurological outcome following cardiac surgery with $\mathrm{CPB}$. Therefore, tight control of mean ABP within the autoregulatory range, avoiding hypercapnia and minimizing hemodilution and hemodynamic fluctuations during CPB will collectively contribute to preservation of CA and a further decrease in PNC occurrence. Although the literature linking cerebral oximetry readings and $\mathrm{PNC}$ remains inconclusive, clinicians should prioritize maintaining an intact CA rather than solely focusing on maintaining $\mathrm{rSO}_{2}$ values above a certain threshold. Future studies should aim at determining personalized values of mean $\mathrm{ABP}$ and $\mathrm{P}_{\mathrm{a}} \mathrm{CO}_{2}$ in order to preserve an intact $\mathrm{CA}$. 


\section{References}

1. Prasongsukarn K, Borger MA. Reducing cerebral emboli during cardiopulmonary bypass. Semin Cardiothorac Vasc Anesth 2005;9:153-158.

2. Ferguson TB, Jr., Hammill BG, Peterson ED, DeLong ER, Grover FL, Committee STSND. A decade of change--risk profiles and outcomes for isolated coronary artery bypass grafting procedures, 1990-1999: a report from the STS National Database Committee and the Duke Clinical Research Institute. Society of Thoracic Surgeons. Ann Thorac Surg 2002;73:9-90.

3. Fink HA, Hemmy LS, MacDonald R, et al. Intermediate- and Long-Term Cognitive Outcomes After Cardiovascular Procedures in Older Adults: A Systematic Review. Ann Intern Med 2015;163:107-117.

4. Clark RE, Brillman J, Davis DA, Lovell MR, Price TR, Magovern GJ. Microemboli during coronary artery bypass grafting. Genesis and effect on outcome. J Thorac Cardiovasc Surg 1995;109:249-257.

5. Arrowsmith JE, Grocott HP, Reves JG, Newman MF. Central nervous system complications of cardiac surgery. Br J Anaesth 2000;84:378-393.

6. Baranowska K, Juszczyk G, Dmitruk I, et al. Risk factors of neurological complications in cardiac surgery. Kardiol Pol 2012;70:811-818.

7. Knapik P, Ciesla D, Wawrzynczyk M, Knapik M, Borkowski J, Zembala M. Incidence and prediction of permanent neurological deficits after cardiac surgery - are the existing models of prediction truly global? Eur J Cardiothorac Surg 2010;37:717-723.

8. Bucerius J, Gummert JF, Borger MA, et al. Stroke after cardiac surgery: a risk factor analysis of 16,184 consecutive adult patients. Ann Thorac Surg 2003;75:472-478.

9. Hogue CW, Jr., Murphy SF, Schechtman KB, Davila-Roman VG. Risk factors for early or delayed stroke after cardiac surgery. Circulation 1999;100:642-647.

10. Likosky DS, Leavitt BJ, Marrin CA, et al. Intra- and postoperative predictors of stroke after coronary artery bypass grafting. Ann Thorac Surg 2003;76:428-434.

11. Fischer GW, Silvay G. Cerebral oximetry in cardiac and major vascular surgery. HSR Proc Intensive Care Cardiovasc Anesth 2010;2:249-256.

12. Cropsey C, Kennedy J, Han J, Pandharipande P. Cognitive dysfunction, delirium, and stroke in cardiac surgery patients. Semin Cardiothorac Vasc Anesth 2015;19:309-317.

13. van Harten $A E$, Scheeren TW, Absalom AR. A review of postoperative cognitive dysfunction and neuroinflammation associated with cardiac surgery and anaesthesia. Anaesthesia 2012;67:280-293.

14. Bevan PJ. Should cerebral near-infrared spectroscopy be standard of care in adult cardiac surgery? Heart Lung Circ 2015;24:544-550.

15. Murkin JM. Cerebral oximetry: monitoring the brain as the index organ. Anesthesiology 2011;114:12-13.

16. Orihashi K, Sueda T, Okada K, Imai K. Near-infrared spectroscopy for monitoring cerebral ischemia during selective cerebral perfusion. Eur J Cardiothorac Surg 2004;26:907-911.

17. Zheng F, Sheinberg R, Yee MS, Ono M, Zheng Y, Hogue CW. Cerebral near-infrared spectroscopy monitoring and neurologic outcomes in adult cardiac surgery patients: a systematic review. Anesth Analg 2013;116:663-676.

18. Ono M, Joshi B, Brady K, et al. Risks for impaired cerebral autoregulation during cardiopulmonary bypass and postoperative stroke. Br J Anaesth 2012;109:391-398.

19. Czosnyka M, Smielewski P, Kirkpatrick P, Menon DK, Pickard JD. Monitoring of cerebral autoregulation in head-injured patients. Stroke 1996;27:1829-1834.

20. Roach GW, Kanchuger M, Mangano CM, et al. Adverse cerebral outcomes after coronary bypass surgery. Multicenter Study of Perioperative Ischemia Research Group and the Ischemia Research and Education Foundation Investigators. N Engl J Med. 1996;335:1857-1863. 
21. Joshi B, Brady K, Lee J, et al. Impaired autoregulation of cerebral blood flow during rewarming from hypothermic cardiopulmonary bypass and its potential association with stroke. Anesth Analg 2010;110:321-328.

22. Murphy GS, Hessel EA, 2nd, Groom RC. Optimal perfusion during cardiopulmonary bypass: an evidence-based approach. Anesth Analg 2009;108:1394-1417.

23. Vretzakis G, Georgopoulou S, Stamoulis K, et al. Cerebral oximetry in cardiac anesthesia. J Thorac Dis 2014;6(Suppl1):S60-69.

24. Scott JP, Hoffman GM. Near-infrared spectroscopy: exposing the dark (venous) side of the circulation. Paediatr Anaesth 2014;24:74-88.

25. Valencia L, Rodriguez-Perez A, Ojeda N, Santana RY, Morales L, Padron O. Baseline cerebral oximetry values depend on non-modifiable patient characteristics. Anaesth Crit Care Pain Med 2015;34:345-348.

26. Nemoto EM, Bragin DE, Statom G, et al. Role of microvascular shunts in the loss of cerebral blood flow autoregulation. Adv Exp Med Biol 2014;812:43-49.

27. Guarracino F. Cerebral monitoring during cardiovascular surgery. Curr Opin Anaesthesiol 2008;21:50-54.

28. Kane JM, Steinhorn DM. Lack of irrefutable validation does not negate clinical utility of nearinfrared spectroscopy monitoring: learning to trust new technology. J Crit Care 2009;24:472e1-7.

29. Moerman A, Vandenplas G, Bove T, Wouters PF, De Hert SG. Relation between mixed venous oxygen saturation and cerebral oxygen saturation measured by absolute and relative near-infrared spectroscopy during off-pump coronary artery bypass grafting. $\mathrm{Br} \mathrm{J}$ Anaesth 2013;110:258-265.

30. Yoshitani K, Kawaguchi M, Tatsumi K, Kitaguchi K, Furuya H. A comparison of the INVOS 4100 and the NIRO 300 near-infrared spectrophotometers. Anesth Analg 2002;94:586-590.

31. Ghosh A, Elwell C, Smith M. Review article: cerebral near-infrared spectroscopy in adults: a work in progress. Anesth Analg. 2012;115:1373-1383.

32. Murkin JM, Arango M. Near-infrared spectroscopy as an index of brain and tissue oxygenation. Br J Anaesth 2009;103(Suppl1):i3-13.

33. Murkin JM. Is it better to shine a light, or rather to curse the darkness? Cerebral near-infrared spectroscopy and cardiac surgery. Eur J Cardiothorac Surg 2013;43:1081-1083.

34. Macmillan CS, Andrews PJ. Cerebrovenous oxygen saturation monitoring: practical considerations and clinical relevance. Intensive Care Med 2000;26:1028-1036.

35. Daubeney PE, Pilkington SN, Janke E, Charlton GA, Smith DC, Webber SA. Cerebral oxygenation measured by near-infrared spectroscopy: comparison with jugular bulb oximetry. Ann Thorac Surg 1996;61:930-934.

36. Lewis SB, Myburgh JA, Thornton EL, Reilly PL. Cerebral oxygenation monitoring by nearinfrared spectroscopy is not clinically useful in patients with severe closed-head injury: a comparison with jugular venous bulb oximetry. Crit Care Med 1996;24:1334-1338.

37. Ter Minassian A, Poirier N, Pierrot M, et al. Correlation between cerebral oxygen saturation measured by near-infrared spectroscopy and jugular oxygen saturation in patients with severe closed head injury. Anesthesiology 1999;91:985-990.

38. Ševerdija EE, Vranken NP, Teerenstra S, Ganushchak YM, Weerwind PW. Impact of intraoperative events on cerebral tissue oximetry in patients undergoing cardiopulmonary bypass. J Extra Corpor Technol 2015;47:32-37.

39. Faulkner JT, Hartley M, Tang A. Using cerebral oximetry to prevent adverse outcomes during cardiac surgery. Perfusion 2011;26:79-81.

40. Rubio A, Hakami L, Munch F, Tandler R, Harig F, Weyand M. Noninvasive control of adequate cerebral oxygenation during low-flow antegrade selective cerebral perfusion on adults and infants in the aortic arch surgery. J Card Surg 2008;23:474-479.

41. Chan SK, Underwood MJ, Ho AM, et al. Cannula malposition during antegrade cerebral perfusion for aortic surgery: role of cerebral oximetry. Can J Anaesth 2014;61:736-740. 
42. Spiess BD, Rotruck J, McCarthy $\mathrm{H}$, et al. Human factors analysis of a near-miss event: oxygen supply failure during cardiopulmonary bypass. J Cardiothorac Vasc Anesth 2015;29:204-209.

43. Wang SC, Lo PH, Shen JL, et al. Innominate artery dissection with presentation of sudden right frontal desaturation detected by cerebral oximetry in complicated thoracic aortic aneurysm repair surgery: a case report. J Clin Anesth 2011;23:137-141.

44. Yao FS, Tseng CC, Ho CY, Levin SK, Illner P. Cerebral oxygen desaturation is associated with early postoperative neuropsychological dysfunction in patients undergoing cardiac surgery. $\mathrm{J}$ Cardiothorac Vasc Anesth 2004;18:552-558.

45. Colak Z, Borojevic M, Bogovic A, Ivancan V, Biocina B, Majeric-Kogler V. Influence of intraoperative cerebral oximetry monitoring on neurocognitive function after coronary artery bypass surgery: a randomized, prospective study. Eur J Cardiothorac Surg 2015;47:447-454.

46. Harrer M, Waldenberger FR, Weiss $G$, et al. Aortic arch surgery using bilateral antegrade selective cerebral perfusion in combination with near-infrared spectroscopy. Eur J Cardiothorac Surg 2010;38:561-567.

47. Yu Y, Lu Y, Meng L, Han R. Monitoring cerebral ischemia using cerebral oximetry: pros and cons. Biomed Res 2015;30.

48. Douds MT, Straub EJ, Kent AC, Bistrick CH, Sistino JJ. A systematic review of cerebral oxygenation-monitoring devices in cardiac surgery. Perfusion 2014;29:545-552.

49. Negargar S, Mahmoudpour A, Taheri R, Sanaie S. The relationship between cerebral oxygen saturation changes and post operative neurologic complications in patients undergoing cardiac surgery. Pak J Med Sci 2007;23:380-385.

50. de Tournay-Jette E, Dupuis G, Bherer L, Deschamps A, Cartier R, Denault A. The relationship between cerebral oxygen saturation changes and postoperative cognitive dysfunction in elderly patients after coronary artery bypass graft surgery. J Cardiothorac Vasc Anesth 2011;25:95104.

51. Fischer GW, Lin HM, Krol M, et al. Noninvasive cerebral oxygenation may predict outcome in patients undergoing aortic arch surgery. J Thorac Cardiovasc Surg 2011;141:815-821.

52. Schoen J, Meyerrose J, Paarmann H, Heringlake M, Hueppe M, Berger KU. Preoperative regional cerebral oxygen saturation is a predictor of postoperative delirium in on-pump cardiac surgery patients: a prospective observational trial. Crit Care 2011;15:R218.

53. Hong SW, Shim JK, Choi YS, Kim DH, Chang BC, Kwak YL. Prediction of cognitive dysfunction and patients' outcome following valvular heart surgery and the role of cerebral oximetry. Eur J Cardiothorac Surg 2008;33:560-565.

54. Fudickar A, Peters S, Stapelfeldt C, et al. Postoperative cognitive deficit after cardiopulmonary bypass with preserved cerebral oxygenation: a prospective observational pilot study. BMC Anesthesiol 2011;11:7.

55. Olsson C, Thelin S. Regional cerebral saturation monitoring with near-infrared spectroscopy during selective antegrade cerebral perfusion: diagnostic performance and relationship to postoperative stroke. J Thorac Cardiovasc Surg 2006;131:371-379.

56. Urbanski PP, Lenos A, Kolowca M, et al. Near-infrared spectroscopy for neuromonitoring of unilateral cerebral perfusion. Eur J Cardiothorac Surg 2013;43:1140-1144.

57. Kakihana $Y$, Okayama N, Matsunaga $A$, et al. Cerebral monitoring using near-infrared timeresolved spectroscopy and postoperative cognitive dysfunction. Adv Exp Med Biol 2012;737:19-24.

58. Hassan MA, Rozario C, Elsayed H, Morcos K, Millner R. A novel application of cerebral oximetry in cardiac surgery. Ann Thorac Surg 2010;90:1700-1701.

59. Greenberg SB, Murphy G, Alexander J, Fasanella R, Garcia A, Vender J. Cerebral desaturation events in the intensive care unit following cardiac surgery. J Crit Care 2013;28:270-276.

60. Senanayake E, Komber M, Nassef A, Massey N, Cooper G. Effective cerebral protection using near-infrared spectroscopy monitoring with antegrade cerebral perfusion during aortic surgery. J Card Surg 2012;27:211-216. 
61. Kamenskaya OV, Cherniavsky AM, Klinkova AS, et al. Efficiency of Various Cerebral Protection Techniques Used during the Surgical Treatment of Chronic Pulmonary Thromboembolism. J Extra Corpor Technol 2015;47:95-102.

62. Murkin JM, Adams SJ, Novick RJ, et al. Monitoring brain oxygen saturation during coronary bypass surgery: a randomized, prospective study. Anesth Analg 2007;104:51-58.

63. Slater JP, Guarino T, Stack J, et al. Cerebral oxygen desaturation predicts cognitive decline and longer hospital stay after cardiac surgery. Ann Thorac Surg 2009;87:36-44.

64. Kok WF, van Harten AE, Koene BM, et al. A pilot study of cerebral tissue oxygenation and postoperative cognitive dysfunction among patients undergoing coronary artery bypass grafting randomised to surgery with or without cardiopulmonary bypass. Anaesthesia 2014;69:613-622.

65. Mohandas BS, Jagadeesh AM, Vikram SB. Impact of monitoring cerebral oxygen saturation on the outcome of patients undergoing open heart surgery. Ann Card Anaesth 2013;16:102-106.

66. Colak Z, Borojevic M, Ivancan V, Gabelica R, Biocina B, Majeric-Kogler V. The relationship between prolonged cerebral oxygen desaturation and postoperative outcome in patients undergoing coronary artery bypass grafting. Coll Antropol 2012;36:381-388.

67. Murkin JM, Adams SJ, Pardy E, Quantz M, McKenzie FN, Guo L. Monitoring brain oxygen saturation during coronary bypass surgery improves outcomes in diabetic patients: a post hoc analysis. Heart Surg Forum 2011;14:E1-E6.

68. McKhann GM, Grega MA, Borowicz LM, Jr., Baumgartner WA, Selnes OA. Stroke and encephalopathy after cardiac surgery: an update. Stroke 2006;37:562-571.

69. Ševerdija EE, Vranken NP, Simons AP, et al. Hemodilution Combined With Hypercapnia Impairs Cerebral Autoregulation During Normothermic Cardiopulmonary Bypass. J Cardiothorac Vasc Anesth 2015 29:1194-1199

70. Ganushchak YM, Fransen EJ, Visser C, De Jong DS, Maessen JG. Neurological complications after coronary artery bypass grafting related to the performance of cardiopulmonary bypass. Chest 2004;125:2196-2205.

71. McKhann GM, Goldsborough MA, Borowicz LM, Jr., et al. Predictors of stroke risk in coronary artery bypass patients. Ann Thorac Sur. 1997;63:516-521.

72. Borger MA, Ivanov J, Weisel RD, et al. Decreasing incidence of stroke during valvular surgery. Circulation 1998;98(19 Suppl):II137-143.

73. Wolman RL, Nussmeier NA, Aggarwal A, et al. Cerebral injury after cardiac surgery: identification of a group at extraordinary risk. Multicenter Study of Perioperative Ischemia Research Group (McSPI) and the Ischemia Research Education Foundation (IREF) Investigators. Stroke 1999;30:514-522.

74. Boeken U, Litmathe J, Feindt P, Gams E. Neurological complications after cardiac surgery: risk factors and correlation to the surgical procedure. Thorac Cardiovasc Surg 2005;53:33-36.

75. Sacco RL, Kasner SE, Broderick JP, et al. An updated definition of stroke for the 21st century: a statement for healthcare professionals from the American Heart Association/American Stroke Association. Stroke 2013;44:2064-2089.

76. Muehlschlegel S, Lobato EB. Con: all cardiac surgical patients should not have intraoperative cerebral oxygenation monitoring. J Cardiothorac Vasc Anesth 2006;20:613-615.

77. Bor-Seng-Shu E, Kita WS, Figueiredo EG, et al. Cerebral hemodynamics: concepts of clinical importance. Arq Neuropsiquiatr 2012;70:352-356.

78. Lin TW, Wang JN, Kan CD. Cerebral Hyperperfusion Syndrome After Surgical Repair of Congenital Supravalvular Aortic Stenosis. Ann Thorac Surg 2015;100:e51-e4.

79. Lassen NA. Cerebral blood flow and oxygen consumption in man. Physiol Rev. 1959;39:183238.

80. Kontos HA, Wei EP, Navari RM, Levasseur JE, Rosenblum WI, Patterson JL, Jr. Responses of cerebral arteries and arterioles to acute hypotension and hypertension. The Am J Physiol 1978;234:H371-H383.

81. Tameem A, Krovvidi, H. Cerebral physiology. Contin Educ Anaesth Crit Care Pain 2013:1-6. 
82. Czosnyka M, Miller C, Participants in the International Multidisciplinary Consensus Conference on Multimodality $M$. Monitoring of cerebral autoregulation. Neurocrit Care 2014;21(Suppl2):S95-S102.

83. Brady K, Joshi B, Zweifel C, et al. Real-time continuous monitoring of cerebral blood flow autoregulation using near-infrared spectroscopy in patients undergoing cardiopulmonary bypass. Stroke 2010;41:1951-1956.

84. Joshi B, Ono M, Brown C, et al. Predicting the limits of cerebral autoregulation during cardiopulmonary bypass. Anesth Analg 2012;114:503-510.

85. Heilbrun MP, Jorgensen PB, Boysen G. Relationships between perfusion pressure and regional cerebral blood flow in patients with intracranial mass lesions. Eur Neurol 1972;8:111-117.

86. McQuillen PS, Nishimoto MS, Bottrell CL, et al. Regional and central venous oxygen saturation monitoring following pediatric cardiac surgery: concordance and association with clinical variables. Pediatric Crit Care Med 2007;8:154-160.

87. Henriksen L. Brain luxury perfusion during cardiopulmonary bypass in humans. A study of the cerebral blood flow response to changes in $\mathrm{CO} 2, \mathrm{O} 2$, and blood pressure. Cereb Blood Flow Metab 1986;6:366-378.

88. Aaslid R. Cerebral autoregulation and vasomotor reactivity. Front Neurol Neurosci 2006;21:216-228.

89. Tiecks FP, Lam AM, Aaslid R, Newell DW. Comparison of static and dynamic cerebral autoregulation measurements. Stroke 1995;26:1014-1019.

90. Ševerdija EE, Gommer ED, Weerwind PW, Reulen JP, Mess WH, Maessen JG. Assessment of dynamic cerebral autoregulation and cerebral carbon dioxide reactivity during normothermic cardiopulmonary bypass. Med Biol Eng Comput. 2015;53:195-203.

91. Nogueira RC, Bor-Seng-Shu E, Santos MR, Negrao CE, Teixeira MJ, Panerai RB. Dynamic cerebral autoregulation changes during sub-maximal handgrip maneuver. PloS one 2013;8:e70821.

92. Ono M, Brady K, Easley RB, et al. Duration and magnitude of blood pressure below cerebral autoregulation threshold during cardiopulmonary bypass is associated with major morbidity and operative mortality. J Thorac Cardiovasc Surg 2014;147:483-489.

93. Kaku Y, Yoshimura S, Kokuzawa J. Factors predictive of cerebral hyperperfusion after carotid angioplasty and stent placement. AJNR Am J Neuroradiol 2004;25:1403-1408.

94. Hori D, Brown C, Ono M, et al. Arterial pressure above the upper cerebral autoregulation limit during cardiopulmonary bypass is associated with postoperative delirium. $\mathrm{Br} \mathrm{J}$ Anaesth 2014;113:1009-1017.

95. Paulson OB, Strandgaard S, Edvinsson L. Cerebral autoregulation. Cerebrovasc Brain Metab Rev 1990;2:161-192.

96. Cook DJ, Proper JA, Orszulak TA, Daly RC, Oliver WC, Jr. Effect of pump flow rate on cerebral blood flow during hypothermic cardiopulmonary bypass in adults. J Cardiothorac Vasc Anesth 1997;11:415-419.

97. Panerai RB, White RP, Markus HS, Evans DH. Grading of cerebral dynamic autoregulation from spontaneous fluctuations in arterial blood pressure. Stroke 1998;29:2341-2346.

98. Pedersen LM, Nielsen J, Ostergaard M, Nygard E, Nielsen HB. Increased intrathoracic pressure affects cerebral oxygenation following cardiac surgery. Clin Physiol Funct Imaging 2012;32:367-371.

99. Siepe M, Pfeiffer T, Gieringer A, et al. Increased systemic perfusion pressure during cardiopulmonary bypass is associated with less early postoperative cognitive dysfunction and delirium. Eur J Cardiothorac Surg 2011;40:200-207.

100. van Mook WN, Rennenberg RJ, Schurink GW, et al. Cerebral hyperperfusion syndrome. The Lancet Neurology 2005;4:877-888.

101. Browne SM, Halligan PW, Wade DT, Taggart DP. Postoperative hypoxia is a contributory factor to cognitive impairment after cardiac surgery. J Thorac Cardiovasc Surg 2003;126:10611064. 


\section{CHAPTER 2}

102. Sanders RD, Degos V, Young WL. Cerebral perfusion under pressure: is the autoregulatory 'plateau' a level playing field for all? Anaesthesia 2011;66(11):968-972.

103. Perry BG, Lucas SJ, Thomas KN, Cochrane DJ, Mundel T. The effect of hypercapnia on static cerebral autoregulation. Physiol Rep 2014;2.

104. Meng L, Gelb AW. Regulation of cerebral autoregulation by carbon dioxide. Anesthesiology 2015;122:196-205.

105. Artru AA, Katz RA, Colley PS. Autoregulation of cerebral blood flow during normocapnia and hypocapnia in dogs. Anesthesiology 1989;70:288-292.

106. McCulloch TJ, Boesel TW, Lam AM. The effect of hypocapnia on the autoregulation of cerebral blood flow during administration of isoflurane. Anesth Analg 2005;100:1463-1467.

107. Paulson OB, Waldemar G, Schmidt JF, Strandgaard S. Cerebral circulation under normal and pathologic conditions. Am J Cardiol 1989;63:2C-5C.

108. Mathew JP, Mackensen GB, Phillips-Bute B, et al. Effects of extreme hemodilution during cardiac surgery on cognitive function in the elderly. Anesthesiology 2007;107:577-584.

109. DeFoe GR, Ross CS, Olmstead EM, et al. Lowest hematocrit on bypass and adverse outcomes associated with coronary artery bypass grafting. Northern New England Cardiovascular Disease Study Group. Ann Thorac Surg 2001;71:769-776.

110. Karkouti K, Djaiani G, Borger MA, et al. Low hematocrit during cardiopulmonary bypass is associated with increased risk of perioperative stroke in cardiac surgery. Ann Thorac Surg 2005;80:1381-1387.

111. Ogawa Y, Iwasaki K, Aoki K, Shibata S, Kato J, Ogawa S. Central hypervolemia with hemodilution impairs dynamic cerebral autoregulation. Anesth Analg 2007;105:1389-1396. 


\section{CHAPTER 3}

\section{Hemodilution combined with hypercapnia impairs cerebral autoregulation during normothermic cardiopulmonary bypass}

EE Ševerdija*, NPA Vranken*, AP Simons, ED Gommer, JH Heijmans, JG Maessen, PW Weerwind

Published in J Cardiothorac Vasc Anesth 2015;29:1194-1199.

*These authors contributed equally to this study. 


\section{CHAPTER 3}

\section{Abstract}

Objective: To investigate the influence of hemodilution and arterial $\mathrm{PCO}_{2}$ on cerebral autoregulation and cerebral vascular $\mathrm{CO}_{2}$ reactivity.

Design: Prospective interventional study.

Setting: University hospital-based single-center study.

Participants: Forty adult patients undergoing elective cardiac surgery using normothermic cardiopulmonary bypass.

Interventions: Blood pressure variations induced by 6/minute metronometriggered breathing (baseline) and cyclic $6 /$ min changes of indexed pump flow at 3 levels of arterial $\mathrm{PCO}_{2}$.

Measurements and main results: Based on median hematocrit on bypass, patients were assigned to either a group of a hematocrit $\geq 28 \%$ or $<28 \%$. The autoregulation index was calculated from cerebral blood flow velocity and mean arterial blood pressure using transfer function analysis. Cerebral vascular $\mathrm{CO}_{2}$ reactivity was calculated using cerebral tissue oximetry data. Cerebral autoregulation as reflected by autoregulation index (baseline 7.5 ) was significantly affected by arterial $\mathrm{PCO}_{2}$ (median autoregulation index amounted to 5.7, 4.8, and 2.8 for arterial $\mathrm{PCO}_{2}$ of respectively $4.0,5.3$, and $6.6 \mathrm{kPa}, \mathrm{p} \leq 0.002$ ) respectively. Hemodilution resulted in a decreased autoregulation index; however, during hypocapnia and normocapnia, there were no significant differences between the two hematocrit groups. Moreover, the autoregulation index was lowest during hypercapnia when hematocrit was $<28 \%$ (autoregulation index 3.3 versus 2.6 for hematocrit $\geq 28 \%$ and $<28 \%$, respectively, $\mathrm{P}=0.014$ ). Cerebral vascular $\mathrm{CO}_{2}$ reactivity during hypocapnia was significantly lower when perioperative hematocrit was $<28 \%(P=0.018)$.

Conclusions: Hemodilution down to a hematocrit of $<28 \%$ combined with hypercapnia negatively affects dynamic cerebral autoregulation, which underlines the importance of tight control of both hematocrit and $\mathrm{P}_{\mathrm{a}} \mathrm{CO}_{2}$ during CPB. 


\section{Introduction}

Cardiopulmonary bypass (CPB) enables complex cardiac surgery. Neurologic complications, however, still remain a major concern and may be linked to altered brain perfusion. ${ }^{1}$ In general, reduced vasomotor reactivity has been associated with an increased risk of death. ${ }^{2}$ In cardiac surgical patients, impaired cerebral autoregulation has been associated with an adverse cognitive outcome. ${ }^{1}$ Others found a clear relationship between perioperative stroke risk and nadir hematocrit values. ${ }^{3}$ An interventional study by Mathew et al. on hemodilution with subsequent decreased levels of hematocrit during hypothermic CPB had to be preliminarily terminated, because of significant occurrence of adverse events in the low hematocrit group. ${ }^{4}$ Moreover, increased levels of arterial $\mathrm{CO}_{2}$ have shown to decrease cerebral autoregulation. ${ }^{5}$ To the best of the authors' knowledge, however, there is no literature available that combines cerebral autoregulation and/or cerebral vasomotor reactivity with both hematocrit level and arterial partial gas pressure of $\mathrm{CO}_{2}\left(\mathrm{P}_{\mathrm{a}} \mathrm{CO}_{2}\right)$.

The aim of this study was to investigate cerebral autoregulation and cerebral vascular reactivity with respect to hemodilution and arterial $\mathrm{CO}_{2}$ levels during normothermic CPB.

\section{Methods}

\section{Study population}

To study dynamic cerebral autoregulation and cerebral vascular reactivity for $\mathrm{CO}_{2}, 40$ random male patients scheduled for elective coronary bypass surgery in the time period July 2009 through July 2012 were included in this prospective explorative study. Presence of an adequate temporal acoustic window was the main inclusion criterion, along with absence of neurologic, renal, liver, or severe pulmonary disorders, diabetes, and severe atherosclerosis of carotid and/or middle cerebral arteries.

The study was approved by the medical ethical committee of the Maastricht University Medical Center (Dutch trial registration: NTR1723). All patients gave written informed consent.

\section{Patient management and conduct of CPB}

General anesthesia was induced with infusion of $1.0 \mu \mathrm{g} / \mathrm{kg}$ of sufentanil (Hameln Pharmaceuticals, Hameln, Germany), $2.0 \mathrm{mg} / \mathrm{kg}$ of propofol (Fresenius Kabi, Zeist, The Netherlands) and $1.0 \mathrm{mg} / \mathrm{kg}$ rocuronium bromide (Fresenius 
Kabi, Zeist, The Netherlands). A subsequent propofol infusion (Fresenius Kabi, Zeist, the Netherlands) was set to $5.0 \mathrm{mg} / \mathrm{kg} / \mathrm{h}$.

During normothermic nonpulsatile CPB using central cannulation, the centrifugal pump bypass flow rate was targeted at $2.4 \mathrm{l} / \mathrm{min} / \mathrm{m}^{2}$ body surface area. Mean arterial blood pressure was kept near the preoperative baseline value (between $70 \mathrm{mmHg}$ and $90 \mathrm{mmHg}$ ) using phenylephrine titration (pharmacy of Radboud UMC, Nijmegen, The Netherlands) via an infusion pump if necessary. Arterial partial gas pressure of $\mathrm{O}_{2}$ was kept between 13 and $20 \mathrm{kPa}$. Cardiac arrest was induced using crystalloid cardioplegia (St. Thomas II, St. Thomas Hospital, Exeter, United Kingdom).

Radial arterial blood pressure (ABP) was measured continuously using a patient monitoring system (Philips Healthcare, Eindhoven, The Netherlands). Pump flow was measured using an ultrasonic flow monitor (Transonic Systems Inc., Ithaca, NY). Cerebral blood flow velocity (CBFV) was measured from the left and right middle cerebral arteries at a depth ranging from 45 to $56 \mathrm{~mm}$ using two $2 \mathrm{MHz}$ transcranial Doppler probes (ST3, Spencer Technologies, Seattle, WA) respectively. Data signals of ABP, pump flow, and CBFV were collected and recorded using a data acquisition system (IDEEQ, Maastricht Instruments, Maastricht, The Netherlands). Cerebral tissue oxygen saturation $\left(\mathrm{S}_{\mathrm{ct}} \mathrm{O}_{2}\right)$ was monitored continuously using near-infrared spectroscopy (ForeSight, Casmed, Branford, CT). Hematocrit, $\mathrm{P}_{\mathrm{a}} \mathrm{CO}_{2}$ and $\mathrm{pH}$ were measured inline continuously (CDI500, Terumo, Tokyo, Japan).

\section{Dynamic assessment of cerebral autoregulation}

Cerebral autoregulation was assessed dynamically prior to administration of preoperative medication in the patient ward at rest (baseline) and in the operating room during CPB. On the ward, hematocrit was determined using a blood sample and autoregulation was assessed analogous to Diehl et al. using metronome-triggered $6 /$ minute breathing to vary cardiac preload and resultant cardiac output. ${ }^{6}$ CBFV was measured using transcranial Doppler sonography, and $A B P$ was measured noninvasively via Portapres (Finapres Medical Systems, Amsterdam, The Netherlands). The cerebral autoregulation index (ARI) was estimated using the resulting step response function in ABP and CBFV. ${ }^{7,8}$ In the operating room during $\mathrm{CPB}$, autoregulation was assessed with the aorta cross clamped and after cardioplegia administration. In contrast to the baseline measurement that used manipulations in cardiac output, during CPB the indexed pump flow was changed in a cyclic manner. During a time frame of 300 seconds, flow was varied with a frequency of $6 \mathrm{cycles} / \mathrm{min}$ and $2.5 \mathrm{~s}$ per indexed flow rate (from $2.4 \mathrm{~L} / \mathrm{min} / \mathrm{m}^{2}$ to $2.0 \mathrm{~L} / \mathrm{min} / \mathrm{m}^{2}$ and back to $2.4 \mathrm{~L} / \mathrm{min} / \mathrm{m}^{2}$, and from $2.4 \mathrm{~L} / \mathrm{min} / \mathrm{m}^{2}$ to $2.8 \mathrm{~L} / \mathrm{min} / \mathrm{m}^{2}$ and back to $2.4 \mathrm{~L} / \mathrm{min} / \mathrm{m}^{2}$, etc.), as described el- 
sewhere. ${ }^{9}$ ARI then was estimated using the recordings of pump flow, ABP, and CBFV.

\section{Assessment of cerebral vascular reactivity}

Cerebral vascular reactivity for $\mathrm{CO}_{2}\left(\mathrm{CO}_{2} \mathrm{R}\right)$ was assessed using the recordings of $\mathrm{S}_{\mathrm{ct}} \mathrm{O}_{2}$ and $\mathrm{P}_{\mathrm{a}} \mathrm{CO}_{2}$. The $\mathrm{P}_{\mathrm{a}} \mathrm{CO}_{2}$ at start of extracorporeal circulation was maintained at $5.3 \mathrm{kPa}$. For measurement purposes, $\mathrm{P}_{\mathrm{a}} \mathrm{CO}_{2}$ was varied stepwise from $4.0 \mathrm{kPa}$ to $5.3 \mathrm{kPa}$ to $6.6 \mathrm{kPa}$ by adjusting sweep gas flow to the oxygenator and brought back to $5.3 \mathrm{kPa}$ at the end of the measurements. The induced hypocapnic and hypercapnic conditions lasted for 5 minutes each. Subsequently, absolute cerebral $\mathrm{CO}_{2} \mathrm{R}\left(\mathrm{CO}_{2} \mathrm{R}_{\mathrm{abs}}\right)$ and relative cerebral $\mathrm{CO}_{2} \mathrm{R}\left(\mathrm{CO}_{2} \mathrm{R}_{\text {rel }}\right)$ were calculated for each change in $\mathrm{P}_{\mathrm{a}} \mathrm{CO}_{2}$ using the following formulae:

cerebral $\mathrm{CO}_{2} \mathrm{R}_{\mathrm{abs}}=\Delta \mathrm{S}_{\mathrm{ct}} \mathrm{O}_{2} / \Delta \mathrm{P}_{\mathrm{a}} \mathrm{CO}_{2}$

and

cerebral $\mathrm{CO}_{2} \mathrm{R}_{\text {rel }}=\left(\text { cerebral } \mathrm{CO}_{2} \mathrm{R}_{\mathrm{abs}} / \mathrm{S}_{\mathrm{ct}} \mathrm{O}_{2 ; 5.3 \mathrm{kPa}}\right)^{*} 100 \%$

where $\Delta \mathrm{S}_{\mathrm{ct}} \mathrm{O}_{2}$ represents the difference in $\mathrm{S}_{\mathrm{ct}} \mathrm{O}_{2}$ measured before and after an alteration of $\mathrm{p}_{\mathrm{a}} \mathrm{CO}_{2}$, during CPB; $\Delta \mathrm{p}_{\mathrm{a}} \mathrm{CO}_{2}$ represents the difference in $\mathrm{P}_{\mathrm{a}} \mathrm{CO}_{2}$. $\mathrm{S}_{\mathrm{ct}} \mathrm{O}_{2 ; 5.3 \mathrm{kPa}}$ represents $\mathrm{S}_{\mathrm{ct}} \mathrm{O}_{2}$ measured at a $\mathrm{P}_{\mathrm{a}} \mathrm{CO}_{2}$ of $5.3 \mathrm{kPa}$.

\section{Data processing and statistical analysis}

Depending on the on-bypass hematocrit level after aortic cross-clamping and after induction of cardiac arrest, patients were assigned to a group with a hematocrit value during CPB $\geq 28 \%$ (high hematocrit group) or $<28 \%$ (low hematocrit group), with $28 \%$ corresponding to the median hematocrit value calculated from all patients. For data of $\mathrm{CBFV}, \mathrm{ARI}$ and $\mathrm{S}_{\mathrm{ct}} \mathrm{O}_{2}$, average values of the left and right cerebral hemispheres were calculated and used for statistical analysis. Data distribution was assessed by performing the Shapiro-Wilk test and visual assessment of histograms. Depending on data distribution, numerical parameters are depicted either in mean and standard deviation or median and interquartile range. Values for $\mathrm{CBFV}, \mathrm{ARI}$, and $\mathrm{S}_{\mathrm{ct}} \mathrm{O}_{2}$ acquired from both left and right hemispheres were averaged. The independent samples Mann-Whitney $U$ test was used for comparison of numerical variables between the 2 groups of hematocrit. Cerebral autoregulation was tested between different levels of $\mathrm{P}_{\mathrm{a}}$ $\mathrm{CO}_{2}$ by the related samples of Friedman's two-way analysis of variance by ranks. If significant, the related samples of Wilcoxon signed rank test was used as a post-hoc test.

Cerebral autoregulation was tested between the 2 levels of hematocrit for each level of $\mathrm{P}_{\mathrm{a}} \mathrm{CO}_{2}$ by using the independent samples of Mann-Whitney U test. A Pvalue $<0.05$ was considered statistically significant for all tests. 


\section{CHAPTER 3}

\section{Results}

Patient demographics and preoperative data for all patients divided according to perioperative hematocrit level are shown in Table 1. Analysis revealed no significant difference between the high $(\geq 28 \%)$ and low hematocrit $(<28 \%)$ groups except for preoperative hematocrit $(P=0.002)$.

Table 2 shows CPB time, aortic cross-clamp time, difference in perioperative hematocrit, and the effect of hematocrit on cerebral $\mathrm{CO}_{2} \mathrm{R}$. Hematocrit during hypercapnia affected neither absolute nor relative cerebral $\mathrm{CO}_{2} \mathrm{R}$. During hypocapnia, in contrast, hematocrit was noted to have a significant effect on cerebral $\mathrm{CO}_{2} \mathrm{R}$ (cerebral $\mathrm{CO}_{2} \mathrm{R}_{\text {abs, hypo }}$ and $\mathrm{CO}_{2} \mathrm{R}_{\text {rel,hypo }}, \mathrm{P}=0.018$ for both).

Table 1. Patient demographics and preoperative data, specified for all $(n=40)$ and per perioperative hematocrit group.

\begin{tabular}{lllll}
\hline hematocrit & $\mathrm{n}=40$ & $\geq 28 \%,(\mathrm{n}=21)$ & $<28 \%,(\mathrm{n}=19)$ & $\begin{array}{l}\text { P-value } \geq 28 \% \\
\text { vs }<28 \%\end{array}$ \\
\hline age (years) & $60.1[55.8-68.6]$ & $58.9[55.4-68.6]$ & $61.2[56.4-68.7]$ & 0.566 \\
$\mathrm{BSA}\left(\mathrm{m}^{2}\right)$ & $2.1[1.9-2.2]$ & $2.1[1.9-2.2]$ & $2.0[1.8-2.1]$ & 0.624 \\
preoperative haematocrit $(\%)$ & $44.0[42.3-46.0]$ & $46.0[43.0-47.0]$ & $43.0[40.8-44.3]$ & 0.002 \\
$\mathrm{ABP}(\mathrm{mmHg})$ & $86.0[78.9-97.0]$ & $86.0[79.3-98.7]$ & $85.7[78.1-95.7]$ & 0.578 \\
$\mathrm{~S}_{\mathrm{ct}} \mathrm{O}_{2}(\%)$ & $71.9[70.0-73.9]$ & $72.0[70.4-74.7]$ & $71.0[68.8-72.3]$ & 0.098 \\
$\mathrm{CBFV}(\mathrm{cm} / \mathrm{s})$ & $40.3[34.5-47.6]$ & $39.3[34.4-47.7]$ & $41.8[36.5-49.7]$ & 0.561 \\
$\mathrm{ARI}$ & $7.5[7.0-8.0]$ & $7.4[6.5-8.0]$ & $7.5[7.1-8.0]$ & 0.671 \\
\hline
\end{tabular}

Data presented as median [interquartile range].

Abbreviations : BSA, body surface area; $A B P$, arterial blood pressure; $\mathrm{S}_{\mathrm{ct}} \mathrm{O}_{2}$, cerebral tissue oxygen saturation; $C B F V$, cerebral blood flow velocity; $A R I$, autoregulation index.

Comparing cerebral autoregulation at the 3 levels of $\mathrm{P}_{2} \mathrm{CO}_{2}$ for all 40 patients, regardless of hematocrit, showed autoregulation to be significantly affected by $\mathrm{P}_{\mathrm{a}} \mathrm{CO}_{2}$ level compared to both baseline (7.5 [7.0-8.0]) and to the other $\mathrm{P}_{\mathrm{a}} \mathrm{CO}_{2}$ levels $(\mathrm{P} \leq 0.002)$; for $\mathrm{P}_{\mathrm{a}} \mathrm{CO}_{2}=4.0,5.3$, and $6.6 \mathrm{kPa}$, the median $\mathrm{ARI}$ was 5.7 [4.86.4], 4.8 [4.0-5.7], and 2.8 [2.3-3.8], respectively. Compared to baseline and regardless of hematocrit, ARI proved lowest during hypercapnia $(P<0.001)$. 
Table 2. Perioperative data and cerebral vascular reactivity for $\mathrm{CO}_{2}$ for the high and low hematocrit group.

\begin{tabular}{llll}
\hline & $\geq 28 \%(\mathrm{n}=21)$ & $<28 \%(\mathrm{n}=19)$ & P-value \\
\hline CPB time $(\mathrm{min})$ & $71.0[58.5-82.5]$ & $82.0[62.0-93.0]$ & 0.231 \\
aortic cross clamp time $(\mathrm{min})$ & $49.0[41.0-58.5]$ & $47.0[38.0-66.0]$ & 0.585 \\
perioperative hematocrit $(\%)$ & $30.0[28.5-31.0]$ & $23.0[22.0-25.0]$ & $<0.001$ \\
cerebral $\mathrm{CO}_{2} \mathrm{R}_{\text {abs,hypo }}\left(\% \mathrm{~S}_{\mathrm{ct}} \mathrm{O}_{2} / \mathrm{kPa}\right)$ & $1.5[1.2-2.3]$ & $0.8[0.4-1.9]$ & 0.018 \\
cerebral $\mathrm{CO}_{2} \mathrm{R}_{\text {rel, hypo }}\left(\% \mathrm{~S}_{\mathrm{ct}} \mathrm{O}_{2} / \mathrm{kPa}\right)$ & $2.3[1.7-3.3]$ & $1.2[0.6-3.1]$ & 0.018 \\
cerebral $\mathrm{CO}_{2} \mathrm{R}_{\text {abs,hyper }}\left(\% \mathrm{~S}_{\mathrm{ct}} \mathrm{O}_{2} / \mathrm{kPa}\right)$ & $2.3[1.7-3.5]$ & $2.7[1.9-3.1]$ & 0.856 \\
cerebral $\mathrm{CO}_{2} \mathrm{R}_{\text {rel, hyper }}\left(\% \mathrm{~S}_{\mathrm{ct}} \mathrm{O}_{2} / \mathrm{kPa}\right)$ & $3.6[2.4-5.4]$ & $4.1[2.9-4.7]$ & 0.705 \\
\hline
\end{tabular}

Data presented as median [interquartile range]. $\mathrm{S}_{\mathrm{ct}} \mathrm{O}_{2}$, cerebral tissue oxygen saturation; CPB, cardiopulmonary bypass; $\mathrm{CO}_{2} R_{\text {abs, hypo }}$, absolute change of cerebral vascular reactivity for $\mathrm{CO}_{2}$ when altering $\mathrm{P}_{\mathrm{a}} \mathrm{CO}_{2}$ from $5.3 \mathrm{kPa}$ to $4.0 \mathrm{kPa} ; \mathrm{CO}_{2} \mathrm{R}_{\text {rel,hypo }}$, relative change of cerebral vascular reactivity for $\mathrm{CO}_{2}$ when altering $\mathrm{P}_{\mathrm{a}} \mathrm{CO}_{2}$ from $5.3 \mathrm{kPa}$ to $4.0 \mathrm{kPa} ; \mathrm{CO}_{2} \mathrm{R}_{\text {abs, hyper, absolute change of cerebral }}$ vascular reactivity for $\mathrm{CO}_{2}$ when altering $\mathrm{P}_{\mathrm{a}} \mathrm{CO}_{2}$ from $5.3 \mathrm{kPa}$ to $6.6 \mathrm{kPa} ; \mathrm{CO}_{2} \mathrm{R}_{\text {rel, hyper, relative }}$ change of cerebral vascular reactivity for $\mathrm{CO}_{2}$ when altering $\mathrm{P}_{\mathrm{a}} \mathrm{CO}_{2}$ from $5.3 \mathrm{kPa}$ to $6.6 \mathrm{kPa}$.

Table 3 shows intraoperative variables at different levels of both $\mathrm{P}_{\mathrm{a}} \mathrm{CO}_{2}$ and hematocrit. Analyzing cerebral autoregulation with respect to hematocrit only showed a significant difference at hypercapnia, during which ARI was lowest in the $<28 \%$ group (3.3 versus 2.6 for hematocrit $\geq 28 \%$ and $<28 \%$ respectively, $\mathrm{P}=0.0014$ ). A more illustrative presentation is provided by Figure 1 . None of the authors' study patients experienced any adverse neurological complications as expressed by delirium, cerebral vascular accident, and transient ischemic attack during the surgical procedure or in a $\mathbf{3 0}$ day follow-up. 


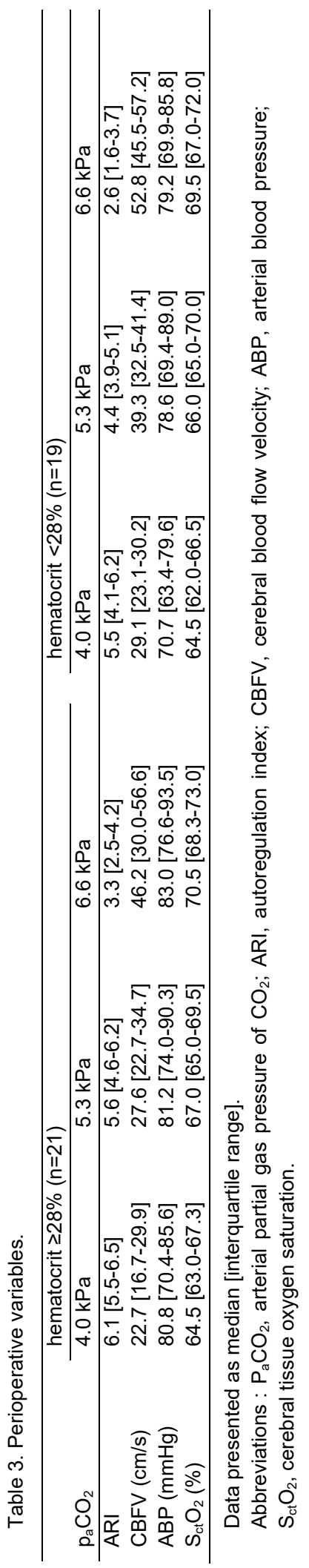




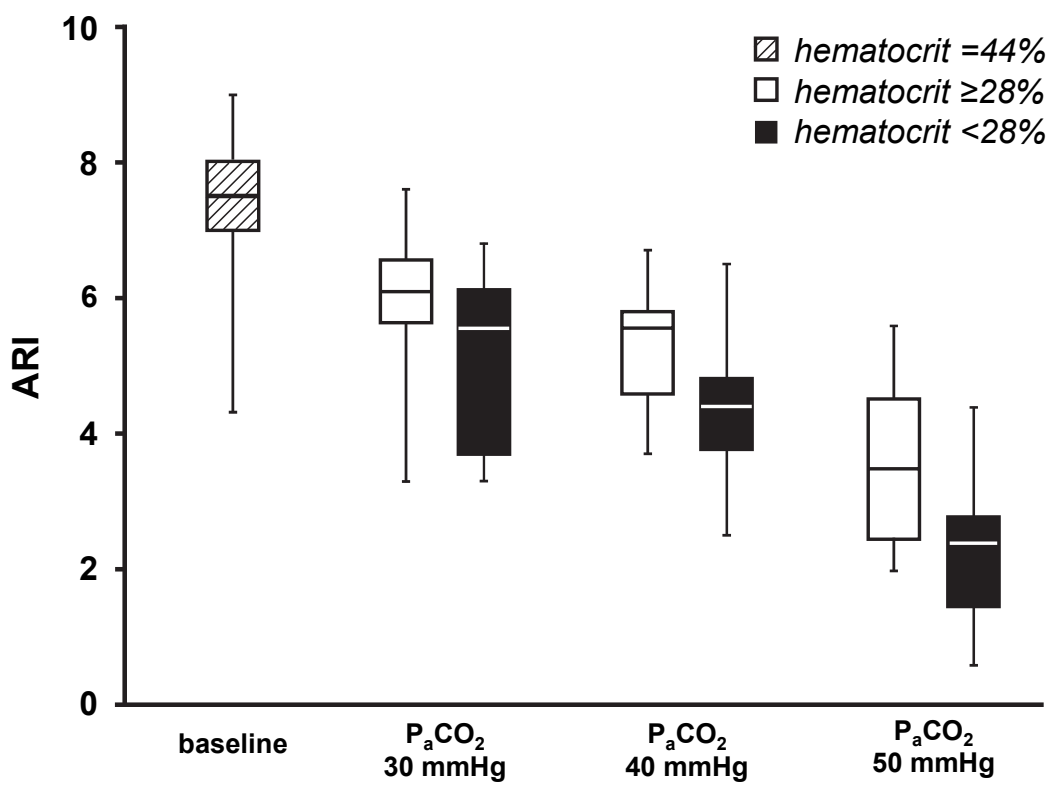

Figure 1. Cerebral autoregulation as indicated by the autoregulation index (ARI) at baseline, at 3 levels of $\mathrm{P}_{\mathrm{a}} \mathrm{CO}_{2}$, and at 2 levels of hematocrit during cardiopulmonary bypass.

\section{Discussion}

This study investigated dynamic cerebral autoregulation (dCA) during normothermic nonpulsatile CPB. Autoregulation proved to be lower compared to preoperative values and was affected by intraoperative hematocrit and $\mathrm{P}_{\mathrm{a}} \mathrm{CO}_{2}$. With impaired cerebral autoregulation being reflected by decreased $\mathrm{ARI}^{7}$, efforts have been made to assess normal values for ARI in both awake and anesthetized patients. ${ }^{10,11}$ In the authors' study, the preoperative median ARI in awake patients at rest was 7.5 (Figure 1). Tiecks et al. found ARI to amount to $5 \pm 1$ in patients at rest during light propofol anesthesia ${ }^{7}$, to which our results closely correspond. The authors measured in normocapnic $\left(\mathrm{P}_{\mathrm{a}} \mathrm{CO}_{2}=5.3 \mathrm{kPa}\right)$ patients a median ARI of 4.8 for the overall study population even though our patients were on full bypass and propofol anesthetized. Engelhard et al. found mean values for ARI to be 5.4 and 5.9 in awake patients prior to induction of anesthe$\mathrm{sia}^{11}$, which are lower compared to the authors' baseline ARI of 7.5. Gommer et al. ${ }^{8}$ showed an average ARI of 6.7 in young healthy volunteers using paced breathing at a 6/min frequency, an ARI higher compared to that for spontaneous breathing. Additionally, Engelhard et al. reported a mean ARI of 4.9 in abdominal surgical patients during anesthesia with combined propofol and remifentanil, 
which closely correlated to the authors' results, showing a median of 4.8 in normocapnic anesthetized patients. Although the hematocrit of the patients in that study was not mentioned, it may be expected that those patients were not exposed to such a relatively high level of hemodilution with resulting low hematocrit as our patients undergoing CPB (hematocrit median $=28 \%$ ). The patients in the study of Engelhard et al., however, showed ARI values relatively similar to those of the authors' patients, therefore suggesting these values to be representative for a normal ARI in the average normocapnic propofol-anesthetized cardiac surgical patient on bypass. In addition, propofol is known to decrease CBFV by reducing the cerebral metabolic rate of oxygen. ${ }^{12,13}$ Nevertheless, cerebral autoregulation has shown to be unaffected by propofol anesthesia, which implies that normal cerebral circulation and metabolism are maintained. ${ }^{14}$ With literature and the athors' data showing comparable values for ARI, their baseline and perioperative normocapnic measurements of ARI may be considered clinically representative for unimpaired (intact) values for cerebral autoregulation. This suggests that their baseline values measured in awake unanesthetized patients also may be applicable to surgical patients in general.

In surgical patients, impaired cerebral autoregulation (i.e., in the authors' data represented by decreased ARI levels) has been associated with increased occurrence of perioperative stroke. ${ }^{15}$ Additionally, a low hematocrit during CPB is known to contribute to postoperative morbidity and mortality. ${ }^{3,4,16}$ The authors' study investigated the effect of perioperative hematocrit on $\mathrm{dCA}$, and found ARI to be decreased at a hematocrit level $<28 \%$ (at a $\mathrm{P}_{\mathrm{a}} \mathrm{CO}_{2}$ level of $6.6 \mathrm{kPa}$ ). The relation between hemodilution and impaired dCA previously was elucidated by Ogawa et al., but they studied awake subjects and did not include measurements of $\mathrm{P}_{\mathrm{a}} \mathrm{CO}_{2}{ }^{17}$ Karkouti et al. found hemodilution to be associated with perioperative stroke. ${ }^{3}$ Roach et al. found that impaired cerebral autoregulation is associated with adverse neurological outcome. ${ }^{1}$ As a result of lowered perioperative hematocrit negatively influencing both cerebral autoregulation and postoperative neurological outcome, low hematocrit levels due to excessive hemodilution should be avoided, and techniques limiting hemodilution could prove beneficial. ${ }^{18,19}$

Arterial $\mathrm{CO}_{2}$ level has been demonstrated to affect cerebral blood flow by altering cerebral vasomotor reactivity. ${ }^{20}$ The authors' data also show that ARI decreases with increasing $\mathrm{P}_{\mathrm{a}} \mathrm{CO}_{2}$. For $\mathrm{P}_{\mathrm{a}} \mathrm{CO}_{2}=4.0,5.3$, and $6.6 \mathrm{kPa}$, the index amounted 5.7, 4.8, and 2.8, respectively. A study conducted by Henriksen et al. showed a negative effect on cerebral autoregulation when $\mathrm{P}_{\mathrm{a}} \mathrm{CO}_{2}$ level was increased. ${ }^{5}$ Moreover, Henriksen et al. found cerebral autoregulation to be nearabsent at a $\mathrm{P}_{\mathrm{a}} \mathrm{CO}_{2}$ level $>50 \mathrm{mmHg}(>6.7 \mathrm{kPa})$. Although the authors used such 
a high $\mathrm{P}_{\mathrm{a}} \mathrm{CO}_{2}$ level as well, results indicated a decreased but still present level of cerebral autoregulation, as depicted by a $35 \%$ reduction (ARI $=2.6)$ and $44 \%$ reduction ( $A R I=3.3)$ of autoregulation for the low and high hematocrit group, respectively, compared to baseline in awake subjects (ARI=7.5). With decreased cerebral autoregulation being associated with impaired or adverse neurological outcome, these data underline the importance of tight control of $\mathrm{P}_{\mathrm{a}} \mathrm{CO}_{2}$ during CPB. ${ }^{1}$

Cerebral autoregulation is a complex physiological mechanism, which is influenced by several factors including hematocrit and $\mathrm{P}_{\mathrm{a}} \mathrm{CO}_{2}{ }^{21,22}$ Ono et al. studied cerebral autoregulation during CPB and found increased $\mathrm{P}_{\mathrm{a}} \mathrm{CO}_{2}$ levels to be a factor of negative influence. ${ }^{15}$ As indicated by the authors' data, dCA was reduced with a lower hematocrit (Table 3 ). The data also showed that increased levels of $\mathrm{P}_{\mathrm{a}} \mathrm{CO}_{2}$ resulted in decreased $\mathrm{ARI}$ as well. Combining hypercapnia with low hematocrit $(<28 \%)$ showed the largest decrease in ARI compared to baseline (median $A R I_{\text {baseline }}=7.5$ (Fig 1). Summarized, the difference in ARI between patients with higher $(\geq 28 \%)$ and lower $(<28 \%)$ hematocrit $(\triangle A R I=4.2$ and $\triangle \mathrm{ARI}=4.9$, respectively) was most pronounced at the lower limit of cerebral autoregulation (2.8 [2.3-3.8]), which is found at a $\mathrm{P}_{\mathrm{a}} \mathrm{CO}_{2}$ level of $6.6 \mathrm{kPa}$. A possible explanation for the authors' finding is that hemodilution induces a reduction in viscosity and compensatory vasodilatation, therefore increasing CBFV, which results in a decreased autoregulatory capacity. ${ }^{23}$ The detrimental effect of combined hypercapnia and hemodilution underlines, once more, the importance of adequate $\mathrm{P}_{\mathrm{a}} \mathrm{CO}_{2}$ monitoring and tight perioperative $\mathrm{P}_{\mathrm{a}} \mathrm{CO}_{2}$ control while avoiding extreme hemodilution in order to diminish the risk of cognitive complications and adverse neurologic clinical outcome.

Cerebral $\mathrm{CO}_{2} \mathrm{R}$ plays an intricate part in the vascular autoregulatory system of the brain and aims at minimizing the effects of fluctuations in arterial blood pressure on cerebral perfusion. ${ }^{24}$ The authors' study showed that in hypocapnia there was a significant positive relationship between cerebral $\mathrm{CO}_{2} \mathrm{R}$ and hematocrit (Table 2). Tu et al. found similar results, reporting a decreased cerebral $\mathrm{CO}_{2} \mathrm{R}$ with isovolemic hemodilution. ${ }^{25}$ In contrast to Tu et al's study, however, the authors included alterations of $\mathrm{P}_{\mathrm{a}} \mathrm{CO}_{2}$ and showed that both hemodilution and arterial $\mathrm{CO}_{2}$ level affect cerebral $\mathrm{CO}_{2} \mathrm{R}$. Henriksen also found that decreased cerebral $\mathrm{CO}_{2} \mathrm{R}$ during hypocapnia is related to distinct changes in hematocrit. ${ }^{5}$ This is in line with the authors' findings of a significant difference in cerebral $\mathrm{CO}_{2} \mathrm{R}$ between the 2 hematocrit groups at a $\mathrm{P}_{\mathrm{a}} \mathrm{CO}_{2}$ level of $4.0 \mathrm{kPa}$ (Table 2). This can be explained by the fact that although cerebral autoregulation is suppressed during hypercapnia, cerebral blood flow as such is present. Blood 
flow even can be increased due to lowered viscosity as a result of hemodilution and increased cerebral $\mathrm{CO}_{2} \mathrm{R}$.

This study investigated cerebral autoregulation and found low hematocrit $(<28 \%)$ combined with hypercapnia to significantly decrease ARI. None the authors' study patients, however, experienced any adverse neurological complications as expressed by delirium, cerebral vascular accident, and transient ischemic attack during the surgical procedure or in a 30-day follow-up. This could be attributed to the short duration of 5 minutes in which hypercapnia was induced. Another explanation can be found in the authors' protocol of keeping mean arterial blood pressure in the $70 \mathrm{mmHg}$-to- $90 \mathrm{mmHg}$ range, which is close to the baseline values of their patients and in which cerebral autoregulation is generally considered present. ${ }^{26}$

In the authors' study, CBFV was measured using transcranial Doppler, a method that presumes the assumption of a constant vessel diameter. ${ }^{27}$ As previously elucidated, both $\mathrm{P}_{\mathrm{a}} \mathrm{CO}_{2}$ and hemodilution significantly affect cerebral $\mathrm{CO}_{2} \mathrm{R}$ and thereby blood flow, two factors that were altered in the authors' study subjects. However, several studies have exemplified that the diameter of larger arteries change minimally during hemodilution and hypercapnia. ${ }^{28,29}$ Therefore, changes in CBFV in the middle cerebral artery measured by Doppler legitimately reflect changes in cerebral blood flow.

Cerebral autoregulation is estimated by measuring CBFV at the middle cerebral artery using transcranial Doppler via the temporal window. ${ }^{24}$ The authors' study showed preoperative CBFV in resting conditions to be around $40 \mathrm{~cm} / \mathrm{s}$ (Table 1). Liboni et al. found CBFV to amount to approximately $67 \mathrm{~cm} / \mathrm{s}^{30}$, whereas Lindegaard et al. found CBFV to vary between 32 to $78 \mathrm{~cm} / \mathrm{s} .{ }^{31}$ Lindegaard et al. and the authors' study, however, included male patients, whereas Liboni et al. measured CBFV in women. In women, a proper acoustic optical temporal window frequently is absent, which impedes measurement of cerebral autoregulation. ${ }^{32}$ Although the authors' study did not include female patients, women show comparable or higher CBFV values ${ }^{30,33}$ and their results on cerebral autoregulation may be applicable to the full cardiac surgical population, including both genders.

\section{Conclusion}

Hemodilution down to a hematocrit of $<28 \%$ combined with hypercapnia negatively affects dynamic cerebral autoregulation, which underlines the importance 
of tight control of both hematocrit and $\mathrm{P}_{\mathrm{a}} \mathrm{CO}_{2}$ during $\mathrm{CPB}$. Perioperative cerebral monitoring proves a valuable tool for future studies evaluating cerebral autoregulation during CPB to, hopefully, clarify optimal perfusion strategies. 


\section{References}

1. Roach GW, Kanchuger M, Mangano, et al. Adverse cerebral outcomes after coronary bypass surgery. Multicenter Study of Perioperative Ischemia Research Group and the Ischemia Research and Education Foundation Investigators. N Engl J Med 1996;335:1857-1863.

2. Portegies ML, de Bruijn RF, Hofman A, et al. Cerebral vasomotor reactivity and risk of mortality: the Rotterdam Study. Stroke 2014;45:42-47.

3. Karkouti K, Djaiani G, Borger MA, et al: Low hematocrit during cardiopulmonary bypass is associated with increased risk of perioperative stroke in cardiac surgery. Ann Thorac Surg 2005;80:1381-1387.

4. Mathew JP, Mackensen GB, Phillips-Bute B, et al. Effects of extreme hemodilution during cardiac surgery on cognitive function in the elderly. Anesthesiology 2007;107:577-584.

5. Henriksen L. Brain luxury perfusion during cardiopulmonary bypass in humans. A study of the cerebral blood flow response to changes in $\mathrm{CO} 2, \mathrm{O} 2$, and blood pressure. J Cereb Blood Flow Metab 1986;6:366-378.

6. Diehl RR, Linden $D$, Lucke $D$, et al. Phase relationship between cerebral blood flow velocity and blood pressure. A clinical test of autoregulation. Stroke 1995;26:1801-1804.

7. Tiecks FP, Lam AM, Aaslid R, et al. Comparison of static and dynamic cerebral autoregulation measurements. Stroke 1995;26:1014-1019.

8. Gommer ED, Shijaku E, Mess WH, et al. Dynamic cerebral autoregulation: different signal processing methods without influence on results and reproducibility. Med Biol Eng Comput 2010;48:1243-1250.

9. Ševerdija EE, Gommer ED, Weerwind PW, et al. Assessment of dynamic cerebral autoregulation and cerebral carbon dioxide reactivity during normothermic cardiopulmonary bypass. Med Biol Eng Comput 2015;53:195-203.

10. Park CW, Sturzenegger M, Douville CM, et al. Autoregulatory response and $\mathrm{CO} 2$ reactivity of the basilar artery. Stroke 2003;34:34-39.

11. Engelhard $\mathrm{K}$, Werner $\mathrm{C}$, Mollenberg $\mathrm{O}$, et al. Effects of remifentanil/propofol in comparison with isoflurane on dynamic cerebrovascular autoregulation in humans. Acta Anaesthesiol Scand 2001:45:971-976.

12. Ogawa $\mathrm{Y}$, Iwasaki $\mathrm{K}$, Aoki $\mathrm{K}$, et al. The different effects of midazolam and propofol sedation on dynamic cerebral autoregulation. Anesth Analg 2010;111:1279-1284.

13. Strebel S, Lam AM, Matta B, et al. Dynamic and static cerebral autoregulation during isoflurane, desflurane, and propofol anesthesia. Anesthesiology 1995;83:66-76.

14. Oshima $T$, Karasawa $F$, Satoh $T$. Effects of propofol on cerebral blood flow and the metabolic rate of oxygen in humans. Acta Anaesthesiol Scand 2002;46:831-835.

15. Ono M, Joshi B, Brady K, et al. Risks for impaired cerebral autoregulation during cardiopulmonary bypass and postoperative stroke. Br J Anaesth 2012;109:391-398.

16. DeFoe GR, Ross CS, Olmstead EM, et al. Lowest hematocrit on bypass and adverse outcomes associated with coronary artery bypass grafting. Northern New England Cardiovascular Disease Study Group. Ann Thorac Surg 2001;71:769-776.

17. Ogawa $\mathrm{Y}$, Iwasaki $\mathrm{K}$, Aoki K, et al. Central hypervolemia with hemodilution impairs dynamic cerebral autoregulation. Anesth Analg 2007;105:1389-1396.

18. Ševerdija EE, Heijmans $J H$, Theunissen $M$, et al. Retrograde autologous priming reduces transfusion requirements in coronary artery bypass surgery. Perfusion 2011;26:315-321.

19. Vandewiele K, Bove T, De Somer FM, et al. The effect of retrograde autologous priming volume on haemodilution and transfusion requirements during cardiac surgery. Interact Cardiovasc Thorac Surg 2013;16:778-783.

20. Battisti-Charbonney A, Fisher J, Duffin J. The cerebrovascular response to carbon dioxide in humans. J Physiol 2011;589:3039-3048. 
21. Buhre W, Weyland A, Grune $F$, et al. Influence of arterial carbon dioxide tension on systemic vascular resistance in patients undergoing cardiopulmonary bypass. Acta Anaesthesiol Scand 1998;42:167-171.

22. Rudolph JL, Sorond FA, Pochay VE, et al. Cerebral hemodynamics during coronary artery bypass graft surgery: the effect of carotid stenosis. Ultrasound Med Biol 2009;35:1235-1241.

23. von Kummer R, Scharf $\mathrm{J}$, Back $\mathrm{T}$, et al. Autoregulatory capacity and the effect of isovolemic hemodilution on local cerebral blood flow. Stroke 1988;19:594-597.

24. Aaslid R, Lindegaard KF, Sorteberg W, et al. Cerebral autoregulation dynamics in humans. Stroke 1989;20:45-52.

25. Tu YK, Liu HM. Effects of isovolemic hemodilution on hemodynamics, cerebral perfusion, and cerebral vascular reactivity. Stroke 1996;27:441-445.

26. Lassen NA. Cerebral blood flow and oxygen consumption in man. Physiol Rev 19599:183-238.

27. Huber P, Handa J. Effect of contrast material, hypercapnia, hyperventilation, hypertonic glucose and papaverine on the diameter of the cerebral arteries. Angiographic determination in man. Invest Radiol 1967;2:17-32.

28. Bruder N, Cohen B, Pellissier D, et al. The effect of hemodilution on cerebral blood flow velocity in anesthetized patients. Anesth Analg 1998;86:320-324.

29. Larsen FS, Olsen KS, Hansen BA, et al. Transcranial Doppler is valid for determination of the lower limit of cerebral blood flow autoregulation. Stroke 1994;25:1985-1988.

30. Liboni W, Allais G, Mana O, et al. Transcranial Doppler for monitoring the cerebral blood flow dynamics: normal ranges in the Italian female population. Panminerva Med 2006;48:187-191.

31. Lindegaard KF, Lundar T, Wiberg J, et al. Variations in middle cerebral artery blood flow investigated with noninvasive transcranial blood velocity measurements. Stroke 1987;18:1025-1030.

32. Marinoni M, Ginanneschi A, Forleo P, et al. Technical limits in transcranial Doppler recording: inadequate acoustic windows. Ultrasound Med Biol 1997;23:1275-1277.

33. Deegan BM, Devine ER, Geraghty MC, et al. The relationship between cardiac output and dynamic cerebral autoregulation in humans. J Appl Physiol 1985;109:1424-1431. 



\section{CHAPTER 4}

\section{Cerebral autoregulation during cardiopulmonary bypass}

NPA Vranken, PW Weerwind

Published in Perfusion 2016;31:440. 


\section{CHAPTER 4}

Dear Editor,

Postoperative cognitive dysfunction (POCD) accompanied by short- and longterm effects remains a major burden for patients' recovery and quality of life following cardiac surgery with cardiopulmonary bypass (CPB). Several patientand procedure-related factors have shown to affect the risk of POCD, as discussed by Messerotti Benvenuti et al. in a recent issue of Perfusion (2015I30:514-516). ${ }^{1}$ They conclude that pre-existing cognitive status and not the duration of CPB is associated with POCD at middle-term postoperative evaluation. However, the authors did not elaborate on the CPB protocol that was used. For adequate interpretation of POCD risk, it is necessary also to take the cerebral autoregulation (CA) into account, as the neuroprotective autoregulatory system prevents both hypo- and hyperperfusion by reactive vasodilation and constriction following changes in arterial blood pressure (ABP) and arterial carbon dioxide tension. ${ }^{2}$ To maintain an intact $\mathrm{CA}$ during $\mathrm{CPB}$, it is, therefore, important to target a mean ABP within the autoregulatory range (60-150 $\mathrm{mmHg})^{2}$ and to maintain normocapnia (4.5-5.5 KPa). ${ }^{3}$ Moreover, it has been shown that avoiding large fluctuations in hemodynamic parameters during CPB results in a decreased risk of postoperative neurologic complications. ${ }^{4}$

In summary, for middle-term evaluation of POCD, it would be interesting to include intraoperative data on hemodynamics and arterial carbon dioxide tension. Taking this into account, apart from the role of patient-related factors, will add to a better understanding of the contributors involved in POCD risk.

\section{Declaration of conflicting interests}

The authors declared no potential conflicts of interest with respect to the research, authorship and/or publication of this article.

\section{Funding}

The authors received no financial support for the research, authorshop and/or publication of this article. 


\section{References}

1. Messerotti Benvenuti S, Patron E, et al. Are patient- or procedure-related factors relevant to middle-term cognitive decline after cardiac surgery? This is the question. Perfusion 2015;30:514-516.

2. Paulson OB, Strandgaard S, Edvinsson L. Cerebral autoregulation. Cerebrovasc Brain Metab Rev 1990;2:161-192.

3. Ševerdija EE, Vranken NP, Simons AP, et al. Hemodilution Combined With Hypercapnia Impairs Cerebral Autoregulation During Normothermic Cardiopulmonary Bypass. J Cardiothorac Vasc Anesth. Epub ahead of print 2 April 2015. DOI: 10.1053/j.jvca.2015.03.022.

4. Ganushchak YM, Fransen EJ, Visser C, et al. Neurological complications after coronary artery bypass grafting related to the performance of cardiopulmonary bypass. Chest 2004;125:21962205 



\section{CHAPTER 5}

\section{Impact of intraoperative events on cerebral tissue oximetry in patients undergoing cardiopulmonary bypass}

EE Ševerdija*, NPA Vranken*, S Teerenstra, YM Ganushchak, PW Weerwind

Published in J Extra Corpor Technol 2015;47:32-37.

${ }^{*}$ These authors contributed equally to this study 


\section{CHAPTER 5}

\section{Abstract}

Previous studies showed that decreased cerebral saturation during cardiac surgery is related to adverse postoperative outcome. Therefore, we investigated the influence of intraoperative events on cerebral tissue saturation in patients undergoing cardiac surgery with cardiopulmonary bypass (CPB).

A total of 52 adult patients who underwent cardiac surgery using pulsatile CPB were included in this prospective explorative study. Cerebral tissue oxygen saturation $\left(\mathrm{S}_{\mathrm{ct}} \mathrm{O}_{2}\right)$ was measured in both the left and right cerebral hemisphere. Intraoperative events, involving interventions performed by anesthesiologist, surgeon, and clinical perfusionist, were documented. Simultaneously, in-line hemodynamic parameters (partial oxygen pressure, partial carbon dioxide pressure, hematocrit, arterial blood pressure, and CPB flow rates) were recorded.

Cerebral tissue saturation was affected by anesthetic induction $(P<0.001)$, placement of the sternal retractor $(P<0.001)$, and initiation $(P<0.001)$ as well as termination of CPB $(P<0.001)$. Placement $(P<0.001)$ and removal of the aortic cross-clamp ( $P=0.026$ for left hemisphere, $P=0.048$ for right hemisphere) led to changes in cerebral tissue saturation. In addition, when placing the aortic cross clamp, hematocrit $(P<0.001)$ as well as arterial $(P=0.007)$ and venous $(P<0.001)$ partial oxygen pressures changed.

Cerebral tissue oximetry effectively identifies changes related to surgical events or vulnerable periods during cardiac surgery. Future studies are needed to identify methods of mitigating periods of reduced cerebral saturation. 


\section{Introduction}

Despite impressive improvements in the overall safety of cardiac surgery, perioperative cerebral injury remains a major concern. ${ }^{1}$ The two major causative factors for neuropsychological dysfunction after cardiac surgery are global brain hypoperfusion and cerebral emboli generated by either surgical or perfusionrelated interventions. ${ }^{2-6}$ Furthermore, worsened control of cerebral blood flow due to hypertension, diabetes, or other conditions imposes patients intraoperatively to increased risk of neurological complications. ${ }^{7,8}$ However, evaluation of cerebral hemodynamics may still not be part of routine practice. ${ }^{9}$

Intraoperative cerebral monitoring to identify vulnerable periods during cardiac surgery that require prompt intervention (e.g., adjusting the partial carbon dioxide gas pressure or fraction of inspired oxygen) should be a major goal in the fields of cardiac anesthesia, surgery, and perfusion. ${ }^{10,11}$ In a randomized, blinded, prospective study of 200 patients, Murkin et al. ${ }^{12}$ demonstrated that noninvasive regional cerebral saturation monitoring is associated with a significant improvement in overall outcome after cardiac surgery.

Moreover, using a protocol-based interventional strategy to maintain cerebral saturation within $75 \%$ of baseline values during cardiopulmonary bypass (CPB) may improve both neurological and multi-organ dysfunction outcomes in cardiac surgery. ${ }^{12,13}$ Using the brain as an index organ for adequate tissue perfusion may therefore be beneficial for all vital organs. ${ }^{14}$ Routine monitoring of cerebral saturation during cardiac surgical interventions may therefore detect early signs of post-surgery neurological deficits.

In this study, intraoperative events were recorded in order to qualify the effects on cerebral tissue oxygen saturation $\left(\mathrm{S}_{\mathrm{ct}} \mathrm{O}_{2}\right)$ in patients undergoing cardiac surgery with pulsatile CPB.

\section{Materials and methods}

\section{Patients}

This prospective, explorative non-randomized clinical study included 52 adult patients (38 male and 14 female) that underwent elective cardiac surgery using pulsatile CPB between November 2011 and May 2012. No restrictions or inclusion criteria were applied. Institutional approval was received for this evaluation and since the study did not influence the routine care of the patient, informed consent was waived.

Non-invasive absolute $\left(\mathrm{S}_{\mathrm{ct}} \mathrm{O}_{2}\right)$ was routinely measured via near-infrared spectroscopy (FORE-SIGHT; CAS Medical Systems, inc., Branford, CT) by placing a fiber optic sensor on each side of the patient's forehead. Cerebral oximetry was 
measured in both the left and right hemisphere. $\mathrm{S}_{\mathrm{ct}} \mathrm{O}_{2}$ data were simultaneously recorded every 2 seconds. All intraoperative events from anesthetic induction to discharge from the operating room were marked including the corresponding time in the data file. No interventions based on $\mathrm{S}_{\mathrm{ct}} \mathrm{O}_{2}$ changes were applied intraoperatively and data used for analysis were routine measurements.

\section{Anesthesia}

After establishing standard anesthetic monitoring including electrocaridogram, oxygen saturation, and invasive arterial blood pressure (ABP) measurement, general anesthesia was induced with $0.5 \mu \mathrm{g} / \mathrm{kg}$ sufentanil, $1.5 \mathrm{mg} / \mathrm{kg}$ propofol, and $0.6 \mathrm{mg} / \mathrm{kg}$ rocuronium. After endotracheal intubation, the patients were ventilated with volume-controlled ventilation with tidal volumes of $7-8 \mathrm{~mL} / \mathrm{kg}$, positive end-expiratory pressure of $5 \mathrm{~cm} \cdot \mathrm{H}_{2} \mathrm{O}$, respiratory rate of $12 / \mathrm{min}$, and a fraction of inspired oxygen of 0.4 , which resulted in normocapnia and normal oxygen oxygen saturation. Anesthesia was maintained with sevoflurane at a minimal alveolar concentration of approximately 0.8. Perioperative analgesic regime contained continuous intravenous administration of (S)-ketamine, lidocaine, and boluses of sufentanil.

Prior to surgery a warming blanket (3M Bair Hugger, 3M Health Care, Delft, The Netherlands) was positioned to maintain normothermia.

\section{Cardiopulmonary bypass}

The CPB system included a standard hollow-fiber membrane oxygenator (Capiox SX18R; Terumo Medical Corps,. Tokyo, Japan), a roller pump (S5; Sorin Group S.p.A, Mirandola, Italy), a cardiotomy reservoir (Capiox CXCRXA, Terumo), a collapsible venous reservoir (JVR 1900; Maquet Cardiopulmonary AG, Rastatt, Germany), and an arterial line filter (Leukogard-6, Pall, East Hills, NY). The standard priming of the CPB circuit consisted of $1500 \mathrm{~mL}$ of $4 \%$ gelofusin (B. Braun Melsungen AG, Melsungen, Germany), $200 \mathrm{~mL}$ of $20 \%$ mannitol (Viaflo; Baxter BV, Utrecht, The Netherlands), $100 \mathrm{~mL}$ of $20 \%$ human albumin (Albuman; Sanquin, Utrecht, The Netherlands), $50 \mathrm{~mL}$ of $8.4 \% \mathrm{NaHCO}_{3}$, and 20 $\mathrm{mL}$ of $10 \%$ calcium gluconate (B. Braun Melsungen $A G$ ). The total volume of the CPB priming amounted to $1870 \mathrm{~mL}$ clear fluid, containing $7500 \mathrm{IU}$ heparin (Leo Pharmaceutical Products BV, Weesp, The Netherlands). The activated coagulation time was kept $>400$ seconds during bypass. Myocardial preservation was provided via the aortic root or selectively via the coronary ostia by a single dose of cardioplegic solution ( $800 \pm 200 \mathrm{~mL}$; St. Thomas' hospital No.1) at $4^{\circ} \mathrm{C}$. Depending on the patients' body surface area, the ascending aorta was cannulated using either a 22- or 24-Fr cannula (Maquet Cardiopulmonary AG). A dual-stage venous cannula (32/40 or 36/51 Fr; Edwards Lifesciences BV, Breda, The Netherlands) was used for gravity drainage during coronary artery 
bypass grafting and aortic valve surgery. In case mitral or tricuspid valve surgery was involved, the venae cavae were cannulated separately using a DLP single-stage metal tip cannula (28 and 31 or 24 and 28 Fr; Medtronic, Inc., Minneapolis, MN).

Target flow rates of $\geq 2.6 \mathrm{~L} / \mathrm{min} / \mathrm{m}^{2}$ body surface area were maintained throughout normothermic $\left(36.3^{\circ} \mathrm{C}\right) \mathrm{CPB}$. Pulsatile flow (radial artery pulse pressure $\geq 25$ $\mathrm{mmHg}$ ) was used only during the period of cross-clamping with a frequency of 70 beats per minute, a base flow of $28 \%(1.4 \mathrm{~L} / \mathrm{min})$, and a pulse width of $50 \%$ (0.42 seconds). Mean ABP was maintained at $80 \pm 10 \mathrm{mmHg}$ by titration of phenylephrine $(0.4 \mathrm{mg} / \mathrm{mL})$ via an infusion pump if necessary. The sweep gas and fraction of inspired oxygen settings for the oxygenator were titrated to maintain normocapnia (arterial partial carbon dioxide pressure $-\mathrm{P}_{\mathrm{a}} \mathrm{CO}_{2} 4.5-5.5 \mathrm{kPa}$ ) and normoxia (partial arterial oxygen pressure $-\mathrm{P}_{\mathrm{a}} \mathrm{O}_{2} 11.0$ - $14.0 \mathrm{kPa}$ ). All patients received tranexamic acid $(2 \mathrm{mg})$ during $\mathrm{CPB}$. The transfusion trigger during CPB was set at a hematocrit level $<25 \%$. Pericardial blood was drained and washed with a cell saver device.

During valve and aortic root procedures carbon dioxide flooding was routinely used. By maintaining in-line normocapnia, no episodes of high $\mathrm{P}_{2} \mathrm{CO}_{2}$ that could have potentially influenced the cerebral saturation occurred.

\section{Near-infrared spectroscopy}

Cerebral tissue oximetry is measured non-invasively as described by Murkin and Arango. ${ }^{14}$ In short, oxygen content in the frontal lobes is measured by nearinfrared light penetrating the skin, skull, and other protective tissues. Nearinfrared light $(660-940 \mathrm{~nm})$ is partly scattered by chromophores within the tissue, absorbed by oxyhemoglobin or deoxyhemoglobin. The fiber optic sensors used in this study emit light at four different wavelengths to obtain greater precision for estimation of oxygen content.

\section{Data processing}

To be able to relate changes in cerebral saturation to occurring events, several hemodynamic parameters were recorded continuously during CPB: pump flow, $A B P$, as well as continuous in-line $\mathrm{P}_{\mathrm{a}} \mathrm{CO}_{2}$ and $\mathrm{P}_{\mathrm{a}} \mathrm{O}_{2}$, venous saturation, and electrolytes measurement via an optical fluorescence and reflectance-based system (CDI-500, Blood Parameter Monitoring System; Terumo, Japan). Pump flow was recorded by an ultrasonic flow monitor (Transonic Systems Europe $\mathrm{BV}$, Maastricht, The Netherlands). All in-line measurements except for $\mathrm{S}_{\mathrm{ct}} \mathrm{O}_{2}$ were collected using a data acquisition system (M-PAQ; Maastricht Instruments, Maastricht, The Netherlands). To combine all data, sample frequencies had to be equalized in all files. To achieve this, data were either averaged (decreasing the frequency of measuring), or the same data point was duplicated and added 


\section{CHAPTER 5}

after its original data point (increasing the frequency of measuring). Subsequently, data synchronization was performed. For further data analysis, samples of 5 minutes were selected. One time sample was selected prior to the event, and the other one during the event.

\section{Statistical analysis}

Data are shown as mean \pm SD or median (interquartile range), depending on data distribution. A P-value of $<.05$ was considered statistically significant.

For events occurring before or after $\mathrm{CPB}$, only cerebral $\mathrm{S}_{\mathrm{ct}} \mathrm{O}_{2}$ and $\mathrm{ABP}$ were compared between samples prior and during the event. For placement and removal of the aortic cross-clamp, cerebral $\mathrm{S}_{\mathrm{ct}} \mathrm{O}_{2}$, mean $\mathrm{ABP}$, pump flow, and blood parameters $\left(\mathrm{P}_{\mathrm{a}} \mathrm{CO}_{2}, \mathrm{P}_{\mathrm{a}} \mathrm{O}_{2}, \mathrm{P}_{\mathrm{v}} \mathrm{O}_{2}\right.$ and hematocrit) were compared. If one or more parameters differed significantly between the two samples, a possible cause of the difference in $\mathrm{S}_{\mathrm{ct}} \mathrm{O}_{2}$ could be determined.

Statistical analysis was performed using the Statistical Package for Social Sciences version 15.0 (SPSS inc., Chicago, IL). Distribution of data was tested using the Shapiro-Wilk test. The paired student's $t$ test or Wilcoxon signed-rank test was used to compare cerebral saturation measurement before and during events.

\section{Results}

Demographic and baseline data for the 52 enrolled patients are listed in Table 1. Surgical- and perfusion-related data are presented in Table 2.

During the entire intraoperative period, cerebral $\mathrm{S}_{\mathrm{ct}} \mathrm{O}_{2}$ showed comparable values for both left and right hemisphere. Left and right mean $\mathrm{S}_{\mathrm{ct}} \mathrm{O}_{2}$ values of $71 \pm 4 \%$ and $70 \pm 4 \%$ were found prior to CPB, $66 \pm 4 \%$ and $65 \pm 4 \%$ during CPB, and $70 \pm 4 \%$ and $69 \pm 5 \%$ after CPB, respectively. Since the difference between the left and right hemisphere can be neglected, the influence of intraoperative events on $\mathrm{S}_{\mathrm{ct}} \mathrm{O}_{2}$ are depicted in Figure 1 using mean values.

Onset of CPB, placement and removal of the aortic cross-clamp (difference in significance between hemispheres, $\mathrm{P}=.026$ for the left and $\mathrm{P}=.048$ for right hemisphere) resulted in a decrease in $\mathrm{S}_{\mathrm{ct}} \mathrm{O}_{2}$, whereas anesthetic induction $(P<.001)$, placement of the sternal retractor $(P<.001)$, and termination of CPB $(P<.001)$ showed to be related to an increase in $\mathrm{S}_{\mathrm{ct}} \mathrm{O}_{2}$ (Figure 1). Furthermore, phenylephrine infusion $(P=.356)$, hemofiltration $(P=.892)$ and removal of the sternal retractor ( $P=.692$ for the left hemisphere, $P=0.123$ for the right hemisphere) did not result in a significant $\mathrm{S}_{\mathrm{ct}} \mathrm{O}_{2}$ change. Aortic cross-clamping showed to have a statistically significant impact on cerebral saturation as shown in Figure 1, which may in part be explained by differences in arterial and venous blood gas pa- 
rameters and hematocrit. During placement of the aortic cross-clamp, hematocrit decreased significantly $(P<.001)$, as well as arterial $(P=.007)$ and venous $(P<.001)$ oxygen levels (Table 3$)$. The changes in hematocrit, arterial, and venous $\mathrm{PO}_{2}$ did not occur during removal of the aortic cross-clamp.

In all cases, the postoperative period was uneventful and no intraoperative cerebral ischemic episode occurred.

Table 1. Demographic and baseline data.

\begin{tabular}{ll}
\hline gender (male/female) & $38 / 14$ \\
age (years) & $68(59.3-75.8)$ \\
$\mathrm{BMI}\left(\mathrm{kg} / \mathrm{m}^{2}\right)$ & $26.0(24.4-27.8)$ \\
diabetes Mellitus (yes/no) & $7 / 45$ \\
peripheral vascular disease (yes/no) & $4 / 48$ \\
mean ABP pre CPB (mmHg) & $102.1 \pm 11.3$ \\
$\mathrm{~S}_{\mathrm{ct}} \mathrm{O}_{2}$ mean pre CPB $(\%)$ & $70(66-71)$ \\
mean Hct pre CPB $(\%)$ & $41.0 \pm 3.9$ \\
\hline
\end{tabular}

ABP, arterial blood pressure; BMI, body mass index; CPB, cardiopulmonary bypass; Hct, hematocrit; $\mathrm{S}_{\mathrm{ct}} \mathrm{O}_{2}$, cerebral tissue oxygen saturation.

Parameters in italics are shown as median (interquartile range), and remaining parameters are shown as absolute numbers or mean \pm SD.

Table 2. Surgical and perfusion data.

\begin{tabular}{ll}
\hline isolated CABG surgery & $59.7 \%(n=31)$ \\
isolated valve surgery & $23.1 \%(n=12)$ \\
CABG + valve surgery & $13.5 \%(n=7)$ \\
ascending aorta replacement & $3.8 \%(n=2)$ \\
CPB time (minutes) & $80(69-105)$ \\
aortic cross clamp time (minutes) & $55(43-70)$ \\
mean Hct (\%) during CPB & $28(25-29)$ \\
mean pump flow (L/min) & $4.3 \pm 0.5$ \\
mean ABP (mmHg) during CPB & $75(71-80)$ \\
\hline
\end{tabular}

ABP, arterial blood pressure; CABG, coronary artery bypass grafting; Hct, hematocrit.

Data for mean pump flow is presented as mean \pm SD. Data for CPB time, aortic cross-clamp time, $\mathrm{Hct}$ and $\mathrm{ABP}$ are presented as median (interquartile range). 


\section{CHAPTER 5}

Table 3. Influence of aortic cross clamping on hemodynamic parameters.

Aortic cross-

Prior to cross-

clamp on

clamping During cross-clamping P-value

Mean ABP $(\mathrm{mmHg})$

72.4 (63.4-80.3)

73.9 (63.5-79.2)

0.420

$\mathrm{P}_{\mathrm{a}} \mathrm{CO}_{2}(\mathrm{kPa})$

$5.5(5.1-5.6)$

$5.4(5.0-5.6)$

0.792

$\mathrm{P}_{\mathrm{a}} \mathrm{O}_{2}(\mathrm{kPa})$

$14.9(12.6-18.0)$

$13.0(12.3-16.5)$

0.007

$\mathrm{p}_{\mathrm{v}} \mathrm{O}_{2}(\mathrm{kPa})$

$5.9 \pm 1.0$

$5.3 \pm 0.6$

$<0.001$

Hct (\%)

28.7 (26.5-31.6)

26.4 (24.6-29.0)

$<0.001$

CPB flow (L/min)

$4.3(3.8-4.7)$

$4.4(4.0-4.7)$

0.680

Aortic cross-

Prior to cross-

After cross-clamp

clamp off

clamp removal

\begin{tabular}{cc} 
Removal & P-value \\
\hline $71.6(67.2-77.7)$ & 0.196 \\
$5.5(5.3-5.7)$ & 0.017 \\
$14.4 \pm 2.7$ & 0.255 \\
$5.1 \pm 0.6$ & 0.535 \\
$27.5(23.7-29.6)$ & 0.761 \\
$3.7(0.1-4.6)$ & 0.093
\end{tabular}

$\mathrm{ABP}$, arterial blood pressure; $\mathrm{CPB}$, cardiopulmonary bypass; $\mathrm{Hct}$, hematocrit; $\mathrm{p}_{\mathrm{a}} \mathrm{CO}_{2}$, arterial carbon dioxide level; $\mathrm{p}_{\mathrm{a}} \mathrm{O}_{2}$, arterial oxygen level; $\mathrm{p}_{\mathrm{v}} \mathrm{O}_{2}$, venous oxygen level.

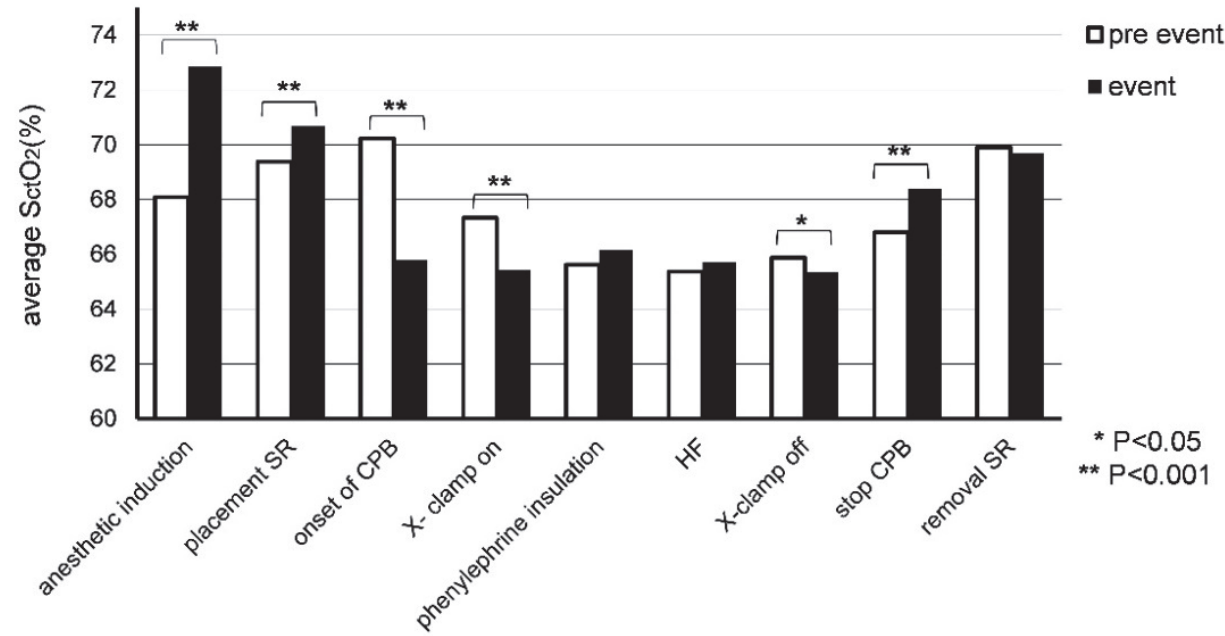

Figure 1. Influence of intraoperative events on mean cerebral $\mathrm{S}_{\mathrm{ct}} \mathrm{O}_{2}$. $\mathrm{CPB}$, cardiopulmonary bypass; $\mathrm{HF}$, hemofiltration; $\mathrm{S}_{\mathrm{ct}} \mathrm{O}_{2}$, cerebral oxygenation; $\mathrm{SR}$, sternal retractor; X-clamp, aortic cross clamp. 


\section{Discussion}

Intraoperative events showed to affect cerebral oximetry in patients undergoing cardiac surgery with CPB. Since previous studies suggest that a fall in cerebral saturation is related to adverse neurological outcome, routine measurement of cerebral saturation warrants early detection of brain ischemia during surgery. ${ }^{12-}$ 14

Our results showed subtle changes in $\mathrm{S}_{\mathrm{ct}} \mathrm{O}_{2}$ readings following several events that appeared statistically significant while absolute differences were relatively small and far from the suggested $20 \%$ decrease when intervention is required. ${ }^{14}$ Presumably the events did not provoke any therapeutically relevant changes in cerebral tissue saturation in our study. One can speculate that maintaining normocapnia, normoxia, and a tight blood pressure control led to minimized fluctuations in cerebral saturation. latrogenic events i.e., placement of the aortic cross-clamp can still induce changes in cerebral saturation, which do not necessarily require intervention. On the other hand, the extent of cerebral desaturation requiring an intervention may vary between different sensors, implying that no fixed thresholds have been set. ${ }^{15}$ Nonetheless, cerebral oximetry enables clinicians to observe slight changes in cerebral saturation, which may help to prevent further desaturations.

Induction of general anesthesia resulted in a steep increase in cerebral $\mathrm{S}_{\mathrm{ct}} \mathrm{O}_{2}$, which may be explained by pre-oxygenation with a high-inspired fraction of oxygen and unchanged cardiac output. ${ }^{16}$ Conversely, a significant decrease in mean $\mathrm{S}_{\mathrm{ct}} \mathrm{O}_{2}$ occurred with onset of $\mathrm{CPB}$, which can presumably be explained by acute hemodilution, as the hematocrit dropped from approximately $41 \%$ to $28 \%$ (Tables 1 and 2). These findings are in line with the study of Han et al. ${ }^{17}$ who showed that acute normovolemic hemodilution is associated with a fall in cerebral saturation. Rapid initiation of CPB mostly provoked a drop in $\mathrm{S}_{\mathrm{ct}} \mathrm{O}_{2}$ as resultant of assanguinous priming solution passage through the cerebral vasculature with inadequate oxygen delivery to the brain.

Placement of the sternal retractor is another factor influencing the cerebral saturation as measured by near-infrared spectroscopy. One could hypothesize that the change in cerebral saturation is caused by strong pain signals transported via the spinal cord during the event. In theory, this causes an immediate elevation in ABP. However, this effect is not observed in this study, which is potentially due to adequate anesthesia and analgesia.

Another theory is that opening the thoracic cavity influenced intrathoracic pressures and venous return, resulting in an increased cerebral saturation. On the 


\section{CHAPTER 5}

other hand, removal of the sternal retractor did not show a significant difference in $\mathrm{S}_{\mathrm{ct}} \mathrm{O}_{2}$. A plausible explanation for this observation is that the hypothesized pain signals were not activated or not in an extent large enough to cause a significant difference. Also, instead of generating pressure on the site of the sternum and surrounding tissue (as in placement of the sternal retractor), the opposite effect could have taken place i.e., relaxation.

Another event that showed to affect cerebral saturation is aortic-cross clamping, which may in part be explained by differences in arterial and venous blood gas parameters and hematocrit (Table 3). Placement of the aortic cross-clamp resulted in sudden excessive withdrawal of blood volume from patient to the heart-lung machine by lowering the CPB flow. This resulted in loss of cardiac output and a drop in ABP with concomitant negative consequences on oxygen delivery to the brain, as reflected by significantly lowered values of $\mathrm{PO}_{2}$ in both arterial and venous blood. CPB flow was not significantly different between samples of placement and removal of the cross-clamp, most likely because the duration of lowered flow was too short and the heart-lung machine was at optimal flow before and after both these events. In contrast, the decrease in arterial and venous $\mathrm{PO}_{2}$ did not appear while removing the cross-clamp as by routine during removal of the aortic cross-clamp the CPB flow and ABP are not actively lowered.

Vasoconstriction using phenylephrine infusion did not appear to affect cerebral saturation, which is in contrast with the results of a previous study by Moerman et al. ${ }^{18}$ However, Brassard et al. ${ }^{19}$ recently showed that the negative effect might only be present in diabetic patients.

Finally, a study limitation is the lack of an intervention-guided design. Physiologic parameters are kept within a certain range, preventing major fluctuations in cerebral tissue saturation during the intraoperative period. Furthermore, data synchronization involving the equalization of the sample frequency led to data (pump flow and ABP) to be leveled out and small fluctuations to be diminished compared to the raw data.

In conclusion, cerebral tissue oximetry by near-infrared spectroscopy effectively identifies subtle changes in cerebral saturation related to surgical events or vulnerable periods during cardiac surgery. Future studies in larger cohorts are required to identify therapeutically relevant changes in cerebral saturation as measured by cerebral oximetry. 


\section{References}

1. Wolman RL, Nussmeier NA, Aggarwal A, et al. Cerebral injury after cardiac surgery: Identification of a group at extraordinary risk. Multicenter Study of Perioperative Ischemia research group (McSPI) and the Ischemia Research Education Foundation (IREF) investigators. Stroke 1999;30:514-522.

2. Roach GW, Kanchuger M, Mangano CM, et al. Adverse cerebral outcomes after coronary bypass surgery. Multicenter Study of Perioperative Ischemia Research Group and the Ischemia Research and Education Foundation Investigators. N Engl J Med 1996;335:1857-1863.

3. Taylor RL, Borger MA, Weisel RD, Fedorko L, Feindel CM. Cerebral microemboli during cardiopulmonary bypass: increased emboli during perfusionist interventions. Ann Thorac Surg 1999;68:89-93.

4. Fearn SJ, Pole R, Wesnes K, Faragher EB, Hooper TL, McCollum CN. Cerebral injury during cardiopulmonary bypass: emboli impair memory J Thorac Cardiovasc Surg. 2001;121:11501160.

5. Prasongsukarn K, Borger MA. Reducing cerebral emboli during cardiopulmonary bypass. Semin Cardiothorac Vasc Anesth 2005;9:153-158.

6. Stockard JJ, Bialford RG, Schauble JF. Pressure-dependent cerebral ischemia during cardiopulmonary bypass. Neurology 1973;23:521-529.

7. Caplan LR, Hennerici M. Impaired clearance of emboli (washout) is an important link between hypoperfusion, embolism, and ischemic stroke. Arch Neurol 1998;55:1475-1482.

8. Millar SM, Alston RP, Andrews PJ, Souter MJ. Cerebral hypoperfusion in immediate postoperative period following coronary artery bypass grafting, heart valve, and abdominal aortic surgery. $\mathrm{Br} J$ Anaesth 2001;87:229-236.

9. Kasman N, Brady K. Cerebral oximetry for pediatric anesthesia: why do intelligent clinicians disagree? Paediatr Anaesth 2011;21(5):473-478.

10. Edmonds HL, Jr. Pro: All cardiac surgical patients should have intraoperative cerebral oxygenation monitoring. J Cardiothorac Vasc Anest. 2006;20:445-449.

11. Yao FSF, Tseng CCA, Ho CYA, et al. Cerebral oxygen desaturation is associated with early postoperative neuropsychological dysfunction in patients undergoing cardiac surgery $\mathrm{J}$ Cardiothorac Vasc Anest. 2004;18(5):2004:552-558

12. Murkin JM, Adams SJ, Novick RJ, et al. Monitoring brain oxygen saturation during coronary bypass surgery: a randomized, prospective study. Anesth Analg 2007;104:51-58.

13. Slater JP, Guarino T, Stack J, et al. Cerebral oxygen desaturation predicts cognitive decline and longer hospital stay after cardiac surgery. Ann Thorac Surg 2009;87:36-45.

14. Murkin JM, Arango M. Near-infrared spectroscopy as an index of brain and tissue oxygenation. Br J Anaesth 2009;103:i3-i13.

15. Apostolidou I, Morrissette G, Sarwar MF, et al. Cerebral oximetry during cardiac surgery: the association between cerebral oxygen saturation and perioperative patient variables. J Cardiothorac Vasc Anesth 2012;6:1015-1021.

16. Ravussin P, Guinard JP, Ralley F, Thorin D. Effect of propofol on cerebrospinal fluid pressure and cerebral perfusion pressure in patients undergoing craniotomy. Anaesthesia 1988;43:3741.

17. Han SH, Ham BM, Oh YS, et al. The effect of acute normovolemic haemodilution on cerebral oxygenation. Int J Clin Pract 2004;58:903-906.

18. Moerman A, Denys W, De Somer F, Wouters PF, De Hert SG.Influence of variations in systemic blood flow and pressure on cerebral and systemic oxygen saturation in cardiopulmonary bypass patients. Br J Anaesth 2013;111:619-626.

19. Brassard $P$, Pelletier $C$, Martin $M$, et al. Influence of norepinephrine and phenylephrine on frontal lobe oxygenation during cardiopulmonary bypass in patients with diabetes. J Cardiothorac Vasc Anesth 2014;28:608-617. 



\section{CHAPTER 6}

\section{Cerebral and limb tissue oxygenation during peripheral veno-arterial extracorporeal life support}

NPA Vranken, AAMA Lindelauf, AP Simons, MJH Ariës, JG Maessen, PW Weerwind

Published in J Intensive Care Med 2017, DOI: 10.1177/0885066617735270. 


\section{CHAPTER 6}

\section{Abstract}

Femoral access in extracorporeal life support (ECLS) has been associated with regional variations in arterial oxygen saturation, potentially predisposing the patient to ischemic tissue damage. Current monitoring techniques, however, are limited to intermittent bedside evaluation of capillary refill among other factors.

The aim of this study was to assess whether cerebral and limb regional tissue oxygen saturation $\left(\mathrm{rSO}_{2}\right)$ values reflect changes in various patient-related parameters during venoarterial ECLS (VA-ECLS).

This retrospective observational study included adults assisted by femorofemoral VA-ECLS. Bifrontal cerebral and bilateral limb tissue oximetry was performed for the entire duration of support. Hemodynamic data were analyzed parallel to cerebral and limb $\mathrm{rSO}_{2}$.

A total of 23 patients were included with a median ECLS duration of 5 [1-20] days. Cardiac arrhythmias were observed in 12 patients, which was associated with a decreased mean $\mathrm{rSO}_{2}$ from $61 \pm 11 \%$ to $51 \pm 10 \%$ during atrial fibrillation and $67 \pm 9 \%$ to $58 \pm 10$ during ventricular fibrillation ( $P<0.001$ for both). A presumably sudden increase in cardiac output due to myocardial recovery $(n=8)$ resulted in a significant decrease in mean cerebral $\mathrm{rSO}_{2}$ from $73 \pm 7 \%$ to $54 \pm 6 \%$ and from $69 \pm 9 \%$ to $53 \pm 8 \%$ for the left and right cerebral hemisphere, respectively $(\mathrm{P}=0.012$ for both hemispheres). Also, right radial artery partial gas pressure for oxygen decreased from $15.6 \pm 2.8$ to $8.3 \pm 1.9 \mathrm{kPa}(P=0.028)$. No differences were found in cerebral desaturation episodes between patients with and without neurologic complications. In six patients, limb $\mathrm{rSO}_{2}$ increased from on average $29.3 \pm 2.7$ to $64.0 \pm 5.1$ following insertion of a distal cannula in the femoral artery $(P=0.027)$. Likewise, restoration of flow in a clotted distal cannula was necessary in four cases and resulted in increased limb $\mathrm{rSO}_{2}$ from $31.3 \pm 0.8$ to $79.5 \pm 9.0 ; P=0.068$.

Non-invasive tissue oximetry adequately reflects events influencing cerebral and limb perfusion and can aid in monitoring tissue perfusion in patients assisted by ECLS. 


\section{Introduction}

Despite the increasing experience and continuously improving technology applied in extracorporeal life support (ECLS), femoral access is still associated with regional variations in arterial saturation driven by an impaired oxygen delivery. ${ }^{1}$ Specifically, femoral artery cannulation may compromise perfusion of the lower limbs, causing limb ischemia and concomitant tissue damage., ${ }^{2,3}$ Besides impaired limb perfusion, veno-arterial ECLS (VA-ECLS) is linked with the delivery of hypoxic blood to the brain (i.e., differential hypoxia or two-circulation syndrome), resulting in an increased risk of brain damage. ${ }^{4}$ Although maintaining adequate tissue oxygenation is vital in critically ill patients, current monitoring techniques are often limited to bedside observation of capillary refill, limb temperature, and limb color. Continuous non-invasive tissue oximetry could be of added value to monitor regional tissue oxygen saturation $\left(\mathrm{rSO}_{2}\right)$ in patients supported by ECLS. This monitoring method is based on the Beer-Lambert law and uses near-infrared spectroscopy (NIRS) to assess local tissue oxygenation. ${ }^{5}$ Tissue oximetry readings are proposed to reflect hemodynamic parameters in real-time, serving as a potential early marker for distal limb and cerebral ischemia. ${ }^{5-7}$ The literature describing the application of this monitoring technique in patients supported by VA-ECLS, however, remains scarce..$^{8-10}$

The aim of this study was to assess the efficacy of cerebral and limb tissue oximetry during VA-ECLS.

\section{Materials and Methods}

\section{Patients}

In this retrospective study, data from adult patients assisted by peripheral femoro-femoral VA-ECLS were consulted. Institutional approval was granted based on a retrospective quality analysis of our patient database (trial number 14-4194). Due to the retrospective nature of the study, informed consent was waived.

Patients were fully sedated and on mechanical ventilation. Support was provided by either a Permanent Life Support system (Maquet Cardiopulmonary AG, Hirlingen, Germany) or a CardioHelp-mounted HLS Advanced 7.0 module (Maquet Cardiopulmonary), both Bioline-coated. Extracorporeal cardiopulmonary resuscitation patients were actively cooled to a rectal temperature of $33^{\circ} \mathrm{C}$ for 24 hours and thereafter gradually rewarmed to $37^{\circ} \mathrm{C}$ using a heater-cooler unit ( $\mathrm{HCU} 30$, Maquet Cardiopulmonary). Arterial cannulation was performed 
using a $19 \mathrm{Fr}$. or $21 \mathrm{Fr}$. HLS cannula (Maquet Cardiopulmonary), whereas venous cannulation was performed using a $26 \mathrm{Fr}$. or $29 \mathrm{Fr}$. multi-stage HLS cannula (Maquet Cardiopulmonary). An additional 8Fr. or 10Fr. cannula (Super Arrowflex percutaneous sheath introducer set, Teleflex Medical Europe Ltd, Westmeath, Ireland) was used to provide distal limb perfusion via antegrade cannulation of the femoral artery if necessary. Heparinization was monitored by activated partial thromboplastin time (targeted between 50 and 70 seconds) and at a hematocrit value less than $25 \%$ patients received transfusion of packed red blood cells (PRBCs).

\section{Data collection}

$\mathrm{Bi}$-frontal cerebral and bilateral limb $\mathrm{rSO}_{2}$ were routinely monitored using noninvasive tissue oximetry using NIRS (INVOS 5100C Cerebral/Somatic Oximeter, Medtronic, Minneapolis, MN, USA). Immediately upon initiation of VA-ECLS, patients' forehead (left and right side) as well as the medial site of the musculus gastrocnemius (of both limbs) were fitted with a disposable self-adhesive sensor. All sensors were replaced once every seven days during the entire period of ECLS.

Data concerning systolic, diastolic and mean radial artery blood pressure, pulse pressure, cardiac rhythm, pulse oximetry, limb temperature, blood loss and number of transfused PRBCs were retrieved from a critical care and anesthesia data system (Philips ICIP Intellispace version F.00.01, Philips, Eindhoven, the Netherlands). Arterial blood gas analyses were executed using blood samples drawn from the right radial artery during the full period of intensive care unit stay according to hospital protocol. Pulse oximetry was performed at the left index finger. All data acquisition and analyses were performed anonymously and in accordance with the Dutch law for approving medical research.

\section{Data processing}

Raw data files retrieved from the clinical oximeter contain one data point every six seconds, i.e. ten data points per minute. The output files were exported to Microsoft Excel (Microsoft Office 2010) for further analysis.

To assess the effect of cardiac rhythm (sinus rhythm, atrial fibrillation (AF), and ventricular fibrillation (VF)) on cerebral $\mathrm{rSO}_{2}$, data were analyzed as follows: first, all cerebral $\mathrm{rSO}_{2}$ data points per patient were clustered in successive groups of 300 data points (30 minutes). For every group, a mean $\mathrm{rSO}_{2}$ value was calculated. A relative difference of $5 \%$ between two subsequent data points was marked as an event. Second, cardiac rhythm and $\mathrm{rSO}_{2}$ data were aligned. In case of an event identified in the cerebral $\mathrm{rSO}_{2}$ data, the cardiac rhythm was 
consulted to see if any arrhythmias occurred. In case of a cardiac arrhythmia, the lowest mean cerebral $\mathrm{rSO}_{2}$ value was derived for the duration of the particular arrhythmia. Also a mean cerebral $\mathrm{rSO}_{2}$ was derived from a 300 data point sample during normal sinus rhythm, resulting in a rhythm-specific mean cerebral $\mathrm{rSO}_{2}$ per patient. When a difference of $\geq 5 \%$ was found between the left and right cerebral hemisphere $\mathrm{rSO}_{2}$, values of both hemispheres were used for data presentation. In case of no difference between the left and right cerebral hemisphere, $\mathrm{rSO}_{2}$ data were presented as one mean value for both hemispheres.

The effect of distal limb perfusion on limb tissue oxygenation was determined by comparison of mean $\mathrm{rSO}_{2}$ values before (pre-event) and after (event) placement of a distal cannula in the femoral artery. Mean $\mathrm{rSO}_{2}$ values were determined by averaging 300 data points before and after placement of the distal cannula. The latter sample was selected immediately following limb $\mathrm{rSO}_{2}$ stabilisation. For comparison of tissue oxygenation values prior to (pre-event) and following (event) distal cannula clot removal, mean $\mathrm{rSO}_{2}$ values were calculated in a similar fashion using 300 data points per sample.

To investigate the difference in cerebral desaturation between patients who did and did not suffer from neurologic complications, a mean cerebral $\mathrm{rSO}_{2}$ was calculated for 30-minute intervals in both cerebral hemispheres for the entire duration of ECLS. A desaturation episode was defined as a mean unilateral cerebral $\mathrm{rSO}_{2}$ below $50 \%$ over a period of 30 minutes. Consecutively, the sum of desaturation episodes was compared between patients with and without neurologic complications.

\section{Statistical analysis}

Numerical variables are depicted either in mean \pm standard deviation or as median [interquartile range] depending on data distribution. Comparison of $\mathrm{rSO}_{2}$ values between the different cardiac rhythms, pre-event samples and event samples was performed using the related samples Wilcoxon signed-rank test. A $\mathrm{P}$-value $<0.05$ was considered statistically significant. All analyses were performed using the Statistical Package for Social Sciences version 22.0 (SPSS Inc., Chicago, IL, USA).

\section{Results}

Twenty-three adult patients assisted by femorofemoral VA-ECLS were included in this retrospective study. Mean age was $59 \pm 13$ years and a total of 18 females 


\section{CHAPTER 6}

and 5 males were included. The median duration of ECLS support was 5 [1-20] days with a mean full ECLS pump flow of $4.5 \pm 0.9 \mathrm{~L} / \mathrm{min}$.

Of the 23 patients, 16 were assisted by femorofemoral VA-ECLS upon resuscitation following an out-of-hospital cardiac arrest. Assistance by VA-ECLS was provided in three postcardiotomy cases. In the remaining four cases, life support was initiated following detection of, for example, pulmonary embolism. Distal cannulation was provided in six cases. Nine patients developed AF, whereas in three patients VF was observed. Development of abnormal cardiac rhythm was immediately followed by a decrease in mean $\mathrm{rSO}_{2}$ from $61 \pm 11 \%$ to $51 \pm 10 \%$ during $\mathrm{AF}$ and from $67 \pm 9 \%$ to $58 \pm 10$ during $\mathrm{VF}$ ( $\mathrm{P}<0.001$ for both). No significant differences were found between the left and right cerebral hemisphere $\mathrm{rSO}_{2}(\mathrm{P}=0.750)$. An example of a decrease in bifrontal cerebral $\mathrm{rSO}_{2}$ during $\mathrm{AF}$ is shown in Figure 1.

In case of a presumably increased cardiac output resulting from myocardial recovery during full ECLS ( $\mathrm{n}=8$, mean flow $4.45 \pm 0.6 \mathrm{~L} / \mathrm{min}$ ), a decrease in cerebral $\mathrm{rSO}_{2}$ was observed from $73 \%$ to $54 \%$ and from $69 \%$ to $53 \%$ for the left and right cerebral hemisphere, respectively ( $\mathrm{P}=0.012$ for both), as depicted in Table 1.

Table 1. Cerebral tissue oxygen saturation values in case of an im promptu increase in cardiac output while on extracorporeal life support. ${ }^{a, b}$

\begin{tabular}{llccl}
\hline & & before increased CO & during increased CO & P-value \\
\hline cerebral $\mathrm{rSO}_{2}(\%)$ & left & $73 \pm 7$ & $54 \pm 6$ & 0.012 \\
& right & $69 \pm 9$ & $53 \pm 8$ & 0.012 \\
arterial oxygen saturation (\%) & $99 \pm 1$ & $85 \pm 8$ & 0.028 \\
arterial $\mathrm{PO}_{2}(\mathrm{kPa})$ & $15.6 \pm 2.8$ & $8.3 \pm 1.9$ & 0.012 \\
pulse oximetry $(\%)$ & $99 \pm 1$ & $97 \pm 5$ & 0.075 \\
mean pressure $(\mathrm{mmHg})$ & $70 \pm 7$ & $80 \pm 15$ & 0.012 \\
\hline
\end{tabular}

Abbreviations: $\mathrm{CO}$, cardiac output; Left, left cerebral hemisphere; right, right cerebral hemisphere; $\mathrm{rSO}_{2}$, regional tissue oxygen saturation; $\mathrm{PO}_{2}$, partial gas pressure for oxygen.

${ }^{a} \mathrm{n}=8$

${ }^{b}$ Values presented as mean \pm standard deviation. 


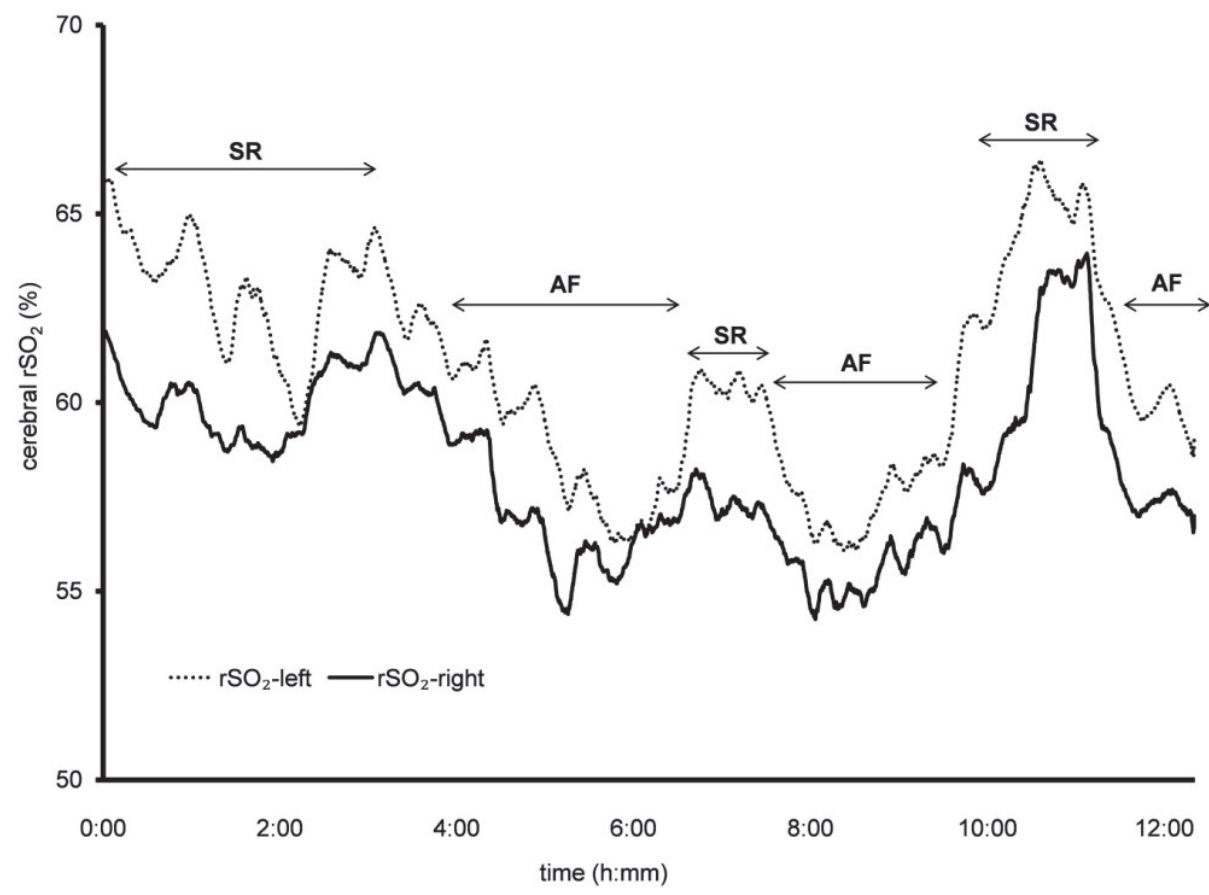

Figure 1. Example of a decrease in bi-frontal cerebral oxygen saturation during consecutive periods of atrial fibrillation and sinus rhythm. AF, atrial fibrillation; ECLS, extracorporeal life support; $\mathrm{rSO}_{2}$, regional tissue oxygen saturation; $\mathrm{rSO}_{2}$-left, regional tissue oxygen saturation left cerebral hemisphere, $\mathrm{rSO}_{2}$-right, regional tissue oxygen saturation right hemisphere; $\mathrm{SR}$, sinus rhythm.

Concomitant partial gas pressure for oxygen $\left(\mathrm{PO}_{2}\right)$ decreased from $15.6 \pm 2.8$ to $8.3 \pm 1.9 \mathrm{kPa}(\mathrm{P}=0.012)$. Arterial saturation values derived from blood gas analyses showed a significant decrease from $99 \pm 1 \%$ to $85 \pm 8 \% \quad(P=0.028)$, while pulse oximetry decreased from $99 \% \pm 1 \%$ to $97 \% \pm 5 \%$ ( $P=0.075)$. In Figure 2 the change in cerebral $\mathrm{rSO}_{2}$ values is shown in case of a sudden increased cardiac output during ECLS without concomitant adjustment of ventilator settings. After approximately one hour, the ventilatory settings were adjusted, resulting in gradual $\mathrm{rSO}_{2}$ normalization.

In the current study, a total of 11 patients $(47.8 \%)$ died while on VA-ECLS due to neurologic complications, deep cardiogenic shock, sepsis, pneumonia, lung edema, myocarditis, multi-organ failure, or intestinal ischemic damage. The total number of cerebral desaturation episodes did not differ between patients who did or did not survive until ECLS weaning (19 versus 12 episodes, respectively, $p=0.695)$. Five patients $(21.7 \%)$ developed neurological complications while on VA-ECLS, which included intracerebral hematoma or extensive ischemic dam- 


\section{CHAPTER 6}

age diagnosed with computed tomography imaging, critical illness neuropathy, and absence of the direct light pupil reflex.

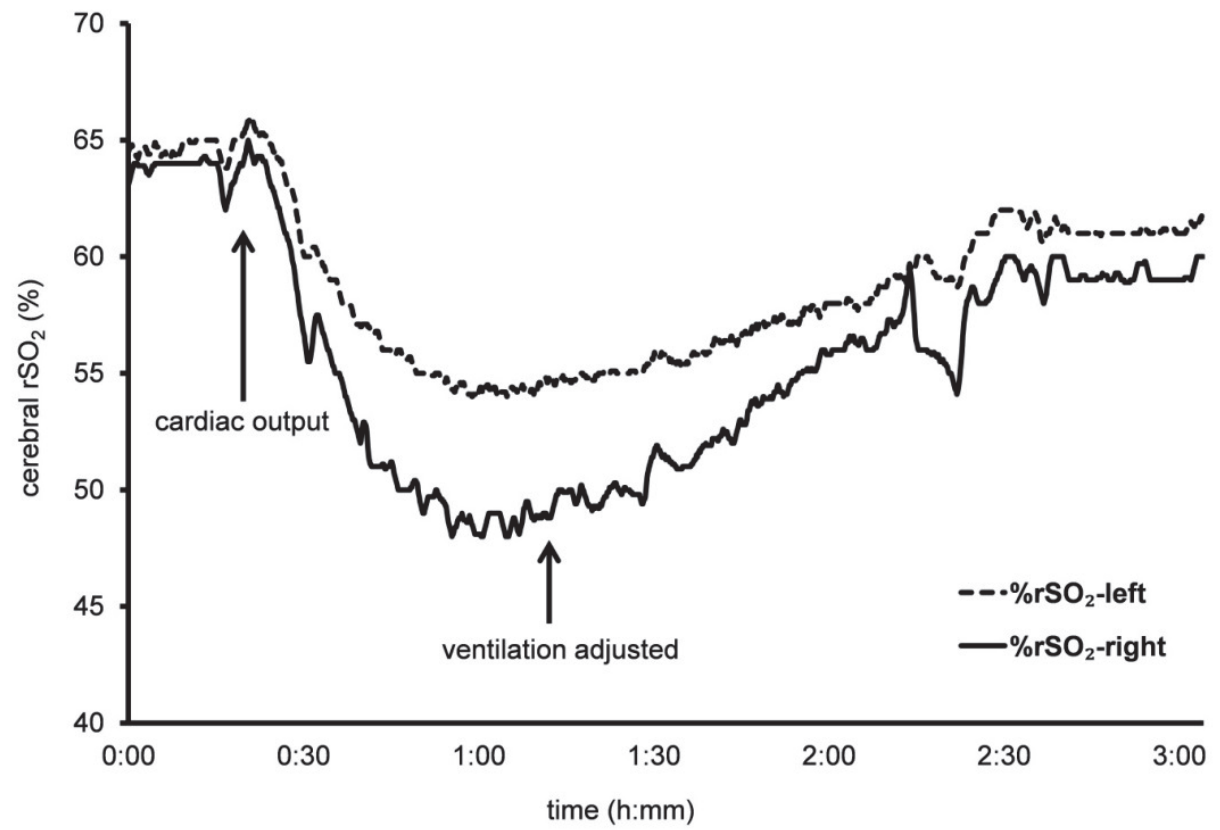

Figure 2. Example of a decrease in bi-frontal cerebral tissue oxygen saturation with an im promptu increase in cardiac output during full extracorporeal life support. $\mathrm{rSO}_{2}$, regional tissue oxygen saturation; $\mathrm{rSO}_{2}$-left, regional tissue oxygen saturation left cerebral hemisphere; $\mathrm{rSO}_{2}$-right, regional tissue oxygen saturation right hemisphere.

Three out of five patients died due to the consequences of neurologic complications while in the remaining two cases one patient died due to lung edema and another survived weaning from ECLS. In the five patients with neurological complications, a median of 13 cerebral desaturation episodes (sum of left and right hemisphere) were observed, while in patients without neurological complications a median of 14.5 desaturation episodes were found $(P=1.000)$. In patients with neurologic complications, the median number of desaturation episodes per day on VA-ECLS was 6.5 , while the median number of desaturation episodes in patients without neurologic complications amounted to 3.0 $(P=0.914)$.

Regarding tissue oximetry performed at the distal limb, $\mathrm{rSO}_{2}$ values of the noncannulated limb amounted to $65 \pm 6 \%$ (mean value) and remained constant throughout the entire duration of ECLS. In six patients (26\%), additional cannulation of the femoral artery proved necessary to ensure adequate blood flow to 
the limb. Following insertion of a distal cannula in the femoral artery, $\operatorname{limb} \mathrm{rSO}_{2}$ increased from $29.3 \pm 2.7$ to $64.0 \pm 5.1(P=0.027)$ as shown in Table 2. An example of a limb $\mathrm{rSO}_{2}$ pattern is provided in Figure 3 .

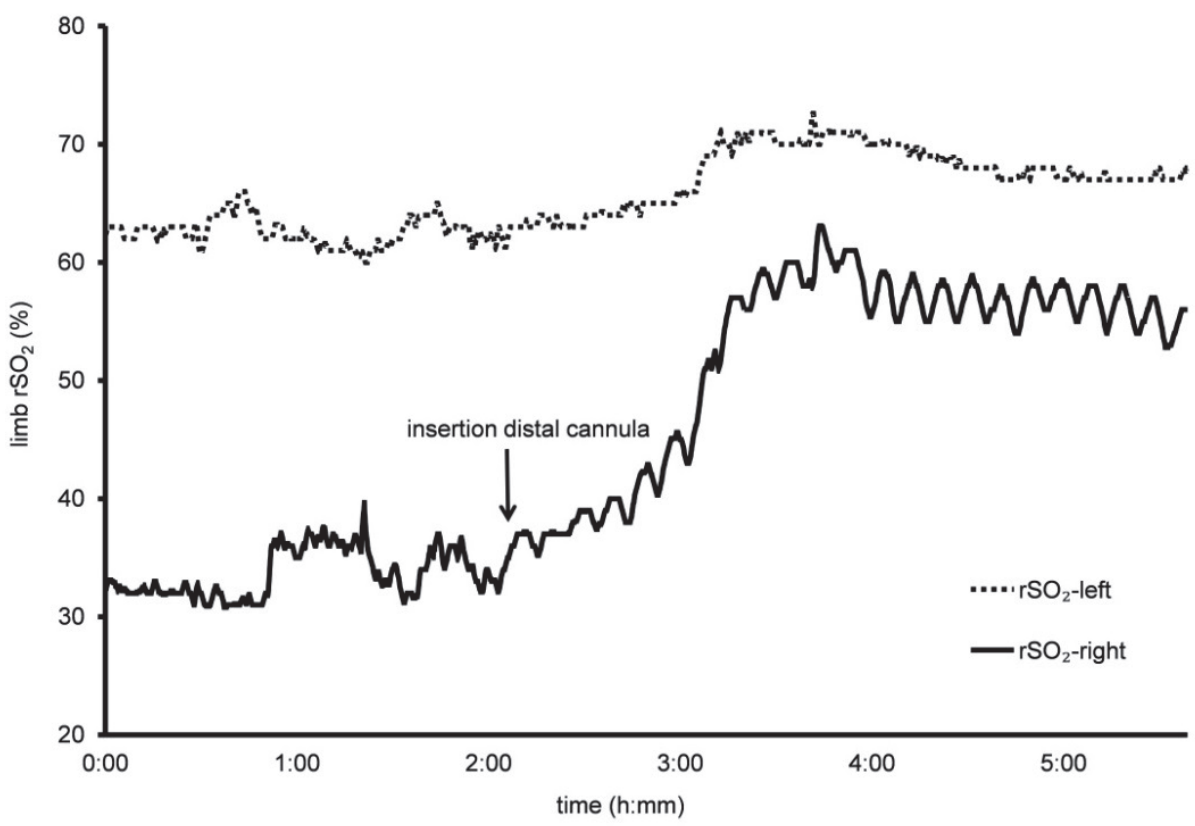

Figure 3. Example of an increase in limb tissue oxygen saturation after restoring blood flow by inserting a distal cannula in the femoral artery. $\mathrm{rSO}_{2}$, regional tissue oxygen saturation; $\mathrm{rSO}_{2}$-left, regional tissue oxygen saturation left limb; $\mathrm{rSO}_{2}$-right, regional tissue oxygen saturation right limb.

Complications with distal cannulation of the femoral artery were observed in four patients (17.4\%) following insertion of the distal cannula, including bleeding and thrombus formation. Due to clotting of the distal cannula, which was the most common complication associated with distal cannulation, limb $\mathrm{rSO}_{2}$ values decreased (Table 2). Blood flow in the distal cannula restored following clot removal by aspiration using a syringe, as reflected by the increase in limb $\mathrm{rSO}_{2}$ (from $31.3 \pm 0.8$ to $79.5 \pm 9.0, \mathrm{P}=0.068$ ). Furthermore, a decrease in temperature was noted in the cannulated limb. Notably, changes in limb temperature became evident after a clear time delay as compared to changes observed in limb $\mathrm{rSO}_{2}$ (Figure 4).

All patients received PRBC transfusion or infusion of fluids (e.g., Ringer lactate and/or Gelofusin $4 \%$ ). Transfusion of 38 PRBC units ( $275 \mathrm{~mL}$ per unit) for 13 anemic patients did not result in a significant change in cerebral $\mathrm{rSO}_{2}$. In contrast, $\mathrm{rSO}_{2}$ levels increased $>10 \%$ after infusion of $>1000 \mathrm{~mL}$ of fluids within one hour $(\mathrm{P}<0.001$, Table 3$)$. 
Table 2: Restoring limb tissue oxygen saturation by inserting a distal cannula in the femoral artery $(n=6)$ and clotting of the distal cannula $(n=4){ }^{a}$

\begin{tabular}{lcccc}
\hline patient \# & $\begin{array}{l}\text { limb rSO } \\
\text { cannulation (\%) }\end{array}$ & $\begin{array}{l}\text { limb rSO } \\
\text { cannulation (\%) }\end{array}$ & $\begin{array}{l}\text { limb } \mathrm{rSO}_{2} \text { clotted } \\
\text { cannula (\%) }\end{array}$ & $\begin{array}{l}\text { limb rSO } \\
\text { removal (\%) }\end{array}$ \\
\hline 4 & $24 \pm 2$ & $63 \pm 3$ & $32 \pm 3$ & $66 \pm 4$ \\
5 & $28 \pm 1$ & $60 \pm 3$ & $31 \pm 2$ & $89 \pm 5$ \\
10 & $32 \pm 2$ & $70 \pm 4$ & - & - \\
11 & $30 \pm 1$ & $59 \pm 2$ & $30 \pm 1$ & $86 \pm 1$ \\
16 & $31 \pm 2$ & $72 \pm 2$ & - & - \\
28 & $31 \pm 3$ & $60 \pm 5$ & $32 \pm 2$ & $77 \pm 3$ \\
\hline
\end{tabular}

Abbreviation: $\mathrm{rSO}_{2}$, regional tissue oxygen saturation.

${ }^{a}$ Data presented as mean \pm standard deviation. $\mathrm{rSO}_{2}$, regional tissue oxygen saturation. Difference between limb $\mathrm{rSO}_{2}$ prior to distal cannulation and $\operatorname{limb} \mathrm{rSO}_{2}$ post cannulation $(n=6): P=0.027$. Difference between limb $\mathrm{rSO}_{2}$ in case of a clotted distal cannula and limb $\mathrm{rSO}_{2}$ after clot removal $(n=4)$ : $\mathrm{P}=0.068$.

Table 3: Effect of transfusion of PRBC and fluid infusion on mean bi-frontal cerebral tissue oxygen saturation. ${ }^{a}$

\begin{tabular}{llll} 
& pre transfusion & post transfusion & P-value \\
\hline PRBC $(n=13)$ & $60 \pm 13$ & $60 \pm 13$ & 0.686 \\
infusion $<1000 \mathrm{~mL}$ fluids $(\mathrm{n}=11)$ & $62 \pm 13$ & $63 \pm 13$ & 0.102 \\
infusion $>1000 \mathrm{~mL}$ fluids $(\mathrm{n}=10)$ & $60 \pm 15$ & $70 \pm 10$ & $<0.001$ \\
\hline
\end{tabular}

Abbreviation: PRBC, packed red blood cells.

${ }^{a}$ Fluid infusion concerns Ringer lactate or Gelofusin. Data are presented as mean \pm standard deviation. 


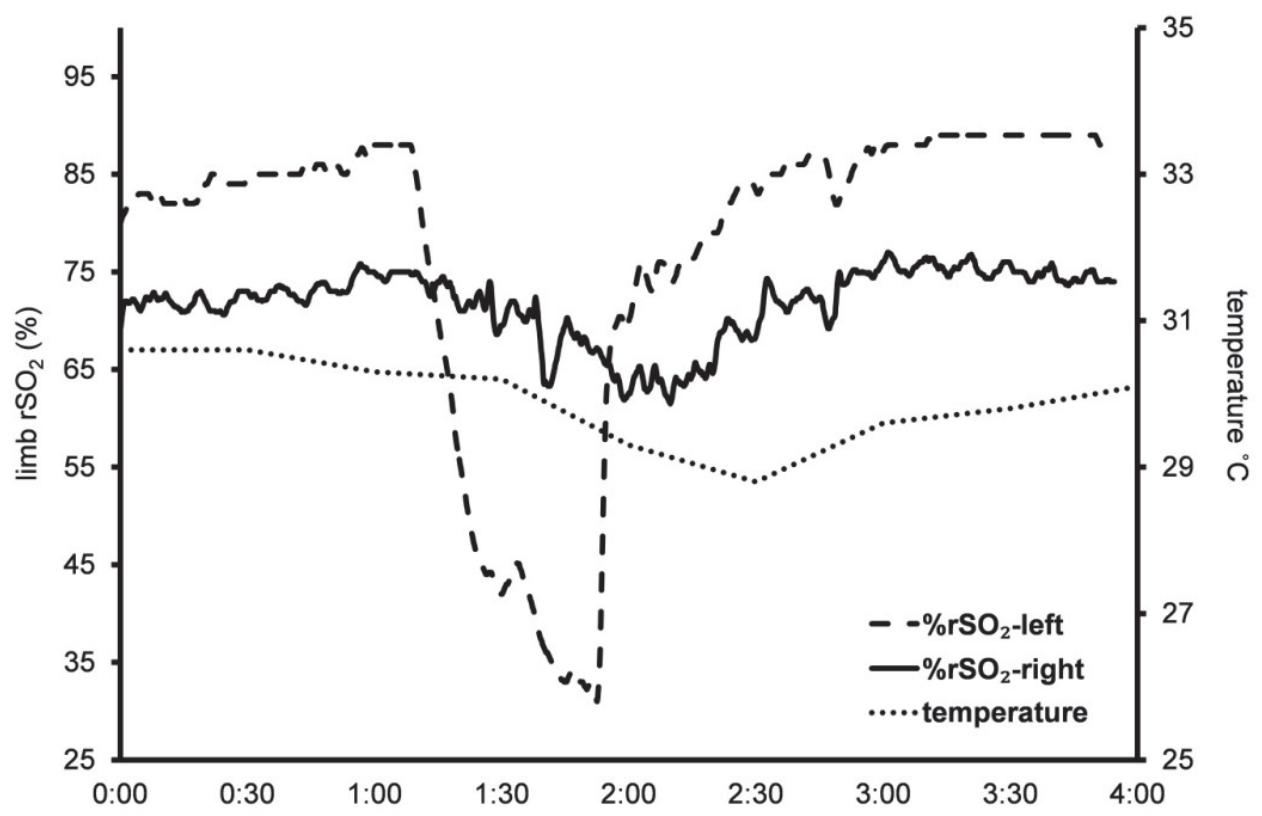

Figure 4. Example of a decrease in limb tissue oximetry values in case of a clotted distal cannula positioned in the left femoral artery. $\mathrm{rSO}_{2}$, regional tissue oxygen saturation; $\mathrm{rSO}_{2}$-left, regional tissue oxygen saturation left limb; $\mathrm{rSO}_{2}$-right, regional tissue oxygen saturation right limb.

\section{Discussion}

This observational study focused on the application of continuous non-invasive tissue oximetry in patients supported by peripheral VA-ECLS. Our results showed cerebral and limb tissue oximetry readings adequately reflect both hemodynamic instability and compromised limb perfusion.

Fluctuations in mean arterial pressure, pulse oximetry values, arterial $\mathrm{pO}_{2}$, and oxygen saturation reflect variations in cardiac output and are often the first signs of hemodynamic instability in patients on ECLS. ${ }^{11,12}$ Maintaining adequate cardiac output is important to prevent ischemic episodes, which can potentially result in complications such as congestive heart failure, neurocognitive impairment, renal dysfunction, infections, and irreversible multi-organ failure. ${ }^{12-16} \mathrm{~A}$ decreased cardiac performance resulting in lowered cardiac output has been associated with decreased cerebral and microvascular perfusion, which is reflected by lowered $\mathrm{rSO}_{2}$ values. ${ }^{17}$ As a compensatory mechanism, brain oxygen extraction has shown to increase in case of reduced cardiac performance with concomitant lowered $\mathrm{rSO}_{2}{ }^{18,19}$ A possible cause of reduced cardiac perfor- 
mance can be an abnormal cardiac rhythm such as $A F .^{20}$ In the current study, AF was noted in nine patients, whereas in three patients VF was observed. Our results confirm that cerebral tissue oxygenation is lowered during episodes of AF and VF. These results indicate a high positive predictive value, suggesting that tissue oximetry can aid in timely recognition of hemodynamic instability in VA-ECLS patients, contributing to early detection of impaired cerebral perfusion.

Femoro-femoral cannulation is a common access technique for VA-ECLS procedures. ${ }^{21} \mathrm{~A}$ consequence of this cannulation method specifically is the development of so-called "differential hypoxia" or "isolated hypoxia" in the upper body. ${ }^{22,23}$ The phenomenon of differential hypoxia can be explained as follows: during full ECLS, the right heart is fully unloaded, the resultant lung circulation is minimal, and mechanical lung ventilation is reduced accordingly. If under these circumstances an increase in cardiac output occurs due to, for example, cardiac recovery, blood ejected by the left ventricle remains hypoxic as a result of the reduced ventilatory settings. Blood pumped by the ECLS system via the arterial femoral cannula retrograde into the aorta is fully saturated with oxygen and encounters the desaturated blood ejected by the left ventricle. When both blood flows meet in the near descending aorta, hypoxic blood will flow through the cervical arteries, whereas fully saturated blood will be diverted to, for example, the left subclavian artery. Subsequently, the brain suffers from an inadequate oxygen delivery, reflected by lowered cerebral $\mathrm{rSO}_{2} \cdot{ }^{9,22,23}$ One may assume that the phenomenon of differential hypoxia occurred in eight of our patients in whom a presumably sudden increase in cardiac output occurred without timely adjustment of mechanical lung ventilation settings (Table 3 ). In line with this hypothesis, a significant decrease in cerebral $\mathrm{rSO}_{2}$ and right radial artery $\mathrm{pO}_{2}$ values were found, while pulse oximetry values (measured at the left index finger) remained unaffected. However, due to the retrospective nature of this study, this could not be confirmed by echocardiographic imaging. Nonetheless, these results suggest that cerebral oximetry enables early identification of differential hypoxia in patients on ECLS. When cardiac recovery is confirmed and a patient becomes candidate for weaning from ECLS, immediate adjustment of mechanical lung ventilation is warranted to prevent differential hypoxia and minimize the risk of neurological complications resulting from cerebral desaturation. The current results indicate that increased lung perfusion without accompanying adapting ventilator settings might be detected by careful (multimodal) monitoring with tissue oximetry. After multidisciplinary discussion, additional treatments might be planned such as fluid unloading or inotropic support to further improve myocardial and lung recovery. In addition, an observed decrease in $\mathrm{rSO}_{2}$ may indicate an increased oxygen extraction and thereby a relative decrease in cer- 
ebral perfusion, increasing the risk of poor neurologic outcome. ${ }^{24}$ Future studies should therefore focus on neurological outcome of patients weaning from VAECLS.

The number of desaturation episodes did not differ between patients with or without a diagnosis of neurologic complications. Although this finding might seem contradictive, one must take into account that the evidence for a causal relationship between cerebral oximetry derived measurement values and neurologic outcome is still lacking. ${ }^{25}$ Obviously, the development of neurologic complications is a very complex process and not in all cases reflected by clear reduction in $\mathrm{rSO}_{2}$ values. One explanation can be found in the fact that the cerebral autoregulatory activity is not considered when measuring regional $\mathrm{rSO}_{2}$. In the case of cerebral hyperperfusion, for example, cerebral $\mathrm{rSO}_{2}$ values may appear normal while the intrinsic neuroprotective mechanism of cerebral autoregulation is severely affected, predisposing the patient to an increased risk of neurologic complications.

Moreover, patients on VA-ECLS are subject to complex physiologic interactions including a whole-body inflammatory response, translating into high morbidity and mortality rates. This, in combination with the limitations inherent to the measurement technique of tissue oximetry using NIRS may be part of the explanation why a clear link between $\mathrm{rSO}_{2}$ and clinical outcomes could not be established. Nevertheless, the results clearly indicate that cerebral tissue oximetry adequately reflects episodes of hemodynamic instability which is also a known factor contributing to postoperative morbidity and mortality.

A possible adverse effect of femoral cannulation is inadequate perfusion of the cannulated limb caused by occlusion of the femoral artery cannula. The limited antegrade flow in the distal artery is exacerbated due to delayed use of a distal artery perfusion cannula. ${ }^{26}$ This may result in lower extremity ischemia, fasciotomy, or even limb amputation. ${ }^{27}$ In the current practice, capillary refill as well as temperature and color of the limb are systematically evaluated for detection of ischemia. Changes in these parameters, however, are subjective with a possible risk of delayed intervention in the case of circulatory compromise. The current study showed that limb $\mathrm{rSO}_{2}$ adequately reflected distal cannula clotting as well as restoration of blood flow (Figure 4). Hence, tissue oximetry aids in early recognition of compromised limb perfusion and contributes to timely intervention by identifying the need for an additional distal cannula. This exemplification underlines the clinical benefit of using noninvasive tissue oximetry in patients assisted by VA-ECLS. 
Packed red blood cell transfusion increases the oxygen content and improves tissue oxygen saturation. ${ }^{28}$ Based on the fact that tissue oximetry enables rapid evaluation of tissue oxygenation, one can expect that transfusion of PRBCs result in an immediate increase in $\mathrm{rSO}_{2}$ values. ${ }^{28-30}$ However, our data did not support this hypothesis. A possible explanation can be found in the critical hemodynamic conditions of our patients who received PRBC transfusion, since twelve patients suffered from severe bleeding. In this case, transfusion of RPBCs may have compensated for the decrease in cardiac output due to blood loss, resulting in a restored cardiac output and thereby preserving bi-frontal cerebral $\mathrm{rSO}_{2}$ (Table 3). Another explanation for the lack of an increase in cerebral $\mathrm{rSO}_{2}$ following PBRC transfusion can be found in the use of vasopressors, considering a study by Brassard et al. showing a decreased cerebral $\mathrm{rSO}_{2}$ due to phenylephrine administration. ${ }^{30}$ Nine of our patients received a relatively high dose of norepinephrine $(1.94 \mu \mathrm{g} / \mathrm{kg} / \mathrm{min}$ at maximum $)$ that could have led to a decrease in cerebral $\mathrm{rSO}_{2}$, masking the effect of PRBC transfusion on $\mathrm{rSO}_{2}$ readings. The study of Brassard et al., in contrast, included young (26 \pm 7 years) and healthy subjects. Our patients had co-morbidities including Q-fever, liver ischemia, pulmonary emboli, and an adenine nucleotide transporter deficiency. In addition, three patients in whom $\mathrm{rSO}_{2}$ was unaffected by PRBC transfusion were diagnosed with either endocarditis or pericarditis. The limited effect of PRBC transfusion in infective patients has been described by Creteur et al. who attributed this effect to diminished microcirculation. ${ }^{31}$ Therefore, it remains debatable whether tissue oximetry is appropriate for assessing the effects of PRBC transfusion on tissue oxygenation in patients assisted by VA-ECLS. On the other hand, when fluid suppletion exceeded $1000 \mathrm{~mL} / \mathrm{h}$, cerebral $\mathrm{rSO}_{2}$ did increase, which was most likely due to a concomitant increase in cardiac output together with timely adjustment of the ventilator settings.

One study limitation that needs to be considered when interpreting the current study results is the relatively small sample size. Despite this fact, the authors were able to show alterations in cerebral and $\operatorname{limb} \mathrm{rSO}_{2}$ as a reflection of changes in several patient-related factors including hemodynamic stability and limb perfusion. In addition, due to the retrospective design of the study, it was not possible to include data regarding blood flow in the distal perfusion cannulae and hemoglobin.

In conclusion, non-invasive tissue oximetry is a viable monitoring method for assessing cerebral and distal limb tissue perfusion is patients assisted by ECLS and should therefore be part of routine monitoring. 


\section{Declaration of conflicting interests}

The author(s) declared no potential conflicts of interest with respect to the research, authorship, and/or publication of this article.

\section{Funding}

The author(s) received no financial support for the research, authorship, and/or publication of this article. 


\section{References}

1. Avgerinos DV, DeBois W, Voevidko L, Salemi A. Regional variation in arterial saturation and oxygen delivery during venoarterial extracorporeal membrane oxygenation. J Extra Corpor Technol 2013;45(3):183-186.

2. Foley PJ, Morris RJ, Woo EY, et al. Limb ischemia during femoral cannulation for cardiopulmonary support. J Vasc Surg. 2010;52(4):850-3.

3. Gander JW, Fisher JC, Reichstein AR, et al. Limb ischemia after common femoral artery cannulation for venoarterial extracorporeal membrane oxygenation: an unresolved problem. J Pediatr Surg 2010;45(11):2136-2140.

4. Choi JH, Kim SW, Kim YU, et al. Application of veno-arterial-venous extracorporeal membrane oxygenation in differential hypoxia. Multidiscip Respir Med 2014;9(1):55.

5. Murkin JM, Arango M. Near-infrared spectroscopy as an index of brain and tissue oxygenation. Br J Anaesth 2009;103(Suppl1):i3-i13.

6. Cole AL, Herman RA, Jr., Heimlich JB, Ahsan S, Freedman BA, Shuler MS. Ability of near infrared spectroscopy to measure oxygenation in isolated upper extremity muscle compartments. J Hand Surg Am 2012;37(2):297-302.

7. Olsson C, Thelin S. Regional cerebral saturation monitoring with near-infrared spectroscopy during selective antegrade cerebral perfusion: diagnostic performance and relationship to postoperative stroke. J Thorac Cardiovasc Surg 2006;131(2):371-379.

8. Ejike JC, Schenkman KA, Seidel K, Ramamoorthy C, Roberts JS. Cerebral oxygenation in neonatal and pediatric patients during veno-arterial extracorporeal life support. Pediatr Crit Care Med 2006;7(2):154-158.

9. Tyree K, Tyree M, DiGeronimo R. Correlation of brain tissue oxygen tension with cerebral near-infrared spectroscopy and mixed venous oxygen saturation during extracorporeal membrane oxygenation. Perfusion 2009;24(5):325-331.

10. Caicedo A, Papademetriou MD, Elwell CE, et al. Canonical correlation analysis in the study of cerebral and peripheral haemodynamics interrelations with systemic variables in neonates supported on ECMO. Adv Exp Med Biol 2013;765:23-29.

11. van Meurs K, Lally K, Peek G, Zwischenberger J. ECMO: extracorporeal cardiopulmonary support in critical care. 3rd ed. An Arbor, MI: Extracorporeal Life Support Organization; 2007.

12. Miller CE, Thompson S, Lozar J. A theoretical evaluation of cardiac output as a function of mean arterial pressure in the human cardiovascular system. J Theor Biol 1976;63(1):89-98.

13. Hoffman GM, Ghanayem NS, Tweddell JS. Noninvasive assessment of cardiac output. Semin Thorac Cardiovasc Surg Pediatr Card Surg Annu 2005:12-21.

14. Mariscalco G, Klersy C, Zanobini M, et al. Atrial fibrillation after isolated coronary surgery affects late survival. Circulation 2008;118(16):1612-1618.

15. Mathew JP, Fontes ML, Tudor IC, et al. A multicenter risk index for atrial fibrillation after cardiac surgery. JAMA 2004;291(14):1720-1729.

16. Ganushchak YM, Fransen EJ, Visser C, De Jong DS, Maessen JG. Neurological complications after coronary artery bypass grafting related to the performance of cardiopulmonary bypass. Chest. 2004;125(6):2196-205.

17. Wutzler A, Nee J, Boldt LH, et al. Improvement of cerebral oxygen saturation after successful electrical cardioversion of atrial fibrillation. Europace 2014;16(2):189-194.

18. Madsen PL, Nielsen HB, Christiansen P. Well-being and cerebral oxygen saturation during acute heart failure in humans. Clin Physiol 2000;20(2):158-164.

19. Koike $\mathrm{A}$, Itoh $\mathrm{H}$, Oohara $\mathrm{R}$, et al. Cerebral oxygenation during exercise in cardiac patients. Chest 2004;125(1):182-190.

20. Dong $\mathrm{YX}$, Madhavan $\mathrm{M}, \mathrm{Wu} \mathrm{JH}$, et al. Acute effects of atrial fibrillation on atrial and ventricular function: a simultaneous invasive-echocardiographic hemodynamic study. Int J Cardiol 2013;169(6):e114-e119. 
21. Spurlock DJ, Toomasian JM, Romano MA, Cooley E, Bartlett RH, Haft JW. A simple technique to prevent limb ischemia during veno-arterial ECMO using the femoral artery: the posterior tibial approach. Perfusion 2012;27(2):141-145.

22. Kitamura $M$, Shibuya $M$, Kurihara $H$, Akimoto $T$, Endo $M$, Koyanagi $H$. Effective crosscirculation technique of venoarterial bypass for differential hypoxia condition. Artif Organs 1997;21(7):786-788.

23. Angleitner $P$ RM, Laufer G, Wiedermann D. Watershed of veno-arterial extracorporeal life support. Eur J Cardiothorac Surg 2016;50(4):785.

24. Buckley E, Sidebotham D, McGeorge A, Roberts S, Allen SJ, Beca J. Extracorporeal membrane oxygenation for cardiorespiratory failure in four patients with pandemic H1N1 2009 influenza virus and secondary bacterial infection. Br J Anaesth 2010;104(3):326-329.

25. Zheng F, Sheinberg R, Yee MS, Ono M, Zheng Y, Hogue CW. Cerebral near-infrared spectroscopy monitoring and neurologic outcomes in adult cardiac surgery patients: a systematic review. Anesth Analg 2013;116:663-676.

26. Wong JK, Smith TN, Pitcher HT, Hirose H, Cavarocchi NC. Cerebral and lower limb nearinfrared spectroscopy in adults on extracorporeal membrane oxygenation. Artif Organs 2012;36(8):659-667.

27. Roberson RS, Bennett-Guerrero E. Impact of red blood cell transfusion on global and regional measures of oxygen. Mt Sinai J Med 2012;79(1):66-74.

28. Sandal G, Oguz SS, Erdeve O, Akar M, Uras N, Dilmen U. Assessment of red blood cell transfusion and transfusion duration on cerebral and mesenteric oxygenation using near-infrared spectroscopy in preterm infants with symptomatic anemia. Transfusion 2014;54(4):1100-1105.

29. Seidel D, Blaser A, Gebauer C, Pulzer F, Thome U, Knupfer M. Changes in regional tissue oxygenation saturation and desaturations after red blood cell transfusion in preterm infants. $\mathrm{J}$ Perinatol 2013;33(4):282-287.

30. Brassard P, Seifert T, Wissenberg M, Jensen PM, Hansen CK, Secher NH. Phenylephrine decreases frontal lobe oxygenation at rest but not during moderately intense exercise. J Appl Physiol 2010;108(6):1472-1478.

31. Creteur J, Neves AP, Vincent JL. Near-infrared spectroscopy technique to evaluate the effects of red blood cell transfusion on tissue oxygenation Crit Care. 2009;13(Suppl5):S11. 



\section{CHAPTER 7}

\section{Vascular occlusion test to dynamically assess microcirculation during normothermic pulsatile cardiopulmonary bypass}

NPA Vranken, YM Ganushchak, HM Willigers, JG Maessen, PW Weerwind Published in J Cardiothorac Vasc Anesth 2016;30:979-984. 


\section{CHAPTER 7}

Abstract

Objective: To evaluate parameters of the vascular occlusion test (VOT) before, during, and after pulsatile cardiopulmonary bypass (CPB).

Design: Prospective, observational study.

Setting: Single-center university hospital.

Participants: Adult patients undergoing elective cardiac surgery with pulsatile CPB.

Interventions: An oximeter sensor and adult-sized pneumatic tourniquet were positioned at the right forearm. A VOT with a predefined ischemic time of 3 minutes was performed before, during, and after CPB. Changes in tissue oxygen saturation were recorded.

Measurements and main Results: Thirty-four patients who underwent cardiac surgery were enrolled in the study. The lowest tissue oxygen saturation measured during the ischemic challenge differed between all 3 stages of surgery, with median values of $62.9 \%$ before, $57.5 \%$ during, and $59.3 \%$ afer perfusion $(P<0.05)$. Both occlusion $(P<0.001)$ and reperfusion $(P<0.05)$ slopes were steeper after bypass compared to before initiating bypass, whereas the reperfusion time remained constant between the different time points.

Conclusions: The microcirculatory function as demonstrated by changes in VOT parameters was enhanced during and after normothermic pulsatile CPB. Clinical relevance, however, needs to be further explored. 


\section{Introduction}

Microvascular alterations after cardiac surgery with cardiopulmonary bypass (CPB) and impaired tissue oxygen saturation $\left(\mathrm{S}_{\mathrm{t}} \mathrm{O}_{2}\right)$ have been associated with adverse patient outcome..$^{1-5}$ Shear stress and contact with foreign surfaces cause transient microcirculatory dysfunction by activation of inflammatory and hemostatic systems. ${ }^{6,7}$ Tissue trauma and anesthesia also influence microcirculation, ${ }^{8,9}$ which may be aggravated by severe total blood volume shifts during surgery. Although the microcirculation is shown to be adversely affected by surgery with $\mathrm{CPB}^{10}$, monitoring of the microcirculatory function is still not part of routine practice. Continuous real-time monitoring may aid in early detection of tissue malperfusion. Measuring $\mathrm{S}_{\mathrm{t}} \mathrm{O}_{2}$ using near-infrared spectroscopy with a reproducible ischemia-reperfusion challenge (ie, vascular occlusion test [VOT]) has shown to be a non-invasive method suitable for assessment of microcirculation. ${ }^{9,11,12}$ The VOT is an application in functional hemodynamic monitoring in which the response to an artificially induced ischemic stress can be followed. This method highly correlates to strain gauge plethysmography, which has been used extensively for measuring vascular function. ${ }^{13,14}$ Furthermore, to the best of the authors' knowledge, only a few reports combining near-infrared spectroscopy and VOT in patients undergoing nonpulsatile CPB have been published to date. ${ }^{9,15-17}$ On the other hand, pulsatile CPB has been shown to preserve microvascular function associated with improved patient outcome. ${ }^{2,18,19}$ Therefore, the aim of this study was to assess dynamic microcirculatory function using the VOT during cardiac surgery in patients undergoing pulsatile CPB.

\section{Methods}

\section{Patients}

After approval by the local ethical committee (reference number 1-4-087), a prospective explorative study was conducted. A total of 34 adult patients were included after they provided written informed consent. The inclusion criterion was elective cardiac surgery with CPB. Exclusion criteria were a body mass index $>30 \mathrm{~kg} / \mathrm{m}^{2}$, chronic advanced peripheral vascular disorders (including subclavian artery stenosis, Diabetes Mellitus, Raynaud's disease, and Raynaud's syndrome), a state of cardiogenic shock (emergency procedures), or patients diagnosed with New York Heart Association class IV.

\section{Anesthesia}

General anesthesia was induced using 0.5 to $1.0 \mu \mathrm{g} / \mathrm{kg}$ of sufentanil (Hameln Pharmaceuticals, Hameln, Germany), 0.6 to $1.0 \mathrm{mg} / \mathrm{kg}$ rocuronium bromide 
(Fresenius Kabi Nederland, Zeist, The Netherlands), and $0.1 \mathrm{mg} / \mathrm{kg}$ of midazolam (Roche Nederland BV, Woerden, The Netherlands). After endotracheal intubation, patients were ventilated with volume-controlled ventilation with tidal volumes of 7 to $8 \mathrm{~mL} / \mathrm{kg}$ and a positive end-expiratory pressure of $5 \mathrm{cmH}_{2} \mathrm{O}$. The respiratory rate was adjusted to maintain normocapnia. Oxygen saturation measured from a pulse oximeter was maintained between 95 and $100 \%$. Anesthesia was maintained with 0.5 to 0.8 minimum alveolar concentration of sevoflurane (AbbVie BV, Hoofddorp, The Netherlands) and continuous intravenous administration or boluses of sufentanil. During bypass, sevoflurane was replaced by infusion of 4 to $6 \mathrm{mg} / \mathrm{kg} / \mathrm{h}$ of propofol (Fresenius Kabi), which was continued until patient arrival at the intensive care unit. Inotropes and vasoconstrictors were administrered according to the hemodynamic status of the individual patient.

Patients were kept normothermic throughout the entire cardiac surgical procedure using a warming blanket (Bair Hugger 505; 3M Deutschland $\mathrm{GmbH}$, Neuss, Germany).

\section{Cardiopulmonary bypass}

Target flow rates of $\geq 2.6 \mathrm{~L} / \mathrm{min} / \mathrm{m}^{2}$ body surface area were maintained throughout normothermic $\left(36.3^{\circ} \mathrm{C}\right) \mathrm{CPB}$. Pulsatile flow (radial artery pulse pressure $\geq 25$ $\mathrm{mmHg}$ ) was used only during the period of cross-clamping, with a frequency of $70 \mathrm{bpm}$, a base flow of $30 \%$, and a pulse width of $50 \%$. Mean arterial blood pressure (ABP) was maintained between 70 and $95 \mathrm{mmHg}$ by titration of 0.4 $\mathrm{mg} / \mathrm{mL}$ phenylephrine (pharmacy of Radboud UMC, Nijmegen, The Netherlands), if necessary. The sweep gas and fraction of inspired oxygen settings for the oxygenator were titrated to maintain normocapnia (partial pressure of carbon dioxide, $4.5-5.5 \mathrm{kPa}$ ) and normoxia (partial pressure of oxygen, 11.0 $14.0 \mathrm{kPa}$ ). All patients received $2 \mathrm{mg}$ of tranexamic acid (Pfizer BV, Capelle a/d IJssel, The Netherlands) during CPB. The transfusion trigger during CPB was set at a hematocrit level $<25 \%$.

\section{Vascular occlusion test}

The Fore-Sight tissue oximeter sensor (CAS Medical Systems Inc., Branford, $\mathrm{CT}$ ) was used for assessing local tissue oxygen saturation, providing absolute $\mathrm{S}_{\mathrm{t}} \mathrm{O}_{2}$ data, which was measured continuously. This device utilizes laser light of 4 different wavelengths $(690,780,805$, and $850 \mathrm{~nm})$ to estimate the oxygen content. ${ }^{20} \mathrm{~A}$ medium-sized sensor (emitter/diode spacing 15 and $40 \mathrm{~mm}$ for the first and second light path, respectively) was placed at the internal surface of the proximal third of the right forearm, and an adult-sized pneumatic tourniquet was positioned at the right brachial artery. After $\mathrm{S}_{\mathrm{t}} \mathrm{O}_{2}$ signal stabilization $(<2 \%$ variation in 30 seconds), the cuff was inflated until pressure reached $30 \mathrm{mmHg}$ 
above the patient's systolic blood pressure. Inflation took 3 to 4 seconds after which the cuff was kept inflated for 3 minutes. Then the cuff was deflated rapidly (within 0.5 seconds), and the response in $\mathrm{S}_{\mathrm{t}} \mathrm{O}_{2}$ was monitored. The VOT was performed at the following 3 predefined time points: after induction of anesthesia and prior to initiation of bypass $\left(T_{0}\right)$, after initiation of bypass and aortic cross-clamping $\left(T_{1}\right)$, and after termination of bypass $\left(T_{2}\right)$.

Tissue oximetry readings were recorded and stored locally using the Fore-Sight oximeter before the data were transferred and saved in Microsoft Office Excel (Microsoft, Redmond, WA) format. The following VOT parameters were calculated: $\mathrm{S}_{\mathrm{t}} \mathrm{O}_{2}$ before occlusion (\%), occlusion slope $\left(\mathrm{S}_{\mathrm{t}} \mathrm{O}_{2} \% / \mathrm{min}\right)$, lowest $\mathrm{S}_{\mathrm{t}} \mathrm{O}_{2}$ in VOT (\%), reperfusion slope $\left(\mathrm{S}_{\mathrm{t}} \mathrm{O}_{2} \% / \mathrm{min}\right)$, reperfusion time $(\mathrm{min}), \mathrm{S}_{\mathrm{t}} \mathrm{O}_{2}$ at end of recovery (\%), hyperemic area $\left(\mathrm{S}_{\mathrm{t}} \mathrm{O}_{2} \% / \mathrm{min}\right)$, and $\mathrm{S}_{\mathrm{t}} \mathrm{O}_{2}$ at end of hyperemia (\%). As a baseline measurement for every VOT, $\mathrm{S}_{\mathrm{t}} \mathrm{O}_{2}$ before occlusion was determined by calculating the average $\mathrm{S}_{\mathrm{t}} \mathrm{O}_{2}$ over a 30 -second interval prior to tourniquet inflation. Occlusion and reperfusion slopes were calculated over the entire slope between occlusion to the lowest $\mathrm{S}_{\mathrm{t}} \mathrm{O}_{2}$ value in VOT and the complete slope between the lowest $\mathrm{S}_{\mathrm{t}} \mathrm{O}_{2}$ value during occlusion and the first data point of $\mathrm{S}_{\mathrm{t}} \mathrm{O}_{2}$ back at baseline level, respectively (Fig 1 ). After the the reperfusion phase, the hyperemic area was determined using integration of the area under the curve (see Fig 1). 


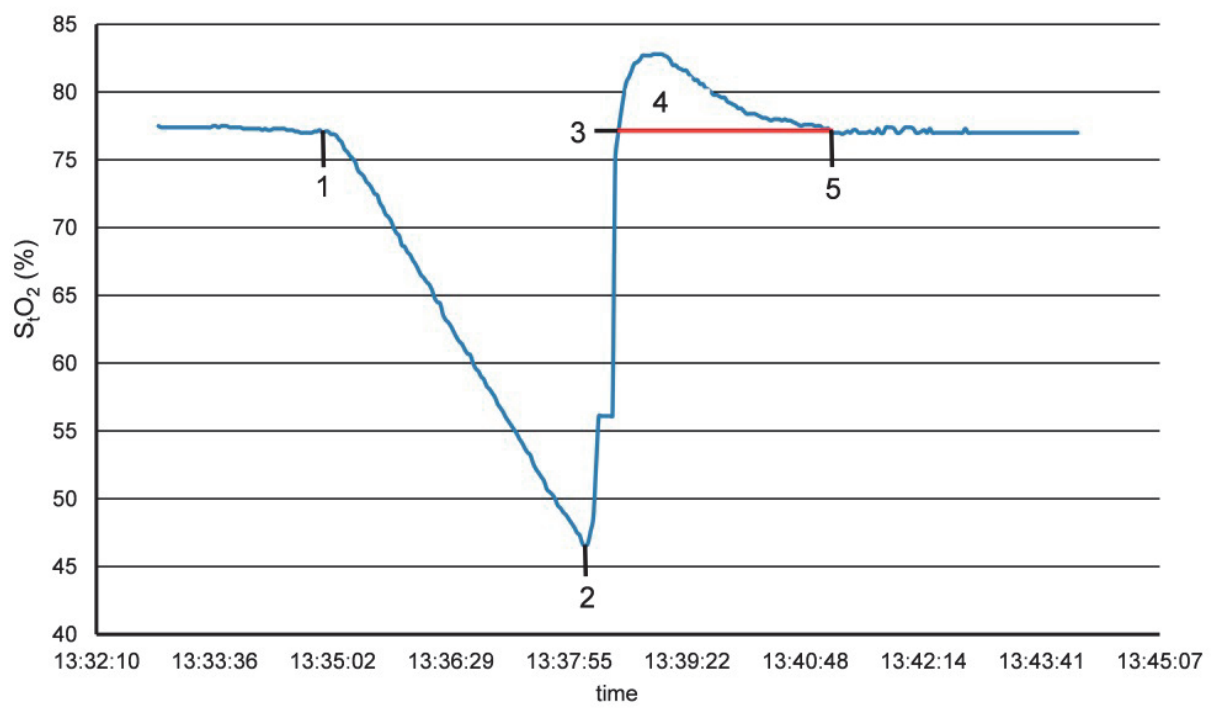

Fig 1. Example of a vascular occlusion test performed in an individual patient.

1 , start of the occlusion phase; 2 , lowest oxygen saturation observed after 3 minutes of occlusion;

3 , end of reperfusion phase; 4 , hyperemic area; 5 , end of hyperemic area where the oxygen saturation has reached pre-VOT values.

The occlusion slope was calculated as the change in oxygen saturation for the interval between data points 1 and 2 divided by 3 minutes. Time for recovery was calculated using the interval between data points 2 and 3 . Calculating the reperfusion slope required dividing the change in oxygen saturation for the interval between data points 2 and 3 by the time for recovery. The hyperemic area was calculated as the area under the curve between datapoints 3 and 5 .

$\mathrm{S}_{\mathrm{t}} \mathrm{O}_{2}$ : tissue oxygen saturation.

\section{Statistical analysis}

Continuous variables are depicted as mean \pm standard deviation or median (interquartile range) depending on data distribution. Statistical analysis was performed using the Statistical Package for Social Sciences, version 22.0 (IBM Corp, Armonk, NY). Distribution of data was tested using the Shapiro-Wilk test. To analyze for differences in VOT parameters before, during, and after CPB, the related-samples Friedman 2-way analysis of variance by ranks was computed. If statistically significant, the related-samples Wilcoxon signed rank test was performed to test pairwise comparisons. A P-value of $<0.05$ was considered statistically significant. 


\section{Results}

Patient demographics and surgery-related variables are summarized in Table 1. In two patients no recognizable VOT curves could be obtained before and after perfusion; therefore, only data points at $T_{1}$ were taken into analysis for these patients. Intraoperative hemoglobin and ABP data are depicted in Table 2. Hemoglobin values differed significantly differed at every predefined time point and every other time point $(P<0.001)$, with the lowest value recorded at $T_{1}(4.8$ $\mathrm{mmol} / \mathrm{L})$. The median ABP was higher at both $\mathrm{T}_{0}(83 \mathrm{mmHg}, \mathrm{p}<0.001)$ and $\mathrm{T}_{2}$ ( $80 \mathrm{mmHg}, \mathrm{P}=0.003)$ compared with $\mathrm{T}_{1}(69 \mathrm{mmHg})$.

VOT parameters at different time points are presented in Table 3. Values for $\mathrm{S}_{\mathrm{t}} \mathrm{O}_{2}$ at the end of the occlusion phase the lowest at $\mathrm{T}_{1}(57.5 \%)$. The occlusion slope was steeper at both $\mathrm{T}_{1}(4.7 \% / \mathrm{min}, \mathrm{p}<0.001)$ and $\mathrm{T}_{2}(5.1 \% / \mathrm{min}, \mathrm{P}<0.001)$ compared with $\mathrm{T}_{0}(3.8 \% / \mathrm{min})$. Analyzing reperfusion slopes revealed a steeper slope at $\mathrm{T}_{2}(36.8 \% / \mathrm{min})$ compared with $\mathrm{T}_{0}(32.8 \% / \mathrm{min}, \mathrm{P}<0.05)$. Changes in $\mathrm{S}_{\mathrm{t}} \mathrm{O}_{2}$ values prior, during, and after bypass are presented in Figure 2 .

Table 1. Patient demographics and surgery-related variables.

\begin{tabular}{lll}
\hline demographic variables & & \\
\hline & gender $(\mathrm{F} / \mathrm{M}), \mathrm{n}(\%)$ & $10(29.4 \%) / 24(70.6 \%)$ \\
& age $($ years $)$ & $68.6 \pm 10.7$ \\
BMI $\left(\mathrm{kg} / \mathrm{m}^{2}\right)$ & $26.0 \pm 3.5$ \\
type of surgery & CABG & $14(41.2 \%)$ \\
& CABG+valve replacement & $8(23.5 \%)$ \\
& valve replacement & $9(26.5 \%)$ \\
& other* & $3(8.8 \%)$ \\
& CPB time (min) & $82.0(71.8-106.0)$ \\
& aortic occlusion time (min) & $54.0(49.5-75.0)$ \\
\hline
\end{tabular}

NOTE. Numerical values are depicted either as mean \pm standard deviation or median (interquartile range), unless specified otherwise.

Abbreviations: BMI, body mass index; CABG, coronary artery bypass grafting; CPB, cardiopulmonary bypass.

*Other types of surgery include ascending aorta replacement with or without CABG or valve surgery. 


\section{CHAPTER 7}

Table 2. Overview of perioperative hemoglobin and blood pressure data.

\begin{tabular}{llll}
\hline & $\mathrm{T}_{0}(\mathrm{n}=32)$ & $\mathrm{T}_{1}(\mathrm{n}=34)$ & $\mathrm{T}_{2}(\mathrm{n}=32)$ \\
\hline hemoglobin $(\mathrm{mmol} / \mathrm{L})^{r}$ & $8.5(7.8-9.0)$ & $4.8(4.1-5.4)$ & $5.8(5.2-6.6)$ \\
mean ABP $(\mathrm{mmHg})^{\dagger, \ddagger}$ & $83(76-94)$ & $69(62-76)$ & $80(71-92)$ \\
systolic pressure $(\mathrm{mmHg})^{\dagger, \S}$ & $117(101-132)$ & $84(76-93)$ & $115(107-126)$ \\
diastolic pressure $(\mathrm{mmHg})^{\dagger}$ & $62(58-79)$ & $56(49-63)$ & $60(54-68)$ \\
pulse pressure $(\mathrm{mmHg})^{\dagger, \S}$ & $53(39-62)$ & $26.9(23-37)$ & $54(49-61)$
\end{tabular}

NOTE. Numerical values are depicted as median (interquartile range).

Abbreviations: ABP, arterial blood pressure; $T_{0}$, before onset of bypass; $T_{1}$, during bypass; $T_{2}$, after cessation of bypass.

* Values all differ from each other $(P<0.001)$.

$\dagger$ Difference between before and during perfusion $(P<0.001)$.

‡ Difference between during and after perfusion $(P=0.003)$.

$\S$ Difference between during and after perfusion $(P<0.001)$.

Table 3. Vascular occlusion test-derived parameters before, during, and after cardiopulmonary bypass.

\begin{tabular}{llll}
\hline & $\mathrm{T}_{0}(\mathrm{n}=32)$ & $\mathrm{T}_{1}(\mathrm{n}=34)$ & $\mathrm{T}_{2}(\mathrm{n}=32)$ \\
\hline $\mathrm{S}_{\mathrm{t}} \mathrm{O}_{2}$ before occlusion $(\%)^{*}$ & $76.4(72.8-79.4)$ & $74.1(72.1-78.6)$ & $76.2(74.1-78.8)$ \\
occlusion slope $\left(\mathrm{S}_{\mathrm{t}} \mathrm{O}_{2} \% / \mathrm{min}\right)^{\dagger, . \neq}$ & $3.8(3.3-5.4)$ & $4.7(3.3-6.6)$ & $5.1(3.8-6.2)$ \\
lowest $\mathrm{S}_{\mathrm{t}} \mathrm{O}_{2}$ in VOT $(\%)^{*, \delta, \|}$ & $62.9(55.8-68.6)$ & $57.5(53.1-64.3)$ & $59.3(53.2-66.2)$ \\
reperfusion slope $\left(\mathrm{S}_{\mathrm{t}} \mathrm{O}_{2} \% / \mathrm{min}\right)^{\|}$ & $32.8(20.0-47.6)$ & $35.3(23.6-47.0)$ & $36.8(27.9-57.1)$ \\
reperfusion time $(\mathrm{min})$ & $0.43([0.33-0.49)$ & $0.43(0.33-0.51)$ & $0.37(0.32-0.52)$ \\
$\mathrm{S}_{\mathrm{t}} \mathrm{O}_{2}$ at end of recovery $(\%)$ & $76.2(72.3-78.6)$ & $73.8(71.0-77.2)$ & $75.4(74.1-77.2)$ \\
hyperemic area $\left(\mathrm{S}_{\mathrm{t}} \mathrm{O}_{2} \% / \mathrm{min}\right)$ & $7.3(3.6-14.3)$ & $6.0(4.7-8.7)$ & $8.0(5.1-9.9)$ \\
$\mathrm{S}_{\mathrm{t}} \mathrm{O}_{2}$ at end of hyperemia $(\%)^{*, \S}$ & $76.3(73.7-80.1)$ & $74.0(71.8-77.9)$ & $77.0(73.9-78.5)$ \\
\hline
\end{tabular}

Numerical values are depicted as median (interquartile range).

Abbreviations: $T_{0}$, before bypass; $T_{1}$, during bypass; $T_{2}$, after cessation of bypass; $S_{t} O_{2}$, tissue oxygen saturation; VOT, vascular occlusion test.

* Difference between $T_{1}$ and $T_{2} ; P<0.05$.

† Difference between $T_{0}$ and $T_{1} ; P<0.01$.

$\ddagger$ Difference between $T_{0}$ and $T_{2} ; P<0.001$.

$\S$ Difference between $T_{0}$ and $T_{1} ; P<0.005$.

$\|$ Difference between $T_{0}$ and $T_{2} ; P<0.05$. 


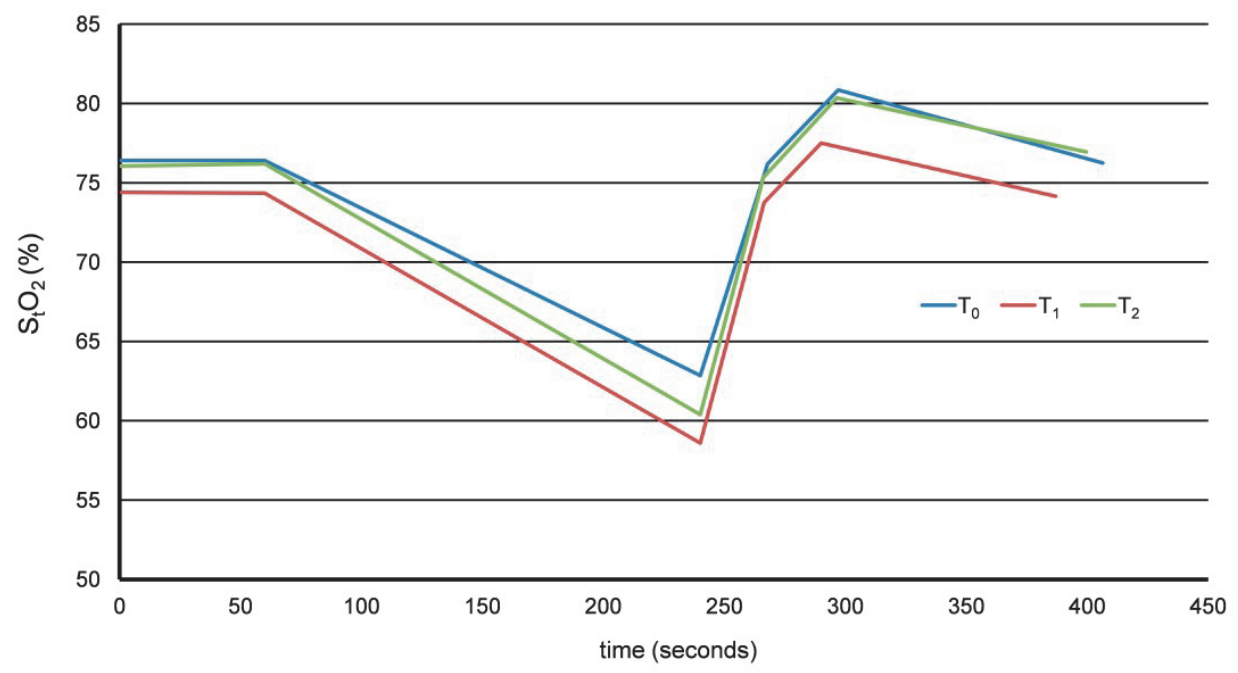

Fig 2. Results of tissue oxygen saturation in the right forearm during the ischemic challenge before, during, and after bypass.

Median values were calculated from all 34 patients (32 during bypass). $\mathrm{S}_{\mathrm{t}} \mathrm{O}_{2}$, tissue oxygen saturation; $T_{0}$, prior to bypass; $T_{1}$, during bypass; $T_{2}$, after cessation of bypass.

\section{Discussion}

Intraoperative monitoring of peripheral microvascular reactivity enables detection of alterations in microcirculatory function and thereby may contribute to preventing impaired tissue perfusion. ${ }^{3,4,17,21}$ This prospective study showed significant changes in VOT parameters between the different stages of cardiac surgery, implying altered vascular reactivity in patients undergoing cardiac surgery with $\mathrm{CPB}$.

The occlusion slope (also referred to as the desaturation slope or rate of deoxygenation) is one of the parameters that reflects the current state of microcirculation and ought to represent the rate of mitochondrial oxygen consumption and local tissue metabolism. ${ }^{22} \mathrm{~A}$ steeper occlusion slope therefore would be indicative of a relatively high local metabolic rate, as reflected by the rapid local decrease in oxyhemoglobin concentration. The results of this study showed a significantly steeper occlusion slope at both $T_{1}$ and $T_{2}$ compared to $T_{0}$, indicating increased oxygen consumption during and after CPB compared with before initiation of CPB. This effect has been previously described and represents the effect of general anesthesia with propofol on oxygen delivery and extraction as well as capillary blood flow. ${ }^{9,23-25}$ Contrastingly, Smith et al. found the occlusion 
slope to be similar across different stages of surgery, ${ }^{17}$ which may be explained partially by methodologic differences that consequently affect the values of VOT-derived parameters. For example, their study did not apply any exclusion criteria, such as Raynaud's disease, which may logically may affect $\mathrm{S}_{\mathrm{t}} \mathrm{O}_{2}$.

Another VOT-derived parameter is the lowest value found during the ischemic period, which provides information regarding the absolute oxygen reserve in the microcirculatory system. The observed decline in the lowest $\mathrm{S}_{t} \mathrm{O}_{2}$ value at $\mathrm{T}_{1}$ suggested that the absolute oxygen reserve was affected during perfusion, probably in part due to hemodilution. This also was reflected by the decreased hemoglobin values during bypass (see Table 2 ).

Since the time required for recovery did not change, it can speculated that perfusion recovery occurred in a more efficient manner while the patient was on bypass. This observed effect can be attributed to an increased blood flow velocity in minor hemodilution by a decrease in systemic vascular resistance. ${ }^{26-27}$ In addition, reduced blood viscosity adds to the increase in blood flow in the capillaries and thereby compensates for the effect of dilution, contributing to maintaining adequate tissue oxygenation. ${ }^{27}$

The reperfusion slope (also referred to as the recovery slope or rate of reperfusion) represents the time required to wash out stagnant blood from the microvasculature and the local reperfusion reserve., ${ }^{9,22}$ Our results did show an increased reperfusion slope at $T_{2}$ compared to $T_{0}$, suggesting altered peripheral microvascular reactivity. The duration of reperfusion remained unchanged, possibly indicating enhanced reperfusion efficiency. It has been proposed that the reperfusion slope is directly proportional to tissue perfusion while that reperfusion time is inversely proportional to tissue perfusion. ${ }^{11}$ Therefore, it can speculated that the observed changes reflect an enhanced tissue perfusion when the patient is on bypass. Hence, our results could not confirm that CPB worsens microcirculatory function. Smith et al., in contrast, reported a decreased reperfusion slope at $T_{1}$ compared with $T_{0}$, implying impaired peripheral microvascular reactivity. ${ }^{17}$ They also found a successive decline in reperfusion slopes with increasing duration of $\mathrm{CPB}$, denoting worsened microcirculatory function. Possible factors contributing to these discrepancies are measurement site and CPB protocol. $\mathrm{S}_{\mathrm{t}} \mathrm{O}_{2}$ measurements in the study presented here were performed at the internal surface of the forearm, which may result in different values for VOTderived parameters compared with positioning the measurement probes at the thenar eminence.

Another VOT-derived parameter considered to reflect vascular reactivity is the hyperemic area, ${ }^{4,17}$ which is reflective of tissue oxygen consumption. ${ }^{28}$ Doerschug et al. reported a significantly lowered reactive hyperemic response in 
septic patients and attributed this finding to a dysregulated microvascular oxygen balance. ${ }^{28}$ In the current study, the hyperemic area did not differ between time points, which was in concordance with previous studies and adds to the notion of preserved peripheral microcirculation during and after $\mathrm{CPB} .^{9,17}$

Discrepancies between previously published studies and the results of this study could be the result of differences in the ischemic challenge protocol. The choice of probe, probe positioning, and duration of ischemia affect the values of VOT-derived parameters. ${ }^{29}$ However, a standardized protocol of VOT is not yet established. One method is the application of a fixed target $\mathrm{S}_{\mathrm{t}} \mathrm{O}_{2}$ for termination of the ischemic period (absolute value for $\mathrm{S}_{\mathrm{t}} \mathrm{O}_{2}$ of $40 \%$ ). ${ }^{9}$ Because a target tissue saturation level may be difficult to reach due to decreased metabolic rate and increased oxygen content during surgery, the study presented here used a fixed interval of 3 minutes occlusion time, similar to another study. ${ }^{17}$ Moreover, position of sensors and probe spacing affect the values of VOT-derived parameters. It was described previously that baseline as well as reperfusion and occlusion slopes were affected by probe placement. ${ }^{29}$ Both this study and the study by Smith et al. used medium-sized probes placed on the brachial artery. ${ }^{17}$ Previous studies report VOT protocols with placement of oximetry sensors at either the forearm or the thenar eminence. ${ }^{9,15-17}$ However, $\mathrm{S}_{\mathrm{t}} \mathrm{O}_{2}$ measured at the thenar muscle may be subject to the body-finger temperature difference in a larger extend than $\mathrm{S}_{\mathrm{t}} \mathrm{O}_{2}$ measured at the forearm. ${ }^{30}$ Inconsistent probe sizing and placement in prior studies make interpretation and comparison of data challenging, and future studies therefore should aim at developing a standardized protocol.

Another source of variation in the reported results could be differences in calculation methods. For example, in the study presented here, data of the entire downward slope were used for calculation of the desaturation slope, whereas others selected a 1-minute interval commencing with $\mathrm{S}_{\mathrm{t}} \mathrm{O}_{2}$ decreasing below baseline ${ }^{17}$ or defined the occlusion slope as the first $25 \%$ of $\mathrm{S}_{\mathrm{t}} \mathrm{O}_{2}$ descent. ${ }^{9} \mathrm{Re}-$ garding the reperfusion slope, other studies used either solely $\mathrm{S}_{t} \mathrm{O}_{2}$ values from the first 14 seconds of reperfusion, ${ }^{4}$ values from the release of occlusion to $85 \%$ $\mathrm{S}_{\mathrm{t}} \mathrm{O}_{2}$ recovery, ${ }^{17}$ or values of the entire reperfusion interval, similar to this study. ${ }^{9}$

Although differences in protocol apparently influence the values of VOT-derived parameters, it is unlikely that the observed changes between the different phases of surgery are affected. Nonetheless, it remains unclear whether these differences significantly contribute to the seemingly opposite physiologic effects described in published reports, underlining the importance of standardizing the VOT in future research. In addition, both baseline and dynamic VOT parameters may be affected by patient-related factors, including differences in subcutane- 


\section{CHAPTER 7}

ous adipose tissue depth. ${ }^{31,32}$ High interindividual variability makes comparison among patients challenging, hence the study presented here focussed on differences between time points.

The influence of propofol on the microcirculatory responsiveness and metabolic rate was precluded in the analysis, which potentially could influence VOT re-

sults. ${ }^{9,23-25}$ However, in the study presented here, the focus predominately was on the effect of CPB rather than the anesthesia protocol. In addition, the use of an $\alpha 1$-antagonist (eg, phenylephrine) also may affect VOT-derived parameters because it causes vasoconstriction, thereby reducing capillary blood flow. In the study presented here, however, the administered dose of phenylephrine was considerably lower compared with the study by Maier et al. that described the effects of phenylephrine on sublingual microcirculation in patients undergoing $\mathrm{CPB} .{ }^{33}$ Therefore, it may assumed that the effects of phenylephrine on the microcirculation in the current study were limited.

\section{Conclusion}

The microcirculatory function as demonstrated by changes in VOT parameters was enhanced during and after normothermic pulsatile CPB. Clinical relevance, however, needs to be further explored. 


\section{References}

1. Koning NJ, Vonk AB, van Barneveld LJ, et al. Pulsatile flow during cardiopulmonary bypass preserves postoperative microcirculatory perfusion irrespective of systemic hemodynamics. $\mathrm{J}$ Appl Physiol 2012;112:1727-1734.

2. Koning NJ, Atasever $B$, Vonk $A B$, et al. Changes in microcirculatory perfusion and oxygenation during cardiac surgery with or without cardiopulmonary bypass. J Cardiothorac Vasc Anesth 2014;28:1331-1340.

3. Pareznik R, Knezevic R, Voga G,et al. Changes in muscle tissue oxygenation during stagnant ischemia in septic patients. Intensive Care Med 32:87-92, 2006.

4. Creteur J, Carollo T, Soldati G, et al. The prognostic value of muscle StO2 in septic patients. Intensive Care Med 2007;33:1549-1556.

5. Sanders J, Toor IS, Yurik TM, et al. Tissue oxygen saturation and outcome after cardiac surgery. Am J Crit Care 2011;20:138-145.

6. Wilcox ME, Charbonney E, d'Empaire PP, et al. Oral neutrophils are an independent marker of the systemic inflammatory response after cardiac bypass. J Inflamm (Lond) 2014;11:32.

7. Gomes V, Gomes MB, Tibirica E, et al. Post-operative endothelial dysfunction assessment using laser Doppler perfusion measurement in cardiac surgery patients. Acta Anaesthesiol Scand 2014;58:468-477.

8. De Backer D, Dubois MJ, Schmartz D, et al. Microcirculatory alterations in cardiac surgery: effects of cardiopulmonary bypass and anesthesia. Ann Thorac Surg 2009;88:1396-1403.

9. Bernet $\mathrm{C}$, Desebbe $\mathrm{O}$, Bordon S, et al. The impact of induction of general anesthesia and a vascular occlusion test on tissue oxygen saturation derived parameters in high-risk surgical patients. J Clin Monit Comput 2011;25:237-244.

10. Koning NJ, Vonk AB, Meesters $\mathrm{Ml}$, et al. Microcirculatory perfusion is preserved during offpump but not on-pump cardiac surgery. J Cardiothorac Vasc Anesth 2014;28:336-241.

11. Skarda DE, Mulier KE, Myers DE, et al. Dynamic near-infrared spectroscopy measurements in patients with severe sepsis. Shock 2007;27:348-353.

12. Lipcsey M, Woinarski NC, Bellomo R. Near infrared spectroscopy (NIRS) of the thenar eminence in anesthesia and intensive care. Ann Intensive care 2012;2:11.

13. Harel F, Denault A, Ngo Q, et al. Near-infrared spectroscopy to monitor peripheral blood flow perfusion. J Clin Monit Comput 2008;22:37-43

14. Joyner MJ, Dietz NM, Shepherd JT. From Belfast to Mayo and beyond: the use and future of plethysmography to study blood flow in human limbs. J Appl Physiol 2001;91:2431-2441.

15. Morel J, Bouchet JB, Vola M, et al. Tissue near infra red spectroscopy change is not correlated with patients' outcome in elective cardiac surgery. Acta Anaesthesiol Scand 2014;58:835-842.

16. Tripodaki ES, Tasoulis A, Koliopoulou A, et al. Microcirculation and macrocirculation in cardiac surgical patients. Crit Care Res Pract 2012:654381.

17. Smith RS, Murkin JM. A novel assessment of peripheral tissue microcirculatory vasoreactivity using vascular occlusion testing during cardiopulmonary bypass. J Cardiothorac Vasc Anesth 2014;28:1217-1220.

18. O'Neil MP, Fleming JC, Badhwar A, et al. Pulsatile versus nonpulsatile flow during cardiopulmonary bypass: microcirculatory and systemic effects. Ann Thorac Surg 2012;94:2046-2053.

19. Murkin JM, Martzke JS, Buchan AM, et al. A randomized study of the influence of perfusion technique and $\mathrm{pH}$ management strategy in 316 patients undergoing coronary artery bypass surgery. II. Neurologic and cognitive outcomes. J Thorac Cardiovasc Surg 1995;110:349-362.

20. Fischer GW, Silvay G: Cerebral oximetry in cardiac and major vascular surgery. HSR Proc Intensive Care Cardiovasc Anesth 2010;2:249-256.

21. De Blasi RA, Palmisani $S$, Alampi D, et al. Microvascular dysfunction and skeletal muscle oxygenation assessed by phase-modulation near-infrared spectroscopy in patients with septic shock. Intensive Care Med 2005;31:1661-1668. 


\section{CHAPTER 7}

22. Gomez H, Torres A, Polanco P, et al. Use of non-invasive NIRS during a vascular occlusion test to assess dynamic tissue $\mathrm{O}(2)$ saturation response. Intensive Care Med 2008;34:16001607.

23. Van der Linden P, Schmartz D, Gilbart E, et al. Effects of propofol, etomidate, and pentobarbital on critical oxygen delivery. Critical Care Med 2000;28:2492-2499.

24. Milne SE, James KS, Nimmo S, et al. Oxygen consumption after hypothermic cardiopulmonary bypass: the effect of continuing a propofol infusion postoperatively. J Cardiothorac Vasc Anesth 2002;16:32-36.

25. Koch $\mathrm{M}$, De Backer $\mathrm{D}$, Vincent $\mathrm{JL}$, et al. Effects of propofol on human microcirculation. $\mathrm{Br} \mathrm{J}$ Anaesth 2008;101:473-478.

26. Meier $\mathrm{J}$, Lauscher $\mathrm{P}$, Kertscho $\mathrm{H}$, et al. The effects of hyperoxic ventilation on tissue oxygenation. TATM 2010;11:30-38.

27. Doss DN, Estafanous FG, Ferrario CM, et al. Mechanism of systemic vasodilation during normovolemic hemodilution. Anesth Analg 1995;81:30-34.

28. Doerschug KC, Delsing AS, Schmidt GA, et al. Impairments in microvascular reactivity are related to organ failure in human sepsis. Am J Physiol Heart Circ Physiol 2007;293:H1065$\mathrm{H} 1071$.

29. Gomez H, Mesquida J, Simon $P$, et al. Characterization of tissue oxygen saturation and the vascular occlusion test: influence of measurement sites, probe sizes and deflation thresholds. Crit Care 2009;13(Suppl5):S3.

30. Uilkema RJ, Groeneveld AB. Correlates of thenar near-infrared spectroscopy-derived tissue O2 saturation after cardiac surgery. Interact Cardiovasc Thorac Surg 2007;6:265-269.

31. Mayeur C, Campard S, Richard C, et al. Comparison of four different vascular occlusion tests for assessing reactive hyperemia using near-infrared spectroscopy. Crit Care Med 2011;39:695-701.

32. Martin DS, Levett DZ, Bezemer R, et al. The use of skeletal muscle near infrared spectroscopy and a vascular occlusion test at high altitude. High Alt Med Biol 2013;14:256-262.

33. Maier S, Hasibeder WR, Hengl $\mathrm{C}$, et al. Effects of phenylephrine on the sublingual microcirculation during cardiopulmonary bypass. $\mathrm{Br} \mathrm{J}$ Anaesth 2009;102:485-491. 


\section{CHAPTER 8}

\section{Non-invasive tissue oximetry following unilateral DIEP-flap reconstruction: a pilot evaluation}

NPA Vranken, PW Weerwind, MA van Onna, EAC Bouman, RRWJ van der Hulst

Published in JPRAS Open 2017;12:59-65. 


\title{
CHAPTER 8
}

\begin{abstract}
Introduction: Post-operative monitoring of a free flap transplant in the form of a deep inferior epigastric perforator flap (DIEP-flap) is crucial for early detection of vascular compromise. The aim of the current study, therefore, is to gain insight whether non-invasive tissue oximetry is suitable for assessment of tissue perfusion following DIEP-flap surgery and whether it can serve as an early marker for vascular compromise.

Methods: Patients $(n=29)$ undergoing secondary unilateral DIEP-flap surgery were included in this prospective explorative study. Non-invasive tissue oxygen saturation $\left(\mathrm{StO}_{2}\right)$ measurements were performed using one sensor positioned on the DIEP-flap and another positioned on the native breast. Measurements were performed directly after the surgical procedure until $24 \mathrm{~h}$ post-operatively. Results: Tissue oxygenation response was swift in the native breast (on average $11.9 \% / \mathrm{h}$ for $84 \mathrm{~min}, \mathrm{n}=28$ ), whereas the DIEP-flap showed a lower and more extended tissue recovery phase of approximately $7.5 \% / \mathrm{h}$ for $6 \mathrm{~h}(\mathrm{n}=23)$. In some of these latter cases $(n=14)$, an acute and second more prolonged response was observed in the DIEP-flap. The average difference between the DIEP-flap and native breast $\mathrm{StO}_{2}$ was $4 \%$ across the entire measurement $(P=0.043)$. Two patients underwent post-operative re-exploration of the DIEPflap, in which an immediate and constant enlarged difference between DIEPflap and native breast $\mathrm{StO}_{2}(\geq 38 \%)$, and a decreased DIEP-flap $\mathrm{StO}_{2}(\leq 43 \%)$ was observed.

Conclusion: Continuous non-invasive tissue oxygen saturation is suitable for postoperative monitoring of DIEP-flaps, and $\mathrm{StO}_{2}$ pattern may aid in early identification of vascular compromise in DIEP-flaps.
\end{abstract}




\section{Introduction}

Increasing awareness of complications associated with silicone breast implants (haematomas, infections, sensory changes, peri-implant capsule formation/contraction and implant perforation or contracture) has generated high interest in breast reconstruction following mastectomy using solely autologous tissue. ${ }^{1}$ Success or failure of a particular free skin transplant, however, is dependent on continuous arterial and venous outflow through patent microvascular anastomoses. ${ }^{2}$ Therefore, postoperative monitoring of a DIEP-flap is crucial for early detection of vascular compromise to maximise chances of flap salvage. ${ }^{3}$ Loss of free flaps due to vascular compromise is a detrimental complication and has been reported to occur in $3.6-6 \%$ of cases, while re-exploration is performed in $5-25 \%$ of cases. ${ }^{4,5}$

In daily practices, clinical observation of skin colour, temperature and capillary refill are used to assess flap perfusion and viability, as well as results obtained by Doppler ultrasonography. ${ }^{6}$ However, these monitoring methods are only performed intermittently and are rather subjective, relying on the experience of the evaluator. Additionally, the results of a literature review conducted by Smit and colleagues implicate that solely performing clinical evaluation for postoperative flap monitoring is unfavourable due to the time needed for clinical signs to become evident. $^{7}$

Non-invasive tissue oximetry using near-infrared spectroscopy (NIRS) is a method that could be used for continuous monitoring of tissue perfusion in free skin flaps. Previous studies suggest that tissue oximetry is capable of early detection of tissue hypoxia in free skin flaps. ${ }^{3,8-10}$ However, these studies only performed unilateral tissue oxygenation measurements. In the current study, tissue oxygen saturation $\left(\mathrm{StO}_{2}\right)$ is monitored simultaneously in the DIEP-flap and native breast (personalised reference value). The present study aims to gain insight in whether non-invasive tissue oximetry is suitable for assessment of tissue perfusion following reconstructive breast surgery with a DIEP-flap and if bilateral tissue oximetry values can potentially serve as an early marker for vascular compromise.

\section{Materials and methods}

\section{Patients}

Female patients undergoing unilateral secondary DIEP-flap surgery were included in this prospective explorative study. A prerequisite was a DIEP-flap 
dimension of at least $50 \mathrm{~mm} \times 85 \mathrm{~mm}$, to allow proper sensor placement. Primary DIEP-flap procedures were not included because the abdominal skin island on the breast is smaller following a primary procedure as compared to a secondary procedure. An exclusion criterion for this study was objection in the patient hospital records against consultation of patient and surgery-related information for research or educational purposes. Data acquisition and analyses for this explorative study were performed anonymously and in accordance with the Dutch law for approving medical research.

\section{Measurements}

Non-invasive tissue oximetry uses NIRS based on the Lambert-Beer law. In short, light of several wavelengths within the near-infrared spectrum is absorbed by chromophores in an oxygen-dependent manner. ${ }^{5,11}$ Characteristic absorption spectra of the chromophores oxyhaemoglobin and deoxyhaemoglobin allow estimation of their concentrations after measuring the optical signals exiting the tissue. $^{12}$ The ratio of oxygenated haemoglobin relative to the total local concentration of deoxygenated haemoglobin is then used to quantify the oxygen content in local tissue. ${ }^{5,11,12}$

In our study, non-invasive tissue oxygenation monitoring was performed using the INVOS 5000C Oximeter (Somanetics Corporation, Troy, Michigan, USA). One self-adhesive disposable NIRS sensor (INVOS SAFB-SM Adult SomaSensor) was positioned on the DIEP-flap below the staple markings and served to measure the Doppler flow on the lower medial site of the flap. The other sensor was positioned on the lower side of the native breast right below the areola and served as a personalised reference value. Since revisions of the anastomoses are mostly performed in the first critical hours following surgery ${ }^{3,13}$, tissue oximetry readings were initiated directly after completion of the surgical procedure and continued until 24 hours postoperatively at the ward. Protocolled transfer of the patient from the operating theater to the recovery room was accommodated after adequate blood flow identification by Doppler ultrasonography.

Flap weight, ischaemia time and postoperative complications emerging before hospital discharge were recorded. Post-operative complications were defined as circulatory failure at the recipient site (DIEP-flap) requiring immediate return to the operating room for re-exploration.

\section{Statistical analysis}

For the a priori sample size calculation a $10 \%$ difference in $\mathrm{StO}_{2}$ was considered a relevant change, considering the inaccuracy of the INVOS $5000 \mathrm{C}$ clinical oximeter of $4.7 \%$. With an $\alpha$ set at 0.05 , a statistical power (1- $\beta$ ) of 0.95 , and $\sigma$ 
of 13.75 (maximum - minimum divided by 4, i.e., 99-44/4), the estimated sample size amounted to 28 patients.

Data were analysed according to the absolute tissue oxygen saturation difference $\left(\Delta \mathrm{StO}_{2}\right.$, depicted in \%) between the DIEP-flap and the native breast. Numerical values are expressed as mean \pm standard deviation. Depending on data distribution, either a paired t-test or Wilcoxon signed-rank test was used for comparison of DIEP and native breast $\mathrm{StO}_{2}$.

\section{Results}

From a practical point of view, a total of 29 patients were included in the study. The mean age and body mass index were $50 \pm 10$ years and $26.3 \pm 3.3 \mathrm{~kg} / \mathrm{m}^{2}$, respectively. The ischaemia time varied from 23 to 75 min (mean $48 \pm 12 \mathrm{~min}$ ) and the weight of the transplant varied from 250 to $1324 \mathrm{~g}$ (mean $645 \pm 237 \mathrm{~g}$ ). On average, $\mathrm{StO}_{2}$ of the native breast amounted to $85 \pm 3 \%$ in the first $24 \mathrm{~h}$ postoperatively, whereas $\mathrm{StO}_{2}$ measured in the DIEP-flap was significantly lower, amounting to $81 \pm 4 \%$ (Wilcoxon signed-rank test, $P=0.043$ ) (Table 1).

Table 1. Study population characteristics.

\begin{tabular}{lccc}
\hline & $\mathrm{n}=29$ & case 1 & case 2 \\
\hline age $(\mathrm{y})$ & $50 \pm 10$ & 52 & 61 \\
$\mathrm{BMI}\left(\mathrm{kg} / \mathrm{m}^{2}\right)$ & $26.4 \pm 3.3$ & 30.0 & 23.5 \\
weight DIEP-flap (g) & $649 \pm 240$ & 1000 & 688 \\
ischemia time DIEP-flap (min) & $48 \pm 12$ & 60 & 37 \\
mean $\mathrm{StO}_{2}$ DIEP-flap (\%) & $81 \pm 4$ & $43 \pm 0$ & $44 \pm 1$ \\
mean $\mathrm{StO}_{2}$ native breast (\%) & $85 \pm 3$ & $86 \pm 4$ & $82 \pm 2$ \\
\hline
\end{tabular}

BMI: body mass index, DIEP flap: deep inferior epigastric perforator-flap, $\mathrm{StO}_{2}$ : tissue oxygen saturation. ${ }^{*}$-value for comparison of the mean $\mathrm{StO}_{2}$ DIEP-flap and mean $\mathrm{StO}_{2}$ native breast: $\mathrm{P}=0.043$ (Wilcoxon signed-rank test).

In the majority of patients, a rapid post-surgical tissue oxygenation response was noted in the native breast, amounting to $11.9 \%$ /hour for 84 min (mean values for 28 patients). One patient lacked an identifiable tissue response, showing stable $\mathrm{StO}_{2}$ values throughout the entire measurement duration. Following tissue oxygenation recovery, native breast $\mathrm{StO}_{2}$ values remained constant $(85.9 \pm 7 \%)$. The DIEP-flap, on the other hand, showed a more extended tissue oxygenation response of $7.5 \% / \mathrm{h}$ for $6 \mathrm{~h}$ (mean value for 23 patients). In some of 


\section{CHAPTER 8}

these patients $(n=14)$, an acute and second more prolonged tissue response could be identified (Graph 1). In those cases, a slope of $12.8 \% / \mathrm{h}$ was observed in the DIEP-flap immediately after initiation of the measurement for $71 \mathrm{~min}$ (mean value), while the second and more prolonged recovery slope amounted to $6.9 \% / \mathrm{h}$ for $165 \mathrm{~min}$ (mean value). After tissue oxygenation recovery, DIEPflap $\mathrm{StO}_{2}$ values remained stable $(81.8 \pm 12 \%)$. In one individual patient with the shortest ischaemia time observed (23 minutes), DIEP-flap and native breast $\mathrm{StO}_{2}$ showed very similar values throughout the entire measurement (Graph 2). In 6 of 29 patients, no clear tissue oxygenation recovery could be identified as tissue oximetry values obtained from the DIEP-flap remained relatively similar throughout the measurement. In three of these patients, DIEP-flap and native breast $\mathrm{StO}_{2}$ also consistently showed comparable values (absolute $\Delta \mathrm{StO}_{2} \leq 10 \%$ throughout the entire measurement duration).

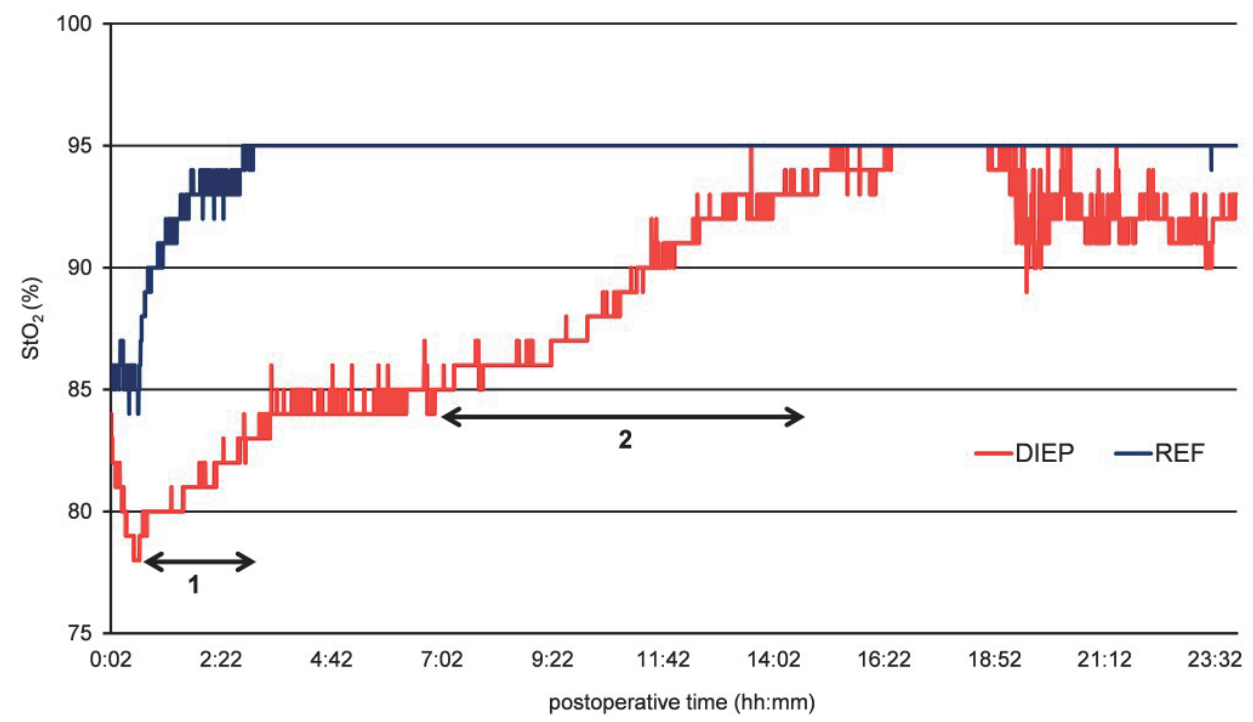

Graph 1. Tissue oximetry readings of an individual patient with an uncomplicated postoperative recovery. 1. Acute tissue oxygenation recovery phase, 2 . Second prolonged tissue oxygenation recovery phase. DIEP: deep inferior epigastric perforator, REF: internal reference measurement, $\mathrm{StO}_{2}$ : tissue oxygen saturation. 


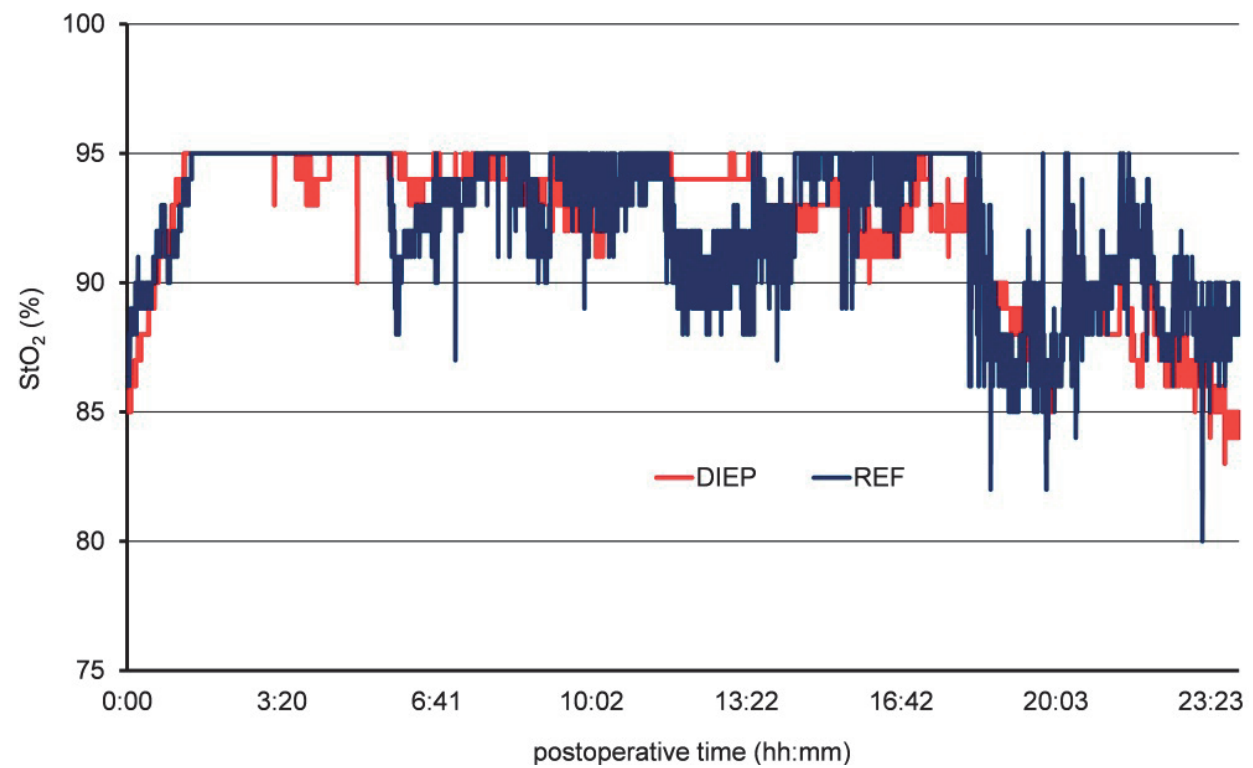

Graph 2. Tissue oximetry readings from a patient with the shortest observed ischemia time $(23$ minutes). DIEP: deep inferior epigastric perforator, REF: internal reference measurement, $\mathrm{StO}_{2}$ : tissue oxygen saturation.

Most patients showed an uncomplicated postoperative course and were discharged from the hospital after 5 days. In two patients (7\%), however, reexploration of the DIEP-flap was performed within $24 \mathrm{~h}$ following clinical signs of vascular compromise and aberrant results obtained by Doppler ultrasonography. An immediate and constant enlarged $\Delta \mathrm{StO}_{2}$ (on average $43 \%$ ) and decreased DIEP-flap $\mathrm{StO}_{2}(43 \%)$ was observed in case 1 (Table 1, Graph 3), which could be explained by a non-patent anastomosis. In this particular patient, the epigastric perforators were anastomosed to the thoracodorsal vessels after failure to locate the internal mammary vessels. A second anastomosis was performed to ensure sufficient tissue perfusion and DIEP-flap salvage. In another patient experiencing postoperative re-exploration, similar $\Delta \mathrm{StO}_{2}$ values (on average $38 \%$ ) and decreased DIEP-flap $\mathrm{StO}_{2}(44 \%)$ were noted (Table 1 , Graph 4). In case 2, re-exploration of the DIEP-flap was performed within $24 \mathrm{~h}$ because of vascular compromise that was suspected based on flap discolouration; however, an evident circulatory defect could not be identified. On the fifth postoperative day, partial necrosis on one side of the DIEP-flap was sensed as palpable firmness identified by physical examination. 


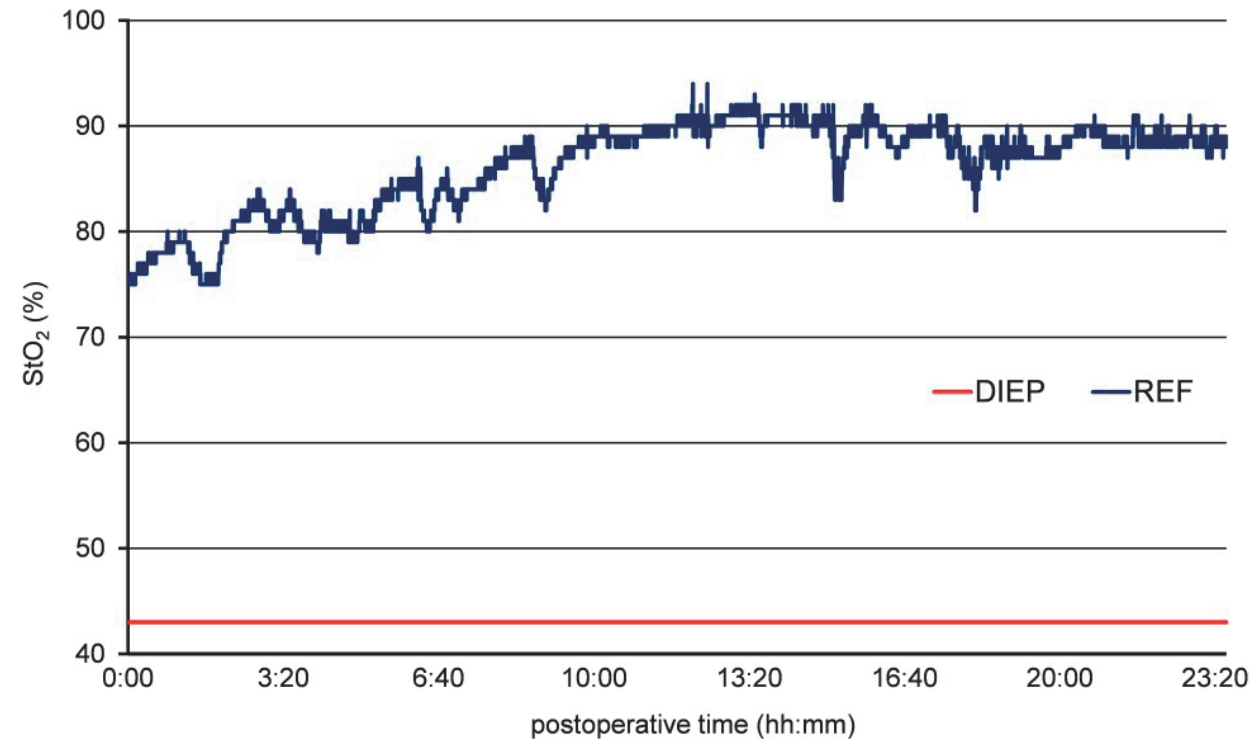

Graph 3. Case 1: Tissue oximetry readings from a patient with a non-patent anastomosis.

DIEP: deep inferior epigastric perforator, REF: internal reference measurement, $\mathrm{StO}_{2}$ : tissue oxygen saturation.

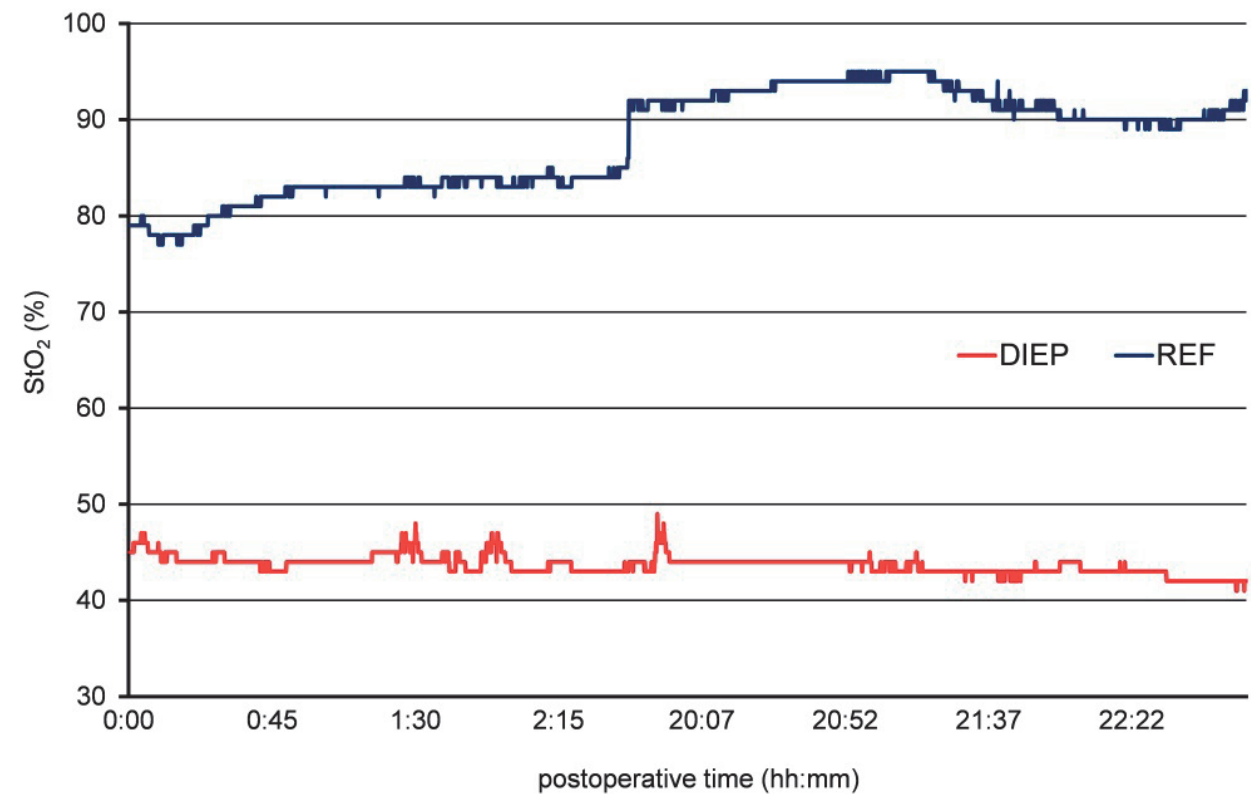

Graph 4. Case 2: Tissue oximetry readings from a patient complicated with partial fat necrosis of the DIEP-flap observed on the fifth postoperative day. DIEP: deep inferior epigastric perforator, REF: internal reference measurement, $\mathrm{StO}_{2}$ : tissue oxygen saturation. Due to dislodgement of measurement probes, data was lost between the $3^{\text {rd }}$ and $20^{\text {th }}$ postoperative hour. 


\section{Discussion}

This explorative clinical study identified several patterns of tissue oximetry readings in the first $24 \mathrm{~h}$ following unilateral secondary DIEP-flap surgery. Most patients showed a gradual recovery of DIEP-flap tissue oxygenation. To the best of our knowledge, this is the first study linking tissue oximetry readings including a personalised reference value to clinical outcome following DIEP-flap surgery.

Although most patients showed a subtle or more pronounced tissue response in the DIEP-flap, some patients showed relatively stable tissue oxygenation values throughout the measurement. Possibly in the latter group of patients $(n=6)$ the tissue response did not exceed the threshold of a detectable $\mathrm{StO}_{2}$ change. In three of these patients, DIEP-flap $\mathrm{StO}_{2}$ did not only lack an identifiable recovery slope but also showed comparable values to the native breast $\mathrm{StO}_{2}$ throughout the entire measurement $(\leq 10 \%$ absolute difference). A possible explanation for these findings is that in this group of patients, DIEP-flap $\mathrm{StO}_{2}$ recovery had already occurred prior to initiation of the measurement.

Following flap elevation, primary ischaemia begins whenever the vascular pedicle is transected - in this case, the vessel responsible for perfusion of the DIEPflap. When the anastomosis is completed and vascular clamps are removed, the initial reperfusion phase starts. Generally, an increased ischaemia time leads to a decreased survival rate of free skin flaps; therefore, one may expect the chance of vascular compromise to be increased with a prolonged ischaemia time. ${ }^{14}$ However, our results do not reflect this statement, as the re-explored DIEP-flaps underwent an ischaemia time of 37 and $60 \mathrm{~min}$, which is within the range of the mean value \pm one standard deviation (36-60 min, Table 1). One could therefore hypothesise that in the studied cases, the ischaemia time was too short to contribute to impaired postoperative tissue recovery.

In total, 2 out of 29 studied patients underwent re-exploration of the DIEP-flap. In case 1 , the anastomosis was insufficient to adequately perfuse the entire DIEP-flap, which was reflected by a $\Delta \mathrm{StO}_{2}$ of $43 \%$ and a DIEP-flap $\mathrm{StO}_{2}$ of $43 \%$. More specifically, an inadequate venous outflow resulted in venous congestion of the DIEP-flap. In contrast, in case 2 no evident cause for impaired tissue perfusion could be identified. Preceding partial necrosis noted on the fifth postoperative day, a consistently lowered $\mathrm{StO}_{2}$ concomitant with an increased $\Delta \mathrm{StO}_{2}$ was measured in the DIEP-flap of this particular patient. These results imply that both an enlarged $\Delta \mathrm{StO}_{2}(\geq 38 \%)$ and decreased $\mathrm{StO}_{2}$ measured in the DIEP-flap $(\leq 43 \%)$ are indicative of inadequate flap perfusion. In both patients, an increased $\Delta \mathrm{StO}_{2}$ as well as a decreased DIEP-flap $\mathrm{StO}_{2}$ were observed im- 
mediately after initiation of the measurement, suggesting that tissue oximetry was capable of providing an early warning of impaired tissue perfusion.

Nevertheless, when determining a clear $\mathrm{StO}_{2}$ or $\Delta \mathrm{StO}_{2}$ threshold necessitating prompt intervention. it is important to consider the limitations of tissue oximetry. Clinical oximeter devices are destined for either trend or absolute $\mathrm{StO}_{2}$ monitoring, as they use an algorithm which requires the assumption of a fixed ratio of arterial to venous blood in the vascular bed. This algorithm, however, cannot adapt to all possible applications of tissue oximetry. Hence, one must be cautious when interpreting absolute $\mathrm{StO}_{2}$ values derived from measurements performed in different areas. When interpreting the current results, it is important to consider the fact that DIEP-flap and personalized reference $\mathrm{StO}_{2}$ reflect the oxygen balance in different types of tissue. Therefore, it can be expected that absolute values derived from both measurements (native breast tissue and abdominal wall tissue) differ to a certain extent, although in the vast majority of patients, the absolute $\Delta \mathrm{StO}_{2}$ was $\leq 10 \%$ after tissue oxygenation recovery. This latter suggests that comparison of DIEP-flap and native breast $\mathrm{StO}_{2}$ is of added value in patients with vascular compromise.

Additional factors to take into account when establishing $\mathrm{StO}_{2}$ thresholds are the clinical oximeter device and type of sensor used. Previous studies used different oximeter devices and NIRS sensors, which makes comparison of study results challenging. In a study by Hyttel-Sorensen and colleagues, three different oximeters were compared. ${ }^{15}$ They found differences in median absolute values, repeatability and dynamic measurements across the different devices, underlining the importance of standardised application of tissue oximetry. Additionally, tissue oxygen saturation values are not only dependent on sensor positioning but are also affected by near-infrared transmitter-receiver spacing, which may vary between sensor types. ${ }^{16}$ The current study used sensors with an estimated depth of measurement of $20 \mathrm{~mm}$, while other studies used oximeters with varying measurement depths of $0-5 \mathrm{~mm}^{13}, 4-6 \mathrm{~mm}^{8}$, or more similar to our study, up to approximately $23 \mathrm{~mm} .{ }^{3}$ Different monitoring devices also use varying numbers and wavelengths of near-infrared light, which also affects estimation and calculation of $\mathrm{StO}_{2}{ }^{17}$

\section{Conclusion}

Continuous non-invasive tissue oxygen saturation patterns may aid in early identification of vascular compromise following DIEP-flap surgery. Future studies should aim at establishing clinically relevant tissue oxygenation thresholds. 


\section{Conflict of interest statement}

None declared.

\section{Funding}

None.

\section{Acknowledgements}

The authors acknowledge Ms. AAMA Lindelauf and Ms. TMH Bosch for their practical support in conducting the measurements. 


\section{References}

1. Teymouri H, Stergioula S, Eder M, Kovacs L, Biemer E, Papadopulos N. Breast reconstruction with autologous tissue following mastectomy. Hippokratia 2006;10:153-162.

2. Cornejo A, Rodriguez T, Steigelman M, et al. The use of visible light spectroscopy to measure tissue oxygenation in free flap reconstruction. J Reconstr Microsurg 2011;27:397-402.

3. Whitaker IS, Pratt GF, Rozen WM, et al. Near infrared spectroscopy for monitoring flap viability following breast reconstruction. J Reconstr Microsurg. 2012;28:149-54.

4. Chen KT, Mardini S, Chuang DC, et al. Timing of presentation of the first signs of vascular compromise dictates the salvage outcome of free flap transfers. Plast Reconstr Surg 2007;120:187-195.

5. Repez A, Oroszy D, Arnez ZM. Continuous postoperative monitoring of cutaneous free flaps using near infrared spectroscopy. J Plast Reconstr Aesthet Surg 2008;61:71-77.

6. Koolen PG, Vargas CR, Ho OA, et al. Does Increased Experience with Tissue Oximetry Monitoring in Microsurgical Breast Reconstruction Lead to Decreased Flap Loss? The Learning Effect. Plast Reconstr Surg 2016;137:1093-101.

7. Smit JM, Zeebregts CJ, Acosta R, Werker PM. Advancements in free flap monitoring in the last decade: a critical review. Plast Reconstr Surg 2010;125:177-185.

8. Keller A. A new diagnostic algorithm for early prediction of vascular compromise in 208 microsurgical flaps using tissue oxygen saturation measurements. Ann Plast Surg 2009;62:538-543.

9. Keller A. Noninvasive tissue oximetry. Clin Plast Surg 2011;38(2):313-324.

10. Lohman RF, Langevin CJ, Bozkurt M, Kundu N, Djohan R. A prospective analysis of free flap monitoring techniques: physical examination, external Doppler, implantable Doppler, and tissue oximetry. J Reconstr Microsurg 2013;29:51-56.

11. Steppan J, Hogue CW, Jr. Cerebral and tissue oximetry. Best Pract Res Clin Anaesthesiol 2014;28:429-439.

12. Scheeren TW, Schober P, Schwarte LA. Monitoring tissue oxygenation by near infrared spectroscopy (NIRS): background and current applications. J Clin Monit Comput 2012;26:279-287.

13. Keller A. Noninvasive tissue oximetry for flap monitoring: an initial study. J Reconstr Microsurg 2007;23:189-197.

14. Kerrigan CL, Daniel RK. Critical ischemia time and the failing skin flap. Plast Reconstr Surg 1982;69:986-989.

15. Hyttel-Sorensen S, Hessel TW, Greisen G. Peripheral tissue oximetry: comparing three commercial near-infrared spectroscopy oximeters on the forearm. J Clin Monit Comput 2014;28:149-155.

16. Bevan PJ. Should cerebral near-infrared spectroscopy be standard of care in adult cardiac surgery? Heart Lung Circ 2015;24:544-550.

17. Yoshitani K, Kawaguchi M, Tatsumi K, Kitaguchi K, Furuya H. A comsparison of the INVOS 4100 and the NIRO 300 near-infrared spectrophotometers. Anesth Analg 2002;94:586-590. 
CHAPTER 9

General discussion 
A number of different technologies have been developed to measure tissue oxygenation with the goal of identifying tissue hypoxia and guiding therapy to optimize end-organ tissue oxygenation, to ultimately, prevent ischemic tissue damage. In specific cases, tissue oximetry may indicate decreased tissue oxygenation such as that occurring during acute brain ischemia. However, the causation between tissue hemoglobin-oxygen desaturation in one organ (e.g., brain or muscle) and global outcomes such as mortality, intensive care unit length of stay, and remote organ dysfunction remains speculative. In this thesis, the current state of evidence for predicting clinical outcomes from tissue oximetry is described and several issues that need to be addressed to clarify the link between tissue oxygenation and outcomes are identified. The analysis finds that despite the increasing amount of literature focusing on the application of tissue oximetry, the association between desaturation episodes and clinical outcomes remains assumptive. Major lacunae include clinically relevant threshold or prediction values for tissue desaturation-related injury in specific organs. Furthermore, defining the types of required interventions to correct changes in tissue oxygenation and defining the effect of these interventions on clinical outcomes is warranted.

\section{Tissue oximetry for brain monitoring}

Neurological complications following cardiac surgical interventions are among the most detrimental adverse outcomes, affecting $1.5-11 \%$ of the patient population. ${ }^{1-3}$ Several studies elaborated on the factors that play a role in the obviously multifactorial development of neurological complications. Regional tissue oxygen saturation $\left(\mathrm{rSO}_{2}\right)$ reflects the balance between arterial oxygen supply and demand in real-time, thus a decrease in oxygen supply or increase in oxygen extraction by metabolic demand in tissue results in a decrease in tissue oximetry readings. ${ }^{4}$ In essence, $\mathrm{rSO}_{2}$ is thought to reflect the local venous oxygen reserve, indicating that any factor that modulates either oxygen supply, oxygen extraction ratio, or both (e.g., anesthetics or cerebrovascular dysfunction) directly affects cerebral $\mathrm{rSO}_{2}$. Cerebral oximetry, however, does not provide any information regarding the cause of a changing $\mathrm{rSO}_{2}$, thus it remains unknown whether the $\mathrm{rSO}_{2}$ changes are attributable to modifiable factors or not. Although several observational and few experimental studies conclude that continuous brain monitoring using near-infrared spectroscopy (NIRS) is a viable method for early detection of cerebral hypoxia, proof for a clear link between cerebral $\mathrm{rSO}_{2}$ and postoperative neurologic complications (PNC) is still lacking. As discussed in Chapter 2, this can be partially explained by the fact that tissue oximetry, due to its measurement principle, is unable to take the intrinsic auto- 
regulatory activity of the cerebral vasculature into account. This is illustrated by the observation of seemingly normal cerebral $\mathrm{rSO}_{2}$ values during cerebral hyperperfusion (i.e., "brain luxury perfusion"), while the cerebral autoregulatory activity is impeded. ${ }^{5}$ Cerebral autoregulation (CA) is known to be intact within a certain range of physiologic cerebral perfusion pressures, and prevents both hypoxia and hyperoxia. The autonomous cerebral protective system prevents hyper- and hypoperfusion by continuous control and modification of cerebrovascular resistance, assuring constant cerebral blood flow. Consequently, impaired CA permits fluctuations in cerebral perfusion pressure which may result in either brain hyper- or hypoperfusion, predisposing the patient to an increased $\mathrm{PNC}$ risk. Rather than solely focusing on preserving cerebral $\mathrm{rSO}_{2}$ within certain predefined limits, maintaining intact CA should be of primary importance in minimizing PNC risk. The clinical relevance of statistically significant decreasing $\mathrm{rSO}_{2}$ values requires further elucidation, therefore it remains of utmost importance to take all available clinical information into account when interpreting $\mathrm{rSO}_{2}$ readings.

One factor contributing to the lack of evidence on the association between cerebral $\mathrm{rSO}_{2}$ and $\mathrm{PNC}$ may be the different perfusion protocols applied across studies. As indicated by Ganushchak et al. ${ }^{6}$, the cardiopulmonary bypass (CPB) technique affects PNC risk though variations in hemodynamic parameters such as mean arterial pressure, systemic vascular resistance, and arterial pulse pressure. Moreover, a prospective study by Ševerdija et al. clearly illustrated that the levels of arterial carbon dioxide level and the extent of hemodilution need to be controlled within a certain range to enable optimal cerebrovascular reactivity and thus intact $C A .{ }^{7}$ The primary requisite for intact $C A$ is a mean arterial blood pressure (ABP) within the lower and upper autoregulatory limit, which are reported to lie around 60 and $150 \mathrm{mmHg}$, respectively. ${ }^{8}$ These values, however, are subject to interpersonal variations, for example differences in sympathetic nervous activity, as is the case in chronic hypertension. ${ }^{9}$ In clinical practice, this may pose a challenge to warrant CA integrity based on preoperative measurements. Besides intraoperative $A B P$, arterial partial gas pressure of carbon dioxide also needs to be maintained at predetermined levels to enable sufficient autoregulatory activity (Chapter 3 ). Moreover, maintaining stable hemodynamics during CPB will contribute to lowering the PNC risk. ${ }^{6}$ Therefore, standardization in the form of strictly regulating patients' hemodynamics between the anticipated autoregulatory limits will contribute to preservation of $C A$ (Chapter 4). Ultimately, this will aid in decreasing the PNC incidence in surgical patients by avoiding unnecessary exposure to CA disturbances. 
Despite the shortcomings of cerebral oximetry inherent to its measurement technique, $\mathrm{rSO}_{2}$ readings can still serve as an additional source of information regarding the current balance between oxygen delivery and consumption. In Chapter 5 , we showed that cerebral oximetry effectively reflects tissue oxygenation changes resulting from several iatrogenic events in cardiac surgical patients. Onset of CPB and placement and removal of the aortic cross-clamp were events that resulted in a decreased $\mathrm{rSO}_{2}$, whereas anesthetic induction, placement of the sternal retractor and termination of CPB were associated with an increase in $\mathrm{rSO}_{2}$. We also illustrated that phenylephrine administration has no relevant effects on cerebral oxygen saturation. This observation is in contrast with the findings of an interventional study by Moerman et al., who concluded that cerebral $\mathrm{rSO}_{2}$ decreases following phenylephrine infusion. ${ }^{10}$ The authors hypothesized that this effect was a functional myogenic response, part of cerebral autoregulatory activity. The reported changes in $\mathrm{rSO}_{2}$ in their publication were statistically significant, but only very small in magnitude (on average $1.8 \%$ ). It is therefore unlikely that vasopressor (e.g., phenylephrine) administration has clinically relevant effects with regards to cerebral tissue perfusion. A previous study by Brassard and colleagues ${ }^{11}$ did show a decrease in cerebral tissue oxygenation following phenylephrine administration, however, this effect was exclusively observed in a specific subset of patients (diabetics) included in the study. The proposed negative effect of phenylephrine on cerebral $\mathrm{rSO}_{2}$ is, therefore, probably not of any clinical importance in non-diabetic patients.

In addition, Chapter 5 illustrates that cerebral oximetry using NIRS is sensitive enough to detect subtle and potentially relevant changes in $\mathrm{rSO}_{2}$ through several stages of CPB. Nonetheless, further clinical studies are warranted to investigate the relationship between subtle and pronounced cerebral desaturations identified by cerebral oximetry and PNC.

Tissue oximetry may also be helpful in continuous assessment of tissue perfusion in patients undergoing long-term cardiopulmonary support, such as venoarterial extracorporeal life support (VA-ECLS). Maintaining adequate cardiac output is especially important in VA-ECLS patients in order to prevent ischemic episodes which can potentially result in cerebral and microvascular malperfusion, contributing to the risk of complications including PNC, congestive heart failure, renal dysfunction, infections, and irreversible multi-organ failure. ${ }^{6,12-15}$ Hemodynamic instability is reflected by fluctuations in oxygen saturation and could thus be identified by tissue oximetry. In a retrospective study, we identified several events which were related to significant changes in cerebral $\mathrm{rSO}_{2}$ (Chapter 6). The analysis showed that cardiac arrhythmias (i.e., atrial fibrillation or ventricular fibrillation) cause a decrease in bi-frontal cerebral $\mathrm{rSO}_{2}$ (both the 
left and the right cerebral hemisphere), most probably as a result of hemodynamic instability.

Another event that manifested in a clear $\mathrm{rSO}_{2}$ decrease was the occurrence of a presumably sudden change in cardiac output without timely adjustment of the ventilator settings. These results indicate that tissue oximetry can aid in timely recognition of hemodynamic instability, contributing to early detection of impaired cerebral perfusion.

Surprisingly, administration of packed red blood cells (PRBC) did not cause a significant change in cerebral $\mathrm{rSO}_{2}$ readings. One might expect that allogeneic blood transfusion would cause an increase in $\mathrm{rSO}_{2}$ values due to its effect on oxygen carrying capacity and cardiac output. Part of the explanation for this seemingly contradictive finding can be found in the critical hemodynamic conditions of the patients receiving PRBC transfusion. In our study, some patients suffered from severe bleeding, which most likely caused blood transfusion to have had a compensatory effect on the decreased cardiac output. This, in turn, resulted in restoration of cardiac output, and thereby preservation of cerebral $\mathrm{rSO}_{2}$ rather than an increased value.

The study results advocate for the application of non-invasive tissue oximetry as a viable monitoring method for assessing cerebral tissue oxygenation during ECLS. Although direct interpretation of measurement values continues to be challenging due to the lack of application-specific $\mathrm{rSO}_{2}$ thresholds, inclusion of tissue oximetry in routine bedside monitoring could aid in early recognition of threats to hemodynamic stability.

\section{Tissue oximetry for somatic monitoring}

Besides the originally intended use of tissue oximetry (brain monitoring), several other clinical applications have been described in the literature. The two most commonly used oximeter devices (Fore-Sight Elite, CAS Medical Systems, Inc., Branford, CT, USA and INVOS 5100C, Medtronic, Minneapolis, MN, USA) provide the option to simultaneously measure cerebral and somatic tissue oxygen saturation with an adapted algorithm for the calculation of local oxygen content in muscle tissue.

Patients undergoing long-term cardiopulmonary support (e.g., VA-ECLS) specifically may benefit from somatic tissue oximetry. In VA-ECLS, femoral artery cannulation is a commonly used technique, however this access technique often compromises perfusion of the lower limbs, causing limb ischemia and concomitant tissue damage. In some cases, placement of a distal cannula is required to prevent fasciotomy or even limb amputation. Chapter 6 shows that tissue oximetry aids in early recognition of compromised limb perfusion and 
contributes to timely intervention by identifying the need for a distal cannula. Moreover, tissue oximetry even appeared superior in terms of early detection of malperfusion as compared to repeated bedside evaluation of limb temperature. In case of clotting in the distal femoral cannula, our analysis showed clear changes in limb $\mathrm{rSO}_{2}$ values before a decrease in limb temperature became evident.

Another potential target for somatic tissue monitoring are free skin transplants. The use of autologous skin and fat tissue supplied by an isolated perforator vessel has gained popularity over the recent years in plastic reconstructive surgery. Free skin-fat transplants, in the literature referred to as a flaps, are increasingly used for autologous breast reconstructive surgery. In the late eighties and early nineties, the deep inferior epigastric perforator (DIEP)-flap was introduced as an alternative to the transverse rectus abdominis myocutaneous (TRAM)-flap. While the latter involves rectus abdominis muscle and fascia excision, the abdominal muscles remain intact in DIEP-flap surgery.

Maintaining abdominal wall integrity contributes to decreased postoperative pain and risk of complications by minimizing donor-site morbidity as compared to TRAM-flap surgery. ${ }^{16}$ The DIEP-flap, however, is particularly susceptible to ischemia in which the quality of the microsurgical anastomoses determines flap perfusion and thereby its viability. Circulatory failure in a DIEP-flap is a detrimental complication that can cause partial or even complete flap loss. While previous reports suggest that non-invasive tissue oximetry might be of added value in perioperative DIEP-flap monitoring, these studies only performed unilateral measurements. In this specific application of tissue oximetry, the direct comparison with an internal or personalized reference value is crucial. Rather than aiming at maintaining stable $\mathrm{rSO}_{2}$ values, which is the commonly used strategy in brain monitoring during cardiac surgery, the intended use of tissue oximetry in free skin transplants is to assess tissue reoxygenation or tissue recovery.

In a prospective explorative study, we identified several patterns of tissue oximetry readings in the first 24 hours following unilateral secondary DIEP-flap breast reconstructive surgery (Chapter 8 ). Most patients showed a gradual recovery of DIEP-flap tissue oxygenation and an uncomplicated postoperative course. Two of the studied patients, however, underwent re-exploration of the DIEP-flap due to a non-patent anastomosis. This was reflected by an enlarged $\triangle \mathrm{rSO}_{2}$ (absolute difference in regional tissue oxygen saturation values between DIEP-flap and native breast), as well as a decreased $\mathrm{rSO}_{2}$ measured in the DIEP-flap as observed in both complicated cases. These aberrant $\mathrm{rSO}_{2}$ values were apparent immediately following initiation of the measurement. In this explorative study, we used tissue oximetry readings in the native breast as a per- 
sonalized reference value. Although the DIEP-flap concerns a different tissue type than the native breast, this personalized reference measurement enabled direct discrimination between cases with apparent circulatory failure of the perforator vessels and uncomplicated cases. These results suggest that the native breast can serve as an internal reference measurement and that non-invasive tissue oximetry values provide an early marker for impaired DIEP-flap perfusion. Nevertheless, in order to enable prompt intervention, further studies are needed to identify optimal $\Delta \mathrm{rSO}_{2}$ thresholds.

\section{Microvascular reactivity}

Apart from cerebral and/or somatic tissue oximetry, NIRS can also be used to gain insight in dynamic parameters, such as microvascular reactivity. Intraoperative monitoring of peripheral microvascular reactivity enables early detection of alterations in microcirculatory function and may contribute to preventing impaired tissue perfusion and adverse patient outcome. Combining continuous non-invasive tissue oxygenation monitoring with a reproducible ischemiareperfusion challenge allows assessment of vascular reactivity and potentially early recognition of altered vascular reactivity and function (Chapter 7 ). Through a prospective study, 34 adult patients undergoing cardiac surgery with CPB were studied. A vascular occlusion test (VOT) was performed by occluding the brachial artery using a pneumatic tourniquet inflated $30 \mathrm{mmHg}$ above the patient's systolic blood pressure for a fixed time frame of 3 minutes. Somatic $\mathrm{rSO}_{2}$ was continuously monitored at the internal surface of the proximal third of the forearm to assess the rate of tissue deoxygenated and reperfusion following the VOT. One of the studied parameters included the occlusion slope, which describes the decrease in $\mathrm{rSO}_{2}$ directly following occlusion of the brachial artery. According to previous studies, this parameter represents the rate of mitochondrial oxygen consumption and local tissue metabolism. ${ }^{17}$ The results showed an increased occlusion slope during and following CPB as compared to prior to $\mathrm{CPB}$, indicating increased oxygen consumption during and after CPB. This change has been described previously, and is explained by the effect of general anesthesia with propofol on oxygen delivery and extraction as well as capillary blood flow. Another VOT-derived parameter which showed significant changes throughout the cardiac surgical procedure is the lowest $\mathrm{rSO}_{2}$ value measured during the ischemic period. This parameter in particular provides information regarding the absolute oxygen reserve in the microcirculatory system. During $\mathrm{CPB}$, this value was lowered as compared to prior to and following CPB, suggesting an effect of CPB on the absolute oxygen reserve. Supported by the decreased hemoglobin values during bypass, part of this effect could be ex- 
plained by hemodilution. Interestingly, the time necessary for $\mathrm{rSO}_{2}$ recovery did not change through the different phases of cardiac surgery. Therefore, one can speculate that reperfusion or tissue oxygenation recovery occurred in a more efficient manner during CPB. A possible explanation can be found in the increased blood flow velocity in minor hemodilution by a decrease in systemic vascular resistance in combination with a reduced blood viscosity. In this case, the increased blood flow in the capillaries compensated for the effects of hemodilution with regards to local $\mathrm{rSO}_{2}$ values.

Another parameter that provides information regarding microcirculatory function is the reperfusion slope or recovery slope. This VOT-parameter reflects the time required to wash out stagnant blood as well as the local reperfusion reserve. In our study, an increased reperfusion slope was seen after termination of CPB compared to prior to $\mathrm{CPB}$, suggesting altered peripheral microvascular reactivity. The duration of reperfusion remained unchanged, which may be indicative of enhanced reperfusion efficiency. Contrastingly, a previous interventional study concluded that CPB worsened microvascular reactivity with decreased microcirculatory function, as illustrated by a successive decline in reperfusion slopes with increasing CPB duration. ${ }^{18}$ Possible factors contributing to this discrepancy include differences across studies with regards to CPB protocol, measurement site, tissue oximetry probe, and ischemic challenge protocol. Besides interindividual variations, VOT-derived measurements are obviously affected by the duration of occlusion as well as the algorithm used to calculate the occlusion and reperfusion slopes, amongst other factors. In addition, the clinical relevance of alterations identified by dynamic measurements of peripheral tissue oxygenation remains to be further explored. Since the current literature describes a variety of measurement protocols and calculation methods, further studies are warranted to determine the optimal approach in performing the VOT.

\section{Considerations of tissue oximetry application}

Despite the need for superior continuous and non-invasive monitoring methods in patient care, tissue oximetry is not yet part of standard routine practice. A multitude of anecdotal reports and recent reviews have tempered the enthusiasm for routine use of $\mathrm{rSO}_{2}$ by questioning whether it leads to improved patient outcomes or not. ${ }^{19}$ One of the causative factors is the lack of interventionguided trials linking disturbances in tissue oxygen saturation to adverse clinical outcome. Although multiple studies reported an association between tissue oxygen desaturation and post-surgical complications, it remains unclear if this is part of a causal relationship or just a reflection of overall morbidity. In addition, some studies elaborated that intraoperative optimization of $\mathrm{rSO}_{2}$ will result in 
fewer complications, however, these studies were mostly observational or underpowered to detect any significant effects. Moreover, in a systematic review conducted by Zheng et al., it was concluded that intraoperative correction of cerebral $\mathrm{rSO}_{2}$ is not associated with improved neurologic outcome. ${ }^{20}$ The role of intrinsic autoregulatory activity was most probably neglected when previous studies attempted to link decreased $\mathrm{rSO}_{2}$ to clinical outcome.

Another factor precluding routine use of tissue oximetry is the lack of clear application-specific $\mathrm{rSO}_{2}$ thresholds requiring immediate intervention. When determining a clear threshold $\mathrm{rSO}_{2}$ or change in $\mathrm{rSO}_{2}$ necessitating prompt intervention, it is important to take the limitations of the tissue oxygenation measurement into account. Clinical oximeter devices are destined for either trend or absolute $\mathrm{rSO}_{2}$ monitoring, utilizing an algorithm that requires the assumption of a fixed ratio of arterial to venous blood in the vascular bed in the area of interest. This algorithm, however, cannot adapt to all possible applications of tissue oximetry. Hence, one must be cautious when interpreting absolute $\mathrm{rSO}_{2}$ values derived from measurements performed in different areas.

To date, there are no clear indications when intervention to correct $\mathrm{rSO}_{2}$ is warranted. One may argue that this is partially due to the fact that studies up untill now failed to demonstrate a causal relationship between tissue oxygen desaturations identified by tissue oximetry and adverse clinical outcome.

Additionally, the use different monitoring devices used across studies makes standardised application of cerebral oximetry even more challenging. Oximeter devices from different manufacturers each use different algorithms for estimation of local oxygen content, and utilize varying numbers and wavelengths of near-infrared light. Furthermore, since every single device differs in terms of hardware as well as software (data acquisition, filtering and processing), each device should be used in concordance with a device-specific and applicationspecific set of desaturation thresholds.

Not only the specific measurement device but also the different applications in tissue oximetry directly affect the measurement and derived $\mathrm{rSO}_{2}$ values. While originally developed for cerebral tissue monitoring, tissue oximetry has been increasingly applied in different clinical settings, including somatic tissue monitoring in autologous tissue transplants ${ }^{21}$ or peripheral tissue, including muscle, ${ }^{22-24}$ as well as monitoring of the central nervous system by assessing spinal perfusion. ${ }^{25}$ Development of standardized desaturation thresholds for the different applications will aid in interpretation of $\mathrm{rSO}_{2}$ values and thereby establish routine use of tissue oximetry.

The main goal goal of continuous $\mathrm{rSO}_{2}$ measurement is to prevent or minimize hypoxemia by early detection of decreased oxygen delivery. The relationship between clinical outcome and changes in $\mathrm{rSO}_{2}$ readings remains doubtful, de- 
spite the large amount of literature desribing the application of tissue oximetry in surgical patients. Nonetheless, it is clear that the measurement technique is capable of identifying hemodynamic fluctuations. In general, microvascular alterations associated with microcirculatory dysfunction are predominant factors in the process of tissue hypoxia. Microcirculatory dysfunction is known to precede tissue hypoxia, and if left untreated results in ischemic tissue damage. Adopting microcirculatory monitoring as the standard of care may prove to be the next big frontier in critical care management. Monitoring microcirculation at the bedside, however, poses several practical challenges, nor is it easy to estimate tissue perfusion from standard physiological monitoring modalities. Now the limitations inherent to using NIRS in non-invasive tissue oximetry are identified, the focus should be on determining the optimal measurement protocol for bedside microvascular monitoring and interpretation of measurement values.

\section{Physiologic knowledge, including definition of thresholds for tissue damage that are associated with adverse outcomes}

This is a critical issue that remains unresolved to date. In previous studies, mostly arbitrary cut-offs are used for analysis of $\mathrm{rSO}_{2}$ values. One difficulty is that injury thresholds may vary among individuals because of differences in age, cerebral metabolism, anaesthetic and sedative regimen, body temperature, and other factors. However, if the technology accounts for changes in oxygenation because of changes in flow and blood volume in the sensor field, then autoregulation of cerebral blood flow should not be a confounder in establishing threshold values, since autoregulation affects vessel diameter and thereby blood flow. The other issue is the "area under the curve" problem: is 3 hours at a $10 \%$ reduced cerebral saturation equivalent in injury to a 1 hour interval at $30 \%$ ? Greater knowledge in this area is critical for study designs because interventions need to be assigned to an appropriate threshold and duration for potential tissue injury. Without appropriate thresholds, interventions will be initiated that are either unnecessary or it may be too late to succesfully alter the chance of adverse patient outcome. Furthermore, interventions have their own risks; for example vasopressors may decrease blood flow in unintended ways, and transfusion of blood products expose patients to a variety of risks.

\section{Conclusion}

Many studies have been conducted implicating a link between changes in regional tissue oxygen saturation observed by tissue oximetry and clinical out- 
comes. Despite this fact, the evidence for a causal relationship between tissue oximetry readings and outcome remains questionable. Well-designed prospective studies testing the hypothesis that monitoring oxygenation status in one organ is predictive for more general patient outcomes still needs to be conducted. Application-specific variables as well as measurement technique-related factors play a role in the failure of studies to demonstrate a clear relationship between tissue oximetry readings and complications resulting from tissue ischemia.

Moreover, there is a lack of intervention-guided studies identifying organspecific thresholds associated with concomittant ischemic tissue damage. Therefore, more work that defines regional variations in tissue oxygenation in critical organs is warranted. Such studies will contribute to the inclusion of monitoring and imaging of tissue oxygenation in routine practice in the care of highrisk patients because the monitors will provide outputs that direct therapy to improve clinical outcomes. 


\section{References}

1. Likosky DS, Leavitt BJ, Marrin CA, et al. Intra- and postoperative predictors of stroke after coronary artery bypass grafting. Ann Thorac Surg. 2003;76:428-434.

2. Roach GW, Kanchuger M, Mangano, et al. Adverse cerebral outcomes after coronary bypass surgery. Multicenter study of Perioperative Ischemia Research Group and the Ischemia Research and Education Foundation Investigators. N Engl J Med 1996;335(25):1857-1863.

3. Baranowska K, Juszczyk G, Dmitruk I, et al. Risk factors of neurological complications in cardiac surgery. Kardiol Pol. 2012;70:811-818.

4. Vretzakis G, Georgopoulou S, Stamoulis K, Stamatiou G, Tsakiridis K, Zarogoulidis P, et al. Cerebral oximetry in cardiac anesthesia. J Thorac Dis. 2014;6 Suppl 1:S60-69.

5. Henriksen L. Brain luxury perfusion during cardiopulmonary bypass in humans. A study of the cerebral blood flow response to changes in $\mathrm{CO} 2, \mathrm{O} 2$, and blood pressure. Cereb Blood Flow Metab. 1986;6:366-378.

6. Ganushchak YM, Fransen EJ, Visser C, De Jong DS, Maessen JG. Neurological complications after coronary artery bypass grafting related to the performance of cardiopulmonary bypass. Chest 2004;125:2196-205.

7. Ševerdija EE, Vranken NP, Simons AP, et al. Hemodilution Combined With Hypercapnia Impairs Cerebral Autoregulation During Normothermic Cardiopulmonary Bypass. J Cardiothorac Vasc Anesth 2015;29:1194-1199.

8. Paulson OB, Strandgaard S, Edvinsson L. Cerebral autoregulation. Cerebrovasc Brain Metab Rev 1990;2:161-192.

9. Tameem A, Krovvidi H. Cerebral physiology. Contin Educ Anaesth Crit Care Pain 2013:1-6.

10. Moerman A, Denys W, de Somer F, Wouters PF, de Hert SG. Influence of variations in systemic blood flow and pressure on cerebral and systemic oxygen saturation in cardiopulmonary bypass patients. Br J Anaesth 2013;111:619-626.

11. Brassard $\mathrm{P}$, Pelletier $\mathrm{C}$, Martin $\mathrm{M}$, et al. Influence of norepinephrine and phenylephrine on frontal lobe oxygenation during cardiopulmonary bypass in patients with diabetes. J Cardiothorac Vasc Anesth 2014;28:608-617.

12. Miller CE, Thompson S, Lozar J. A theoretical evaluation of cardiac output as a function of mean arterial pressure in the human cardiovascular system. J Theor Biol 1976;63(1):89-98.

13. Hoffman GM, Ghanayem NS, Tweddell JS. Noninvasive assessment of cardiac output. Semin Thorac Cardiovasc Surg Pediatr Card Surg Annu 2005;12-21.

14. Mariscalco G, Klersy C, Zanobini M, Banach M, Ferrarese S, Borsani P,et al. Atrial fibrillation after isolated coronary surgery affects late survival. Circulation 2008;118(16):1612-1618.

15. Mathew JP, Fontes ML, Tudor IC, et al. A multicenter risk index for atrial fibrillation after cardiac surgery. JAMA 2004;291(14):1720-1729.

16. Allen RJ, Treece P. Deep inferior epigastric perforator flap for breast reconstruction. Ann Plast Surg 1994;32:32-38.

17. Gomez H, Torres A, Polanco P, et al. Use of non-invasive NIRS during a vascular occlusion test to assess dynamic tissue $O(2)$ saturation response. Intensive Care Med 2008;34:16001607.

18. Smith RS, Murkin JM. Novel assessment of peripheral tissue microcirculatory vasoreactivity using vascular occlusion testing during cardiopulmonarybypass. J Cardiothorac Vasc Anesth 2004;28:1217-1220.

19. Ghosh A, Elwell C, Smith M. Review article: cerebral near-infrared spectroscopy in adults: a work in progress. Anesth Analg 2012;115:1373-1383.

20. Zheng F, Sheinberg R, Yee MS, Ono M, Zheng Y, Hogue CW. Cerebral near-infrared spectroscopy monitoring and neurologic outcomes in adult cardiac surgery patients: a systematic review. Anesth Analg 2013;116:663-676.

21. Keller A. Noninvasive tissue oximetry. Clin Plast Surg 2011;38(2):313e324. 
22. Bernet C, Desebbe O, Bordon S, et al. The impact of induction of general anesthesia and a vascular occlusion test on tissue oxygen saturation derived parameters in high-risk surgical patients. J Clin Monit Comput 2011;25:237-244.

23. Redlin M, Boettcher W, Huebler M, et al. Detection of lower torso ischemia by near-infrared spectroscopy during cardiopulmonary bypass in a $6.8-\mathrm{kg}$ infant with complex aortic anatomy. Ann Thorac Surg 2006;82(1):323-325.

24. Vranken NPA, Ganushchak YM, Willigers HM, Maessen JG, Weerwind PW. Vascular occlusion test to dynamically assess microcirculation during normothermic pulsatile cardiopulmonary bypass. J Cardiothorac Vasc Anesth 2016:30(4):979-984.

25. Nicolaou G, Clarke C, Murkin JM, Badner N, Forbes T. Use of spinal near-infrared spectroscopy (NIRS) for monitoring spinal cord perfusion in endovascular repair of throacoabdominal aneurysm, Proceedings, 13th annual outcomes meeting Accra Beach, Barbados, West Indies. 



\section{Summary}


The introduction of near-infrared spectroscopy for assessment of regional tissue oxygenation was an important landmark in the history of tissue perfusion monitoring. Since then, non-invasive tissue oximetry gained wide interest with subsequent studies addressing the clinical importance of continuous monitoring of tissue perfusion. An increasing amount of literature including many observational and few intervention-guided studies elucidated on the added value of primarily regional cerebral oximetry in terms of predicting neurologic outcome following cardiopulmonary bypass. Some studies even suggested that cerebral oximetry can be used as an organ index, meaning that maintaining adequate tissue oximetry levels is beneficial for all vital organs. Furthermore, continuous tissue oximetry proved to be a valuable addition in various clinical applications (short-term and prolonged cardiopulmonary support, and monitoring graft viability ensuing transplant surgery), as it effectively identifies changes in tissue oxygenation following several iatrogenic events.

Despite these proposed benefits, routine use of tissue oximetry in the clinical setting is, as of now, far from evident. For a compelling part this is due to the lack of well-designed interventional studies showing a clear association between tissue oximetry values and outcome, as well as discordance regarding clinically relevant and application-specific tissue oxygenation thresholds predictive for adverse outcome. Moreover, different applications of tissue oximetry require different interpretation strategies due to the absence or presence of regional vascular autoregulatory activity. Especially during cerebral oximetry, intact or any extent of temporary or permanently disturbed cerebral autoregulation directly affects oxygen delivery. In this case, assumptions as part of the algorithm used for calculation of oxygenated and deoxygenated hemoglobin may contribute to interpretation errors in apparent normal tissue oxygenation. Therefore, it remains of utmost importance to include all available clinical information when performing tissue oximetry.

Taking the aforementioned into account, non-invasive tissue oximetry aids in prompt assessment of tissue oxygenation and may thereby contribute to prevention of complications associated with hypoxia. The latter catalyzes indivertible developments for various prospective clinical applications. 


\section{Samenvatting}


De introductie van nabij-infrarood spectroscopie voor het regionaal monitoren van weefseloxygenatie was een belangrijke mijlpaal in de geschiedenis van weefselperfusie monitoring. Sindsdien is non-invasieve weefseloxymetrie meer onder de aandacht gekomen en richten studies zich op het klinische belang van continue weefselmonitoring. Een toenemende hoeveelheid literatuur waarvan enkele interventionele en vele observationele studies focust op voornamelijk regionale cerebrale oxymetrie in de context van het voorspellen van neurologische complicaties na cardiopulmonale bypass. Sommige studies suggereren zelfs dat cerebrale oxymetrie als een orgaanindex kan worden toegepast, hetgeen betekent dat behoud van adequate weefseloxymetrie waarden gunstig zou zijn voor alle vitale organen. Continue weefseloxymetrie is een bewezen waardevolle aanvulling in verscheidene klinische toepassingen (kort- en langduringe cardiopulmonale ondersteuning en monitoren van de levensvatbaarheid van een transplantaat), daar het effectief blijkt in identificatie van veranderingen in weefseloxygenatie ten gevolge van verschillende iatrogene gebeurtenissen.

Ondanks deze voorgestelde voordelen is routinematig gebruik van weefseloximetrie in de klinische setting bij lange na niet vanzelfsprekend. De oorzaak hiervan kan deels gezocht worden in het gebrek aan correct opgezette interventionele studies die een duidelijke associatie tussen weefseloxymetrie waarden en relevante uitkomsten aantonen. Daarbij bestaat ook tegenstrijdigheid in klinisch relevante en applicatie-specifieke grenswaarden voor weefseloxygenatiewaarden die gelinkt zijn aan nadelige gezondheidseffecten. Tevens behoeven de verschillende afzonderlijke toepassingen van weefseloxymetrie verschillende interpretatiestrategieën vanwege de aan- of afwezigheid van regionale autoregulatoire vasculaire acitiviteit. Vooral bij cerebrale oxymetrie is intacte cerebrale autoregulatie, of een verstoring hiervan, direct van invloed op de zuurstofvoorziening van het brein. In beide gevallen dragen aannames, welke onderdeel uitmaken van het algoritme dat gebruikt wordt voor de berekening van geoxygeneerd en gedeoxygeneerd hemoglobine, bij aan interpretatiefouten bij ogenschijnlijk normale weefseloxygenatie waarden. Het is daarom van groot belang om rekening te houden met alle beschikbare klinische informatie bij het toepassen van weefseloxymetrie.

Met inachtneming van de voorgenoemde zaken kan gesteld worden dat noninvasieve weefseloxymetrie bijdraagt in directe beoordeling van weefseloxygenatie en daarbij preventie van complicaties ten gevolge van hypoxie. Laatsgenoemde katalyseert de onvermijdbare ontwikkeling van nieuwe klinische toepassingen. 


\section{Valorization}




\section{Non-invasive tissue oximetry - an integral puzzle piece}

Inadequate tissue oxygen delivery is known to result in complications, contributing to morbidity and mortality following or during medical procedures. In order to minimize the risk of adverse outcome, close monitoring of patient's hemodynamic status at all times is indispensable. Non-invasive tissue oximetry is a monitoring method for continuous assessment of tissue oxygenation, which may aid in detection of hemodynamic instability and otherwise unnoticed hypoxia.

To date, numerous studies (of which mostly observational) focused on the use of non-invasive tissue oximetry in surgical patients, proposing its predictive value in relation to clinical outcome. Cerebral oximetry in particular has been the focus in the context of preventing neurological complications following cardiac surgery. These complications, including stroke which appears to be the most detrimental, are complex in nature and elicited by a multitude of preoperative and perioperative factors. Intraoperative cerebral hypoxia resulting from hypoperfusion is generally accepted as a factor contributing to the risk of adverse neurologic outcome. ${ }^{1,2}$ Although the exact etiology is not yet completely understood, continuous assessment of tissue perfusion may aid to a better understanding of the role of tissue hypoxia in the development of postoperative cognitive complications.

While the incidence of neurological complications may seem relatively low, the effects on the patient's physical and psychological health are tremendous with serious implications for the quality of life. ${ }^{3}$ The reported incidence of stroke following cardiac surgery varies around $4.2 \%$, meaning that every year 33 patients are affected based on 800 procedures annually. ${ }^{4}$ Postoperative stroke entails prolonged hospital stays of on average seven days with an incremental increase of hospital resources. ${ }^{5,6}$ In the United States, for each affected patient the estimated added costs make up to $\$ 18,552$, of which $\$ 1,000$ are attributable to each additional day of hospitalization. ${ }^{7}$

Another type of neurological complication that may emerge following cardiac surgery is delirium, which is characterized by a state of confusion and inattention. Although often seen as a reversible condition, delirium contributes to persistent functional decline and significant morbidity and mortality risk. ${ }^{8}$ Postoperative delirium is associated with only four extra hospitalization days, but is far more common as compared to stroke, with incidence rates varying around $55 \%{ }^{9,10}$ If non-invasive tissue oximetry could help to prevent part of the neurologic complications, such as hypoxia-related stroke or delirium ${ }^{2,11}$, the odds of an uncomplicated prosperous recovery would increase and a substantial pro- 
portion of hospital costs could be saved. The costs of performing the measurement include the purchase of disposable self-adhesive sensors (usually two, for bilateral measurement of tissue oxygenation), which in the United States cost around $\$ 200$ per patient ${ }^{12}$, and a one-time investment for purchasing the oximeter device. The costs for routine application of clinical oximetry, however, are only marginal compared to the major additional expenses associated with ischemic-related stroke and delirium ${ }^{13}$, let alone the deleterious long-term effects of these complications, i.e. the quality of life.

The pathophysiology of neurologic postoperative complications is complex and multifactorial in nature. Therefore, some neurologic complications are nearly impossible to prevent due to unforeseen events occurring in the perioperative period (e.g. embolism originated from the cardiopulmonary bypass circuit) and the role of certain patient characteristics is not subject to change (pre-existing co-morbidities and positive family history of adverse neurovascular events). Another substantial proportion with less of a complex etiology is caused by modifiable factors and therefore theoretically concerns preventable cases. For example, hemodynamic instability is known to affect the risk of hypoxia. Moreover, hypercapnia and excessive hemodilution are thought to alter the risk of neurologic complication (chapter 3 ). ${ }^{14}$ The cardiopulmonary bypass protocol is, therefore, an important factor in enabling and maintaining adequate tissue perfusion and should be critically evaluated in order to minimize the risk of neurologic complications. Strict monitoring routines concern another factor of importance in preserving hemodynamic integrity, specifically monitoring at the tissue level since general hemodynamic factors may not adequately represent local tissue oxygenation status. ${ }^{15}$

With non-invasive tissue oximetry on the rise and being increasingly applied as a brain monitor, the technique appears to be a viable assessment method for diverting adverse neurologic outcome. On that note, cerebral oximetry showed to adequately reflect real-time changes in tissue oxygenation readings following several iatrogenic events. Despite the abundance of studies implying that oxygen desaturations detected by cerebral oximetry predict neurological outcome, evidence for a causal relationship remains scarce. Part of the explanation can be found in the fact that the development of neurological complications is a complex process, as mentioned beforehand, which is still not entirely understood. Deoxygenation episodes detected by cerebral oximetry should probably be considered as a contributor, rather than an independent causative factor for clinical neurologic damage and evident changes in neurocognitive function (chapter 2). 
In addition to the latter, when performing cerebral oximetry it is important to consider the intrinsic system of cerebral autoregulation. When intact, reactive vasoconstriction and vasodilatation ensures adequate tissue oxygenation, providing cerebral protection. Although often unacknowledged, disturbances in autoregulatory function have shown to result in neurologic complications and thus should be avoided at all times. In this thesis, several modifiable factors requiring strict regulation in order to maintain intact cerebral autoregulation are identified. In turn, a perfusion protocol that includes maintaining these factors within the physiologic range confers to the observed low incidence of neurological complications by enabling intact autoregulatory function.

Taking these practical considerations into account, one may conclude that tissue oximetry, inherently due to its measurement technique and thus noninvasive nature, cannot independently predict the occurrence of complications with a multifactorial nature such as ischemic stroke or delirium. Similar to most non-invasive monitoring tools and methods, tissue oximetry readings should be interpreted in the context of all clinical information available. The scientific value of this thesis is that non-invasive tissue oximetry derived measurement values should be viewed as an integral piece of information rather than a superior monitoring method.

Besides its original intended use (i.e. brain monitoring), non-invasive tissue oximetry is increasingly applied in somatic tissue monitoring. One example is assessment of distal limb perfusion in patients supported by veno-arterial extracorporeal life support (VA-ECLS). Femoral access techniques often used in VAECLS may compromise limb perfusion, therefore predisposing the patient to concomitant tissue damage with potential disastrous effects. Tissue oximetry performed at the calf muscle proved effective for identification of endangered limb perfusion by showcasing aberrant tissue oximetry readings before any other clinical parameters showed any evident change (chapter 6).

Another example of somatic tissue oximetry applies to monitoring autologous breast reconstructive surgery, in which abdominal wall tissue is transplanted to the chest area using microsurgical anastomoses. Graft failure, in the worst case, could lead to loss of the entire tissue flap with a major additional risk of physical and psychological burden for the patient. By immediately depicting deviant measurement values as compared to the expected physiologic tissue response, tissue oximetry appears superior to other applied monitoring techniques, which solely provide delayed timing of alarm signals. Tissue oximetry could aid in timely detection of circulatory compromise and thereby lower the rate of complications resulting from ischemic tissue damage. Successively, 
avoiding complications contributes to minimizing postoperative morbidity and mitigating health care costs. As is the case in brain monitoring, the costs for performing tissue oximetry are only marginal compared to the costs associated with postoperative complications. In case of arterial or venous thrombosis, surgical re-intervention is necessary to increase the chance of successful flap salvage. This will add around $\$ 76,000$ per hour spent in the operating room to the hospital costs. Also, patients experiencing complications generally consume two extra hospital days, leading to another $\$ 7,000$ in added costs per patient operated in the United States. ${ }^{16}$ In uncomplicated cases, tissue oximetry eliminates the need for prolonged intensive monitoring with savings of $\$ 1,337$ (or $6.3 \%{ }^{17}$ ) that far outweigh the costs associated with routine use of tissue oximetry. ${ }^{17,18}$

The relationship between aberrant tissue oximetry readings and clinical outcome appears to be more clear in the somatic applications of tissue oximetry. Complications arising from peripheral tissue ischemia (e.g. the distal limb and autologous breast flaps) are elementary in nature due to the absence of an intrinsic homeostatic autoregulatory system. In cerebral oximetry, one attempts assessing an entire organ system that is only represented by a regional assessment of tissue oxygenation in the prefrontal cortex. In somatic tissue oximetry on the other hand, the readings appear more representative for clinical outcome.

The versatility of tissue oximetry in the clinical setting may broaden the scope for future studies to focus on new potential applications. One prospective application is assessment of the microcirculatory function. Since microcirculatory dysfunction precedes tissue hypoxia, adopting tissue oximetry as a part of standard microcirculatory monitoring may prove to be the next big frontier in critical care management.

With the limitations of non-invasive assessment of tissue oxygenation being identified, future studies should focus on interpretation of measured data and aim at determining clinically relevant and application-specific threshold values for tissue desaturation-related injury. Furthermore, the types of interventions necessary for correcting tissue oxygenation values and its effects on clinical outcome require further clarification.

Overall, non-invasive tissue oximetry is a promising tool for (regional) assessment of tissue oxygenation. Its measurement readings should be considered as an integral source of information, a puzzle piece that together with all clinical information can aid in decision making and minimizing the risk of postoperative complications. 


\section{References}

1. Jannati Y, Bagheri-Nesami M, Sohrabi M, Yazdani-Cherati J, Mazdarani S. Factors associated with post-surgical delirium in patients undergoing open heart surgery. Oman Med J. 2014; 29(5):340-345.

2. Kazmierski J, Kowman M, Banach M, et al. Incidence and predictors of delirium after cardiac surgery: results from the IPDACS study. J Psychosom Res. 2010;69(2):179-185.

3. Newman MF, Grocott HP, Mathew JP, et al. Report of the substudy assessing the impact of neurocognitive function on quality of life 5 years after cardiac surgery. Stroke. 2001;32:28742881.

4. da Costa MAC, Gauer MF, Gomes RZ, Schafranski MD. Risk factors for perioperative ischemic stroke in cardiac surgery. Rev Bras Cir Cardiovasc. 2015; 30(3): 365-372.

5. Brown $\mathrm{CH}$. Delirium in the cardiac surgical intensive care unit. Curr Opin Anaesthesiol. 2014;27(2):117-122.

6. Palmerini T, Savini C, Di Eusanio M. Risks of stroke after coronary artery bypass graft - recent insights and perspectives. ICR. 2014;9(2).

7. Anyanwu AC, Filsoufi F, Salzberg SP, Bronster DJ, Adams DH. Epidemiology of stroke after cardiac surgery in the current era. J Thorac Cardiovasc Surg. 2007;134(5):1121-1127.

8. Leslie DL, Inouye SK. The importance of delirium: economic and societal costs. Am Geriatr Soc. 2011;59(Suppl 2):S241-S243.

9. Brown $\mathrm{CH}$, Laflam A, Max L, et al. The impact of delirium after cardiac surgery on postoperative resource utilization. Ann Thorac Surg. 2016;101(5):1663-1669.

10. Smulter N, Lingehall HC, Gustafson Y, Olofsson B, Engström KG. Delirium after cardiac surgery: incidence and risk factors. Interact Cardiovasc Thorac Surg. 2013;17(5):790-796.

11. Scott DA, Evered LA, Silbert BS. Cardiac Surgery, the brain, and inflammation. J Extra Corpor Technol. 2014;46(1):15-22.

12. Steppan J, Hogue Jr, CW. Cerebral and tissue oximetry. Best Pract Res Clin Anaesthesiol. 2014;28(4):429-439.

13. Edmonds Jr HL. 2010 standard of care for central nervous system monitoring during cardiac surgery. J Cardiothorac Vasc Anesth. 2010;24(4):541-543.

14. Mathew JP, Mackensen GB, Phillips-Bute B, et al. Effects of extreme hemodilution during cardiac surgery on cognitive function in the elderly. Anesthesiology 2007;107:577-584.

15. Gutierrez G, Vincent JL. Update in intensive care and emergency medicine - tissue oxygen utilization. Berlin: Springer-Verlag; 1991.

16. Fischer JP, Sieber B, Nelson JA, et al. Comprehensive outcome and cost analysis of free tissue transfer for breast reconstruction: an experience with 1303 flaps. Plast Reconstr Surg 2013;131:195-203.

17. Pelletier A, Tseng C, Agarwal S, et al. Cost analysis of near-infrared spectroscopy tissue oximetry for monitoring autologous free tissue breast reconstruction. J Reconstr Microsurg 2011;27:487-494.

18. Ricci JA, Vargas CR, Ho OA, et al. Evaluating the use of tissue oximetry to decrease intensive unit monitoring for free flap breast reconstruction. Ann Plast Surg. 2017;79(1):42-46. 
Dankwoord 
Daar zijn we dan, het dankwoord van het proefschrift. Een toch wel veel gelezen onderdeel van het boekje. Er zijn zovelen die ik graag wil bedanken, zovelen die op hun eigen manier een steentje hebben bijgedragen aan dit proefschrift, direct of indirect. Zonder elk van hen was dit proefschrift er niet geweest. Daarom wil ik, zonder iemand tekort te doen, een aantal mensen in het bijzonder bedanken.

Allereerst Jos Maessen, mijn promotor, bedankt voor het in mij gestelde vertrouwen. Ik ben ontzettend dankbaar voor de kans om van mijn onderzoeken, beginnend als stagiaire, mijn promotie te maken, bedankt!

Mijn copromotores, Patrick en Steven, bedankt voor de steun en feedback die ik van jullie heb mogen ontvangen. Door jullie input zijn de manuscripten iedere keer sterker geworden. Patrick, heel erg bedankt voor alles! Het vertrouwen dat je in mij toonde heb ik zeer op prijs gesteld, en gaf mij ook vertrouwen in mijzelf en mijn kunnen. Bedankt voor de feedback en de lange gesprekken, face to face of per telefoon, waarin we álles doorspraken; alle lopende projecten, toekomstige projecten, overwinningen klein en groot, en struikelblokken. Vele uren in het provisorium maar ook op andere locaties onder het genot van een california roll. Daar waar ik ogenschijnlijk beren op de weg zag, wist jij altijd een alternatieve route te vinden! Je enthousiasme voor onderzoek heeft me aangestoken, ontzettend bedankt!

Steven, ontzettend bedankt voor alle inzicht en kennis die je met mij hebt gedeeld. Jouw blik op zaken en mijn gestelde vragen heeft mij geholpen om de projecten tot een hoger niveau te tillen en ook mijn eigen blik aan te scherpen. Je feedback met betrekking tot (de mogelijkheden en valkuilen in) data analyse en statistische toetsing hebben mij enorm geholpen, dat merkte ik niet alleen bij het werken aan de onderzoeksprojecten maar ook tijdens mijn studies.

Anouk en Juan, mijn paranimfen, dank voor de hulp bij het regelwerk. Jullie tijd en toewijding om deze promotie te laten lopen zoals ik dat voor ogen had, heeft dé dag gemaakt tot 'mijn' dag. Ik ben blij met jullie aan mijn zijde, op "de grote dag" en gedurende het proces. Met me meedenken, overleggen, "oké, maar wat als we het zo of zó doen?", "maar wat denk jij?", "kom, we doen even een koffie", het zijn deze momenten die misschien niet in eerste instantie niet zo belangrijk lijken in het hele proces, maar toch...

Anouk, dankjewel voor de altijd prettige samenwerking! Alhoewel we vaak allebei belachelijke agenda's hadden, was je altijd bereid tijd voor mij vrij te maken. Die vele malen dat ik je in de weekenden of op onmogelijke tijdstippen bevroeg over zaken waar ik tegenaan was gelopen heb je altijd getolereerd en me nog 
geholpen ook! Juan, bedankt voor je betrokkenheid en enthousiasme. Jouw dedication is bewonderenswaardig! En natuurlijk ook voor "take me home country roads", die zal ik niet snel vergeten!

En dan natuurlijk mijn lieve perfusiecollega's en oud-perfusiecollega's, ik ben jullie dankbaar voor de ontzettend leuke en leerzame tijd. Ik was de stagiaire die eerst nog even bleef plakken, weer even terug naar school ging en daarna weer terugkwam, jullie kwamen maar niet van me af. Allen bedankt voor jullie luisterend oor, jullie hulp in praktische en inhoudelijke zaken en jullie interesse in wat mij bezighield. Er was altijd plek voor een grapje, wat de samenwerking prettig maakte. Ik ben dankbaar dat ik onderdeel mocht zijn van een team als deze. Yvonne, Nicole, Diana, Zaheer, Yuri, Rik, Erik, Ervin, Nico, Arne, Susan, en

Cheryl, bedankt!

Antoine, wat hebben we samen veel gelachen en ook gediscussieerd, gemopperd, zaken voor Ervin's promotie geregeld, en chocolade gegeten (of ander foute zoetigheden). Bedankt voor al je hulp. Je hebt me wegwijs gemaakt toen ik net begon als stagiaire, en nu nog sta je altijd voor me klaar. Dank daarvoor!

Professor van der Hulst, René, bedankt voor de prettige (multidisciplinaire) samenwerking! Het is een bijzonder iets om deel uit te mogen maken van een project als de DIEP-flap studie. Ondanks dat cardiothoracale chirurgie en plastische chirurgie ogenschijnlijk zo ver van elkaar verwijderd zijn, hebben we samen toch een mooi en voor mij heel belangrijk project opgezet.

De leden van de beoordelingscommissie, prof. dr. Roekaerts, prof. dr. Bekers, prof. dr. Boer, prof. dr. Bogers, en dr. Houben, bedankt voor jullie tijd en inspanningen om mijn proefschrift te lezen en goedkeuring te verlenen.

Monique Loo, bedankt voor de hulp en het meedenken, door je oplettendheid heb ik spoedig het een en het ander in gang kunnen zetten.

Ajay, it was a pleasure working with you. You helped me writing and presenting important parts of my research. Thank you for sharing your perspectives and suggestions, workwise and otherwise.

Lieve vriendjes en vriendinnetjes, Leonie 'Leo', Veronica 'Vero', Ilse, en Magne, bedankt voor de nodige afleiding; samen uit, verjaardagen vieren, maar vooral samen lachen, eten en cocktails drinken. Niks blijft onbesproken en ik kan altijd mijn ei kwijt wanneer we weer een avondje met de squad hebben. Ik kijk nu 
alweer uit naar de Sinterkerstsurprise!

Tamara 'Tamaar', bedank veur dien hulp! De woars altied bereid mich te hellepe, aug wanneer ig zelf neet doa koos zeen veur 'n meting te starte bie de DIEP. Doe stings veur mich kloar en heelps mich oet de brand. Aug al wirkse al 'n tiedje neet mier bie de perfusie, ig bin blie dat v'r nog ummer good contac hubbe.

Dank aan de patiënten die bereid waren deel te nemen aan mijn onderzoeken, zonder hen was het klinische aandeel van het proefschrift niet tot stand kunnen komen.

Philipp, although I could easily fill a whole page, let me keep is short and sweet. Thank you for never getting tired of me trying to get some work done when you wanted to go watch a movie. Most importantly, thank you for always standing by my side.

Last but not least; pa, ma, dank veur uch onveurwaardelikke steun. Al die joare van studeren hub geer miene kal aan motte heure euver vanalles en nog get. Dank dat geer d'r altied veur mich zeet. 
Curriculum vitae 
Nousjka Vranken is geboren op 28 september 1991 te Geleen. In 2008 behaalde zij haar Havo diploma aan de Scholengemeenschap Groenewald te Stein. In hetzelfde jaar startte zij haar opleiding Biometrie aan de Zuyd Hogeschool in Heerlen. In 2013 startte zij met de opleiding Gezondheidswetenschappen aan de Universiteit Maastricht en tegelijkertijd haar functie als promovendus bij het Maastricht Universitair Medisch Centrum. In 2016 behaalde zij haar bachelordiploma Gezondheidswetenschappen met Cum Laude onderscheiding in de richting Biologie en Gezondheid. Later dat jaar in september 2016 startte zij met de masteropleiding Arts-Klinisch Onderzoeker aan de Universiteit Maastricht.

Nousjka Vranken was born in Geleen, the Netherlands, on September $28^{\text {th }}$ 1991. In 2008 she graduated from Scholengemeenschap Groenewald in Stein. Immediately thereafter she started studying Biometrics at Zuyd Hogeschool. After graduating from Biometrics she initiated her studies Health Sciences at Maastricht University with as field of expertise Biology and Health. At the same time, she started her work as a PhD student at the Maastricht University Medical Center. In 2016 she received her bachelor diploma from Health Sciences with Cum Laude distinction. Later that year, in September 2016, she started the master's study Physician-Clinical Investigator at Maastricht University. 
Publications 
Vranken NPA, Lindelauf AAMA, Simons AP, Ariës MJH, Maessen JG, Weerwind PW. Cerebral and limb tissue oxygenation during peripheral venoarterial extracorporeal life support. J Intensive Care Med 2017.

DOI: $10.1177 / 0885066617735270$.

Vranken NPA, Weerwind PW, Sutedja NA, Ševerdija EE, Barenbrug PJC, Maessen JG. Cerebral oximetry and autoregulation during cardiopulmonary bypass: a review. J Extra Corpor Technol 2017;49:182-191.

Vranken NPA, Weerwind PW, van Onna MA, Bouman EAC, van der Hulst RRWJ. Non-invasive tissue oximetry following unilateral DIEP-flap reconstruction: A pilot evaluation. JPRAS Open 2017;12:59-65.

Vranken NP, Ganushchak YM, Willigers HM, Maessen JG, Weerwind PW. Vascular occlusion test during normothermic pulsatile cardiopulmonary bypass. J Cardiothorac Vasc Anesth 2016;30(4)979-984.

Vranken NP, Weerwind PW. Cerebral autoregulation during cardiopulmonary bypass. Perfusion 2016;31(5):440.

Kumar N, Dinh T, Phan K, Timmermans C, Philippens S, Dassen W, Vranken $\mathrm{N}$, Pison L, Maessen J, Crijns HJ. Adenosine testing after second-generation cryoballoon ablation (ATSCA) study improves clinical success rate for atrial fibrillation. Europace 2015;17(6):871-876.

Ševerdija EE, Vranken NP, Simons AP, Gommer ED, Heijmans JH, Maessen JG, Weerwind PW. Hemodilution combined with hypercapnia impairs cerebral autoregulation during normothermic cardiopulmonary bypass. J Cardiothorac Vasc Anesth 2015;29:1194-1199.

Ševerdija EE, Vranken NP, Teerenstra S, Ganushchak YM, Weerwind PW. Impact of Intraoperative events on cerebral tissue oximetry in patients undergoing cardiopulmonary bypass. J Extra Corpor Technol 2015;47:32-37.

Vranken NP, Weerwind PW, Barenbrug PJ, Teerenstra S, Ganushchak YM, Maessen JG. The role of patient's profile and allogeneic blood transfusion in development of post-cardiac surgery infections: a retrospective study. Interact Cardiovasc Thorac Surg 2014;19(2):232-238. 


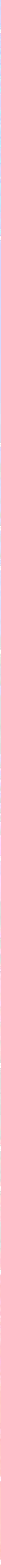

